\title{
Mind the (Convergence) Gap: Bond Predictability Strikes Back!
}

\author{
Andrea Berardi, Michael Markovich, Alberto Plazzi, and Andrea Tamoni*
}

This version: May 18, 2020

\begin{abstract}
We show that the difference between the natural rate of interest and the current level of monetary policy stance, which we label Convergence Gap (CG), contains information that is valuable for bond predictability. Adding CG in forecasting regressions of bond excess returns significantly raises the $R^{2}$, and restores countercyclical variation in bond risk premia that is otherwise missed by forward rates. Consistent with the argument that CG captures the effect of real imbalances on the path of rates, our factor has predictive ability for real bond excess returns. The importance of the gap remains robust out-of-sample and in countries other than the U.S. Furthermore, its inclusion brings significant economic gains in the context of dynamic conditional asset allocation.
\end{abstract}

Keywords: Bond risk premia, Forward rates, Monetary policy, Natural rate of interest, Bond Predictability

JEL Classification: E0, E43, G0, G12

*Berardi is with the Department of Economics, Università Ca' Foscari Venezia, Fondamenta San Giobbe 873, 30121, Venezia, Italy, Email: andrea.berardi@unive.it. Markovich is with Credit Suisse, Kalanderplatz 1, WJSQ, 8070, Zurich, Switzerland, Email: michael.markovich@credit-suisse.com. Plazzi is with the Institute of Finance, Università della Svizzera italiana and SFI, Via Buffi 13, 6900, Lugano, Switzerland, E-mail: alberto.plazzi@usi.ch. Tamoni is with the Department of Finance, Rutgers Business School, 1 Washington Park, Newark, NJ 07102, E-mail: andrea.tamoni@business.rutgers.edu. We thank John Cochrane, Carlo Favero, Jingzhi Huang, Anh Le, Sydney Ludvigson, Davide Pettenuzzo, Riccardo Rebonato, Claudio Tebaldi, and Allan Timmermann, and seminar participants at the EFA 2019, Queen Mary, Luxembourg School of Finance, and Warwick Business School for comments. Berardi gratefully acknowledges financial support from the European Union's Horizon 2020 research and innovation programme under the Marie Sklodowska-Curie grant agreement No 793763. 


\section{Introduction}

Starting with the seminal studies of Fama and Bliss (1987) and Campbell and Shiller (1991), the ability of interest rate variables, like the slope of the term structure, to forecast excess bond returns has received considerable attention in the fixed-income literature. Subsequently, Cochrane and Piazzesi (2005) make an important contribution to this literature by showing that a combination of forward rates across different maturities explains a substantial fraction of common fluctuations in bond risk premia.

Despite the role of forward rates as natural conditioning variables, recent studies cast doubt on the statistical and economic relevance of bond predictability. For example, Thornton and Valente (2012) use forward rates to forecast bond excess returns in the context of dynamic portfolio allocation. They conclude that deviations from the Expectations Hypothesis lead to economic gains that are small. Analogous conclusions are drawn by Della Corte, Sarno and Thornton (2008) working at the very short end (from overnight to 3 months) of the yield curve. Moreover, Ludvigson and Ng (2009) note that forward-only factors appear to miss cyclical variations in bond risk premia, an unappealing feature from a theoretical perspective.

In this paper, we investigate whether bond predictability can be enhanced by integrating information provided by forward rates with that arising from monetary policy actions. Specifically, our proposed variable is the gap between the natural rate of interest and the real Fed Funds rate. We label this variable Convergence Gap (CG). The logic behind the choice of this variable is the following: The natural rate of interest indicates the real interest rate consistent with a closed output gap and stationary inflation (see Wicksell (1936), and more recently Woodford (2003, Ch. 4.1-4.2)). To the extent that central bank's targeting rule can be traced (directly or indirectly) to the natural rate, we expect a positive convergence gap - yields below their natural level - to signal that the central bank will act in the Federal Funds rate market to close the gap, i.e. that short term yields are likely to increase in the 
future. ${ }^{1}$ Since yield and bond return predictability are intimately related, it is natural to ask whether CG helps predicting excess returns and restoring countercyclicality in risk premia.

We begin by studying the role of the convergence gap in the predictive regression of average bond excess returns. We find that CG significantly predicts returns when entering alone, or together with forward rates. In particular, its inclusion increases the regression $R^{2}$ from $23 \%$ (with forward rates only) to $34 \%$, and the statistical significance of the forward rates is enhanced. An important aspect we document is that CG eliminates systematic patterns in forecast errors which are related to the state of the economy, and hence to the cyclical nature of risk premia. When only forward rates are included in the bond return regression, the resulting residuals tend to be countercyclical, as they are predictable by variables such as the Chicago Fed National Activity Index and the NBER dummy. However, when combining the forward rates with $\mathrm{CG}$, the residuals become nearly unpredictable. This evidence implies that CG restores the countercyclicality of risk premia that is partly missed out by forward rates. Thus, CG uncovers a component of risk premia that is not only statistically, but also economically relevant.

Following Cochrane and Piazzesi (2005), we construct a bond risk factor from the fitted value of the regression jointly containing the forward rates and CG. When using this factor for predicting individual bond return series, we find that its statistical significance across the full spectrum of maturities remains intact even after controlling for interest rate volatility, the macro factor of Ludvigson and $\mathrm{Ng}$ (2009), and the Cieslak and Povala (2015) cycle factor. The comparison with Cieslak and Povala (2015) is particular insightful. In fact, despite being both significant predictors of excess bond returns, our factor and the cycle factor differ along important dimensions in line with their economic underpinning. First, our analysis shows that different maturities do not move on a single factor: the predictive content of our factor

\footnotetext{
${ }^{1}$ The turbulent Global Financial Crisis period, with the prospect of long stretches constrained by the effective lower bound, have commentators wondering whether inflation targeting regimes are still the right approach for central banks (Williams, 2016). Accordingly, recent monetary policy discussions (see, e.g. Yellen, 2015; Kaplan, 2018) focus on the equilibrium real interest rate because it provides a gauge of a "neutral" stance of monetary policy.
} 
for future returns is stronger at short maturities, whereas the Cieslak and Povala (2015) factor conveys additional information particularly at long maturities. This finding is easy to interpret since CG works through a mean reversion of the real short rate toward the natural rate, while the cycle factor operates through the nominal short rate mean reverting toward a slowly moving trend in inflation, which is known to have a persistent level effect on the yield curve. Second, we document that CG enhances the predictability of forward rates for excess returns on U.S. TIPS, whereas the Cieslak and Povala (2015) factor does not. Once again, this finding is in line with the economic foundation of CG: the gap between the real short rate and the natural rate aims at capturing the effect of transitory imbalances in the real economy on the path of interest rates through central bank's decisions.

We further show that CG helps predicting future yields. When used alone or together with the slope, CG reduces significantly the out-of-sample root mean squared error in predicting future changes in one-year yield compared to the benchmark random walk model. This ability to forecast yields and the restored countercyclical variation in risk premia are two sides of the same coin. Indeed, the convergence gap enters the bond return regressions with a negative coefficient. Thus, risk premia are deemed to be lower when yields are below their natural rate, i.e the central bank is accommodative, everything else equal. This is consistent with the evidence that, over our sample, positive values of CG are recorded in periods that anticipate an increase in future yields and economic activity, i.e. periods when risk premia are likely to decline.

We measure the economic value of the documented predictability solving a dynamic portfolio choice problem that involves a risk-free asset and a portfolio of bonds. In particular, we adopt the approach of Brandt and Santa-Clara (2006) and estimate the optimal policy for a risk-averse investor who dynamically adjusts her position based on a set of predictors. We find that adding CG to the information set substantially improves the portfolio allocation and its performance. The Sharpe Ratio increases by about 0.10 compared to the forward-only allocation, which corresponds to an economic gain (or equalization fee) of $2 \%$ per annum. 
These results hold for monthly as well as annual non-overlapping bond returns, persist outof-sample, when trading individual bonds, and even if we prevent the investor from taking large positions. The economic magnitude of these effects confirms that deviations from the Expectations Hypothesis are indeed quite relevant, consistent with recent evidence by Gargano, Pettenuzzo and Timmermann (2019).

Spurred by the statistical and economic significance of the gap, we investigate its driving forces. Our empirical design draws inspiration from Lunsford and West (2019), who explore the potential drivers of the long run safe interest rate in a reduced-form setting. We complement the work of Lunsford and West (2019) along several important dimensions. First, we do not investigate the drivers of the natural rate but rather of the convergence gap, which reflects deviations from the natural rate triggered by monetary policy actions. Second, we ask which of the drivers in turn capture a predictable component of bond risk premia. Finally, while Lunsford and West (2019) use annual data and look at long-term correlations, our analysis focuses on monthly, hence higher frequency, information revealed by a widening of the gap, which is closed afterwards.

Overall, we find that demographic variables (such as, the employment to population ratio and the ratio of middle-aged to young adults) are either significant drivers of CG, valid predictors of bond returns, or both. We also find some albeit weaker evidence for productivity-related variables (such as, the Arouba-Diebold-Scotti index and total factor productivity), and little role for measures of flows or budget savings. At the same time, the component not explained by these variables, which captures the (unobservable) determinants of FED's decision to manoeuvre the real policy rate, still plays an important role in predicting bond returns. We thus confirm that the gap acts as the right summary statistic to capture how these and possibly other shocks influence monetary policy decisions and, in turn, the future path of interest rates.

Our findings are robust to using annual holding period returns sampled at the quarterly and annual frequency, vintage data for GDP and inflation following Ghysels, Horan and 
Moench (2018), and monthly holding period returns. We also extend our analysis to countries other than the U.S., namely Canada, the U.K., and Germany/Eurozone. In each of these markets, the convergence gap continues to enter the bond return forecasting regressions with a negative and significant coefficient, helps forward rates to track bond risk premia, and adds economic value to bond predictability. Finally, we carry a full out-of-sample experiment, which shows that the combined factor reduces significantly the mean squared forecast error from predicting bond excess returns.

Our study contributes to the literature on bond returns "excess" predictability, that is, predictability achieved with variables other than current yields. Among others, Cooper and Priestley (2009) and Ludvigson and Ng (2009) propose macroeconomic factors that help tracking bond risk premia. ${ }^{2}$ In independent work, Bauer and Rudebusch (2017) also use the natural rate of interest in the context of term structure modeling. Our study provides complementary views on the importance of monetary policy-related variables for bond predictability. Specifically, unlike Bauer and Rudebusch (2017), we analyse the role of the gap as unspanned factor in a standard affine term structure model, without introducing time-varying trends, and quantify its economic value within an asset allocation framework. ${ }^{3}$

Our paper also contributes to the unsettled debate on the economic value of bond returns predictability. In contrast to Thornton and Valente (2012), we do find significant economic gains compared with a model based on the Expectation Hypothesis. In this respect, our results are consistent with those in Gargano, Pettenuzzo and Timmermann (2019). Importantly, our paper complements their findings. Gargano et al. (2019) find that models that allow for time-varying parameters and time-varying volatility manage to produce better outof-sample forecasts than simpler models. Differently from them, we show that even simple models can generate better out-of-sample forecasts, once these models account for monetary policy conduct and yields movements, as proxied by our proposed variable CG.

\footnotetext{
${ }^{2}$ See Table 9, in Cooper and Priestley (2009), and Table 2, in Ludvigson and Ng (2009).

${ }^{3}$ To the best of our knowledge, the first analysis of using the natural rate for bond predictability is presented in Markovich and Plazzi (2013).
} 
The remainder of the paper is organized as follows. Section 2 presents the convergence gap and discusses its construction, time-series pattern and statistical properties. The main empirical results concerning the predictability of U.S. bond returns and the corresponding construction of a bond risk premia factor are contained in Section 3. There, we also show that CG helps predicting future yields. Section 4 investigates the economic drivers of CG. Section 5 contains the dynamic portfolio choice exercise that exploits the established predictability. Section 6 collects additional analyses, namely the international evidence, the out-of-sample exercise, and various robustness checks. Finally, Section 7 provides concluding remarks.

\section{The Convergence Gap}

Our candidate conditioning variable is the convergence gap, CG, defined as the difference between the natural rate of interest and the ex-ante real federal funds rate.

A large body of research has established that the difference between the real rate and potential output is a valid monetary policy cycle indicator. In particular, the indicator properties of the gap for forecasting inflation and/or output have been analyzed by, e.g., Orphanides and Williams (2002) and Amato (2005) for the U.S., Neiss and Nelson (2003) for the UK, and Mesonnier and Renne (2007) and Garnier and Wilhelmsen (2009) for the EMU. Bomfim (1997) uses the monetary cycles identified by Romer and Romer (1989), and shows that periods of monetary tightening are consistently identified as those where policy rates are persistently above their equilibrium level. In the sample 1990-2013, Barsky et al. (2014) show that a considerable degree of wage and price inflation stabilization could have been achieved if the Federal Reserve had tracked the natural rate. Finally, Curdia et al. (2015) show that a specification of monetary policy in which the interest rate tracks the Wicksellian efficient rate as the primary indicator of real activity, fits the U.S. data better than otherwise identical Taylor rules.

From a monetary policy viewpoint, if the central bank follows a targeting rule which 
can be traced (directly or indirectly) to the natural rate, then it may act in the Federal Funds rate market to close the gap. As such, the gap represents the central bank's main control variable to achieve its policy objectives and provides information about the current stance of monetary policy, restrictive versus accommodating, that helps to either stimulate or slow down demand and consequently to spur or cool inflation. The gap between the current real rate and its equilibrium level thus naturally embeds information about the future path of rates, with periods of positive convergence gap being generally associated with an increase in future yields. At the same time, central bank activity co-moves with changes in economic conditions. Thus, the convergence gap is a natural candidate to capture correlated movements in bond risk premia and future rates that happen at business cycle frequency.

Turning to some specifics, we define the natural rate of interest as the real policy interest rate consistent with a closed output gap (real GDP equal to potential in the absence of transitory shocks to demand) and stationary (i.e. non-accelerating) inflation (at/around target in the absence of transitory shocks to supply). ${ }^{4}$ Economic theory implies that the natural rate of interest varies over time in response to shifts to preferences and the growth rate of potential output. Hence, the natural rate is related to unobservable factors, and several techniques have been adopted to estimate it, including Kalman filtering (see e.g. Laubach and Williams, 2003). In the main part of our work, we proxy for the natural real rate of interest with potential real GDP growth. ${ }^{5}$ Specifically, we first extract the trend component of quarterly real GDP using a one-sided Hodrick and Prescott (1997) filter and

\footnotetext{
${ }^{4}$ See Wicksell (1936). Woodford (2003) formalizes the Wicksellian perspective in DSGE models. The Wicksellian natural rate of interest is different from the equilibrium rate of interest in that the former is expected to fluctuate considerably over the business cycle, whereas the latter should evolve more slowly over time. Having said so, the distinction between the two rates is not always drawn as finely. For a comprehensive overview on different definitions, estimation concepts and relevant horizons associated with the natural rate of interest we refer to Giammarioli and Valla (2004) and Kiley (2015).

${ }^{5}$ This is equivalent to assume that: (1) the natural rate of interest is primarily related to the productivity of capital, and (2) when the policy rate equals the natural rate, the output gap is zero. The interrelation between the real natural rate of interest and trend growth rate of potential output is also empirically confirmed by Laubach and Williams (2003).
} 
linearly interpolate the resultant series to obtain monthly observations. ${ }^{6}$ We then define the natural rate of interest as the year-to-year log change in monthly trend GDP. In constructing the ex-ante real rate, we proxy inflation expectations with a four quarter moving average of past inflation and subtract it from the nominal funds rate. Finally, the convergence gap, is obtained as the difference between the natural rate and the real funds rate.

Figure 1 displays the $\mathrm{CG}_{t}$ series, together with NBER recession bars. The evolution of CG lines up with several Fed's monetary policy interventions in response to changed economic outlook. For example, the first peak in CG towards the end of 1967 anticipates the 1968 tax hike and the highly restrictive monetary policy by the Fed in 1969. Negative values of CG generally correspond to NBER recessions, during which a slowdown in the economy is associated with monetary policy turning accommodative. Such paths are clearly observed for the recessions in the first part of the sample, such as the periods 1969/01 to 1970/12, 1974/07 to $1975 / 06$, and 1981/07 to $1982 / 12$. Interestingly, the CG series anticipates the anti-inflationary Fed tightening cycle starting around the mid of 1977, then followed by the so-called "Volcker experiment" with monetary policy targeting money growth rates and reserves instead of short-term rates.

In the second half of the sample, we observe a relatively smoother CG series between 1985 and the Great Recession. This pattern reflects the aggressive anti-inflationary monetary policy implemented by the Fed during the 1979-1982 period which led to the Great Moderation, a prolonged period of relatively stable inflation rates and declining interest rates. During this period, CG turns negative only during the Saving and Loan crisis of 1989 and the subsequent recession of 1990-1991, whereas it appears less affected by the LTCM crisis (autumn 1998) and the 2001 recession. Interestingly, during the 2007-2009 Great Recession, CG turns positive at the peak of the crisis in autumn 2008 as the strongly negative real interest rates more than offset the negative growth. ${ }^{7}$ The CG seems to correctly predict the significant

\footnotetext{
${ }^{6}$ Following common practice we set the smoothness penalty $\lambda=1600$ to HP-filter the quarterly GDP series. Also, note that the filter is first applied to $\log$ GDP; we then take the exponential of the trend component.

${ }^{7} \mathrm{~A}$ similar effect is observed around March 1975, when the real federal funds rate decreased to about $4 \%$.
} 
tightening cycles implemented by the Fed in the second half of the sample. Indeed, we notice that the series anticipates the reference rate increases starting in February 1994 and June 2004, and the interest rate normalization process initiated by the Fed in December 2016.

On a statistical ground, the convergence gap has been on average positive at about $1 \%$ throughout the sample, but with a relatively large volatility of $2 \%$. The autocorrelation of about 0.96 at monthly frequency decays rapidly to 0.87 at the quarterly horizon, and is 0.57 at the annual horizon. Contrary to other series widely used in the literature (see, e.g. Cieslak and Povala, 2015), CG does not exhibit marked trending patterns. Hence, our analysis is different from, and complementary to, the term structure literature with shifting endpoints (see Kozicki and Tinsley, 2001; Bauer and Rudebusch, 2017). Finally, Figure E.1 in the Appendix shows that the evolution of $\mathrm{CG}$ is similar when alternative proxies for potential GDP or natural rate proposed in the literature are used to construct the series.

\section{Bond Predictability and the Convergence Gap}

This section collects the analysis on the effect of adding the convergence gap in the context of bond predictability. In Section 3.1, we focus on the predictive regression of average excess returns and construct our bond risk factor, while in Section 3.2 we carry out a similar analysis on individual bond excess returns. Section 3.3 investigates if the convergence gap has predictive ability for real bond excess returns. Finally, Section 3.4 provides evidence that the convergence gap also helps predicting future changes in nominal yields.

\subsection{Bond risk factors}

We first analyze the role of the convergence gap in forecasting average (across maturities) annual bond excess returns constructed using Fama and Bliss yields data from Le and Singleton (2013). ${ }^{8}$

\footnotetext{
${ }^{8}$ We thank Ahn Le for sharing the data with us. The Fama-Bliss CRSP dataset only has maturities of $1,2, \ldots, 5$ years. On the other hand, Le and Singleton (2013) provide monthly-spaced maturities Fama-Bliss
} 
Specifically, consider a zero-coupon bond that matures at $t+n$ with a payoff of $\$ 1$, current price $P_{t}^{(n)}$ and $\log$ yield $y_{t}^{(n)} \equiv-\frac{1}{n} p_{t}^{(n)}$. The superscript refers to the bond's remaining maturity. The bond's log excess return from $t$ to $t+1$ is $r x_{t+1}^{(n)} \equiv p_{t+1}^{(n-1)}-p_{t}^{(n)}-y_{t}^{(1)}$. We denote with $\overline{r x}_{t+1}$ the average annual bond excess return across maturities of $n=2$ to 5 years.

Panel A of Table 1 reports the results for various set of predictors during the 1964-2017 sample period. In specification $(\mathrm{CP})$, the regressors are the five forward rates as in Cochrane and Piazzesi (2005), that is, we estimate regression

$$
\overline{r x}_{t+1}=\delta_{0}+\delta_{1}^{\prime} \boldsymbol{f}_{t}+\epsilon_{t+1}
$$

where $\boldsymbol{f}_{t}=\left[f_{t}^{(1)} f_{t}^{(2)} f_{t}^{(3)} f_{t}^{(4)} f_{t}^{(5)}\right]$ collects the one-year forward rates implied from the bond yields. ${ }^{9}$ Collectively, the forward rates capture $21 \%$ of the overall variance in future excess returns over 1964-2017. We denote the fitted value from this regression as the "CP" factor, i.e. $\mathrm{CP}_{t}=\widehat{\delta}_{0}+\widehat{\delta}_{1}^{\prime} \boldsymbol{f}_{t}$.

Due to the overlapping nature of the return series, a usual concern in bond predictability studies is that of high residual autocorrelation. To this end we employ conservative standard errors from reverse regressions proposed by Hodrick (1992) and extended by Wei and Wright $(2013) \cdot \cdot^{10}$

In specification (CG), we predict $\overline{r x}_{t+1}$ with the convergence gap CG. The corresponding coefficient is negative at -0.42 , statistically significant with a $t$-statistic of -2.16 and an $R^{2}$ of 0.08 . The importance of the gap becomes even more prominent when it is used as conditioning variable together with forward rates. In specification (CPG), we employ both

data, which is needed to run the reverse regressions. Importantly, Le and Singleton (2013) apply the same filter to remove bonds that are illiquid or have embedded options, and the same Fama-Bliss bootstrap method as CRSP (see Bliss, 1997).

${ }^{9}$ We use the same notation as in Cochrane and Piazzesi (2005) and Cieslak and Povala (2015). However, the " $t+1$ " should be read as " $t+1$ year" as there is effectively a 12 -month lag between the dependent and the independent variables.

${ }^{10}$ Using Newey and West (1987) standard errors and conservative $p$-values from the theory of Kiefer and Vogelsang (2005) does not alter our conclusion. 
forward rates and $\mathrm{CG}_{t}$ as predictors, that is we estimate regression

$$
\overline{r x}_{t+1}=\delta_{0}^{C G}+\delta_{1}^{C G^{\prime}} \boldsymbol{f}_{t}+\delta_{2}^{C G} \mathrm{CG}_{t}+\epsilon_{t+1}^{C G}
$$

Several noteworthy facts emerge. First, the coefficient on CG now rises to -0.74 with an associated $t$-statistic of -3.17 . Second, its inclusion in general reduces the estimation error of forward rates coefficients, as documented by their increased $t$-statistics. Third, the associated $R^{2}$ jumps to 0.33 , a nearly $50 \%$ increase with respect to the specification without the gap. The negative sign on $\mathrm{CG}$ means that a positive convergence gap reduces the expectations about future returns, everything else constant. This is consistent with the evidence in Figure 1 that periods when yields are below their convergence level are usually associated to expectations of increased future yields, and with business cycle expansionary periods. We denote the fitted value from regression (2) as the "CPG factor", i.e. $\mathrm{CPG}_{t}=\widehat{\delta}_{0}^{C G}+\widehat{\delta}_{1}^{C G}{ }^{\prime} \boldsymbol{f}_{t}+\widehat{\delta}_{2}^{C G} \mathrm{CG}_{t}$.

In Panel A of Figure 2, we plot the estimated loadings on forward rates from specifications (CP) and (CPG), namely $\widehat{\delta}_{1}$ and $\widehat{\delta}_{1}^{C G}$. It is interesting to notice that, for the sample 1964-2017 considered in our analysis, the coefficients from specification $(\mathrm{CP})$ do not have the symmetric pattern documented by Cochrane and Piazzesi (2005) over 1964-2003. Interestingly, however, conditioning forward rates on the gap makes the loadings on the former quite aligned with those from Cochrane and Piazzesi (2005), and thus more stable over time. ${ }^{11}$

In Panel $\mathrm{B}$ of Figure 2, we display the time-series of the $\mathrm{CP}$ and $\mathrm{CPG}$ factors. In the first part of the sample, which was characterized by relatively low yields, CPG tends to be lower on average than CP thus forecasting lower excess returns. The opposite is true for the late 1990s and 2000s. Some notable differences are also seen in the 2000s. The period between 2002 and 2007 is often referred to as the interest rate "conundrum" (see Greenspan, 2005), in which the increase in short-term federal fund rates did not translate into higher long-maturity yields partly because of strong demand from foreign savings. During this

\footnotetext{
${ }^{11}$ We draw similar conclusions working on rolling windows, namely, the coefficients in specification (CPG) tend to be more stable and statistically significant than those from specification $(\mathrm{CP})$.
} 
period, the yield curve was flat to downward sloping and the corresponding negative CP factor forecasted low or even negative bond returns.

To dig further into our findings, we project the residuals from the average bond return predictive regressions on the following variables: inflation (CPI), the Chicago Fed National Activity Index (CFNAI), and the NBER recession dummy. ${ }^{12}$ The first row of Panel B of Table 1 reports the results for the residuals from specification $(\mathrm{CP})$, which includes forward rates only. We note that the regressors collectively capture about $13 \%$ of the residual variance. Even more importantly, CPI and CFNAI enter the regression with negative and significant coefficients, while the loading on NBER is positive and significant. Hence, forward rates fail to capture a component of bond risk premia that is linked to macro conditions in a countercyclical way - i.e., bond return forecast errors are positive during recessions, a point which has previously been made by Ludvigson and Ng (2009).

The second row of Panel reports the results for the residuals from specification (CPG), where both forward rates and CG are used to predict bond returns. The $R^{2}$ is down to 0.06, and only the coefficient on the NBER dummy is now marginally significant. Therefore, conditioning on the gap helps capturing predictable patterns in bond risk premia that are countercyclical in nature. Notably, in the robustness section 6.3 , we find that the risk premia become even more countercyclical when we construct CG using alternative estimates of potential GDP growth or natural rate proposed in literature. Hence, the results of Table 1 shall be taken as a lower bound. Nonetheless, we stick to the current definition of CG because of its simplicity and parsimonious modelling assumptions.

\subsection{Individual bond regressions}

We now turn our attention to individual bonds. Panel A through D of Table 2 report the in-sample results for the predictive regression of bond excess returns with maturities ranging

\footnotetext{
${ }^{12}$ Our conclusions remain unaltered if we replace the CFNAI with Industrial Production growth.
} 
from two to five years, respectively, on a set of regressors $X_{t}$ :

$$
r x_{t+1}^{(n)}=a_{n}+b_{n}^{\prime} X_{t}+\epsilon_{t+1}, \quad n=2,3,4,5 .
$$

Within each panel, we consider various combinations of $X_{t}$ in order to highlight the impact of our novel bond risk factor, $\mathrm{CPG}_{t}$.

The predictive ability of the Cochrane and Piazzesi (2005) factor is shown in specification (1). Its loading is 0.42 for two-year returns ( $t$-statistic of 1.89$)$ with an $R^{2}$ of 0.17 . The coefficient increases almost linearly with maturity, reaching 1.52 for five-year returns, with an $R^{2}$ of 0.22 .

In specification (2), we forecast bond returns using both forward rates and the convergence gap as summarized by the CPG factor. The corresponding coefficients are comparable to those of CP but are characterized by a much stronger statistical significance and predictive power. For two-year bonds, the coefficient on CPG is 0.46 with an associated $t$-statistic of 3.36 and the $R^{2}$ equals 0.32 - a full 0.15 increase with respect to specification (1). Similar conclusions arise across all other maturities, with $R^{2}$ s for three-, four-, and five-year bonds all above 0.30 .

Next, we compare the predictive content of our $\mathrm{CPG}_{t}$ factor to that of the celebrated Cieslak and Povala (2015) cyclical return-forecasting factor, $c f_{t}$. Our choice of $c f_{t}$ as a benchmark is natural since, similar to our convergence gap, $c f$ can also be interpreted as a gap variable capturing the degree of divergence/convergence between nominal yields and long-run inflation. However, despite this similarity, our factor and the Cieslak and Povala (2015) are most likely capturing different phenomena. Our factor is motivated by the monetary policy literature that posits a steady-state real rate consistent with output being at potential. By measuring the gap between the current real rate and its equilibrium level we aim to capture the current stance of monetary policy, which naturally embeds information about the future path of interest rates. Indeed, while CG works through a mean reversion of the real short rate 
toward the natural rate, $c f$ operates through the nominal short rate mean reverting toward a slowly moving trend in inflation. From an economic standpoint, both mechanisms can coexist but their relative importance is an empirical matter which we address in specifications (3) to $(5)$ in Table 2.

In specification (3) we run regressions of individual excess returns, $r x_{t+1}^{(n)}$, on the Cieslak and Povala (2015) cycle factor and we show that $c f_{t}$ is a significant return predictor across different maturities. Specification (4) reports bivariate predictive regressions in which we include both the $\mathrm{CP}$ factor and the cycle factor $c f_{t}$ as regressors. In our extended sample period, we confirm the original analysis of Cieslak and Povala (2015): for all bond maturities, the CP factor becomes statistically insignificant and has no incremental explanatory power beyond $c f_{t}$. In specification (5) we report a similar bivariate predictive regression with CP replaced by our CPG factor. We find that the $\mathrm{CP}$ factor amended by the convergence gap, i.e. CPG, is statistically significant for all bond maturities even after controlling for $c f$. More importantly, specification (5) is informative about the relative predictive content of $\mathrm{CPG}_{t}$ and $c f_{t}$. At short maturities, CPG is more important than $c f$ as confirmed by a statistically insignificant coefficient on $c f_{t}$. However, as we move toward longer maturities we observe that $c f_{t}$ conveys additional information relative to the CPG factor. Indeed, the difference in $\mathrm{R}^{2} \mathrm{~s}$ between specifications (2, CPG only) and (5, CPG and $\left.c f\right)$ almost doubles from $3 \%$ to $7 \%$ as we shift focus from the 2-year to the 5-year maturity. Analogously, the difference in $\mathrm{R}^{2} \mathrm{~s}$ between specifications (3, cf only) and (5, CPG and $\left.c f\right)$ decreases from $10 \%$ to $6 \%$. We conclude that different maturities do not move on a single factor: the predictive content of CPG for future returns is present across the term structure, but more so at short maturities; the $c f$ factor conveys additional information particularly at long maturities.

\subsection{Predicting real bond returns}

The finding of multiple cycles with predictive content for future returns is easy to understand at the light of the different economic drivers captured by the convergence gap and $c f_{t}$. 
The Cieslak and Povala (2015) factor relies on a long-run anchor based on inflation, which is known to have a persistent level effect on the yield curve. On the other hand, the gap between the real short-term rate and the natural rate aims at capturing the effect of more transitory divergences or imbalances in the real economy on the path of policy rates, as it also emerges from our analysis in Section 4 below. ${ }^{13}$

To test this economic explanation of different predictive content conveyed by the two cycles, $\mathrm{CPG}_{t}$ and $c f_{t}$, we next employ real bonds as test assets. Specifically, we run univariate and bivariate regressions similar to those in Table 2 but instead of predicting excess returns on nominal bonds, we forecast excess returns on U.S. TIPS (Treasury inflation-protected securities). ${ }^{14}$ Table 3 presents the corresponding results using the same format as in Table 2.

In line with the hypothesis that the $c f_{t}$ factor operates mostly through (changing inflation expectations in) the nominal economy, we find that $c f_{t}$ has no predictive ability for excess returns on real bonds (specification (3) in Table 3). On the contrary, our CPG factor predicts real bond returns of all maturities (specification (2)). Furthermore, the regression coefficients and the $R^{2}$ from specification (2) are hardly affected by the inclusion of the Cieslak and Povala (2015) cycle factor (compare specification (2) with (5)).

Additionally, Appendix Table B.1 documents that the inclusion of CG enhances the predictability of excess returns to real bonds in the U.K. Overall, this evidence highlights the relative importance of disturbances in the real economy relative to inflation-driven divergences in the nominal economy for bond risk premia.

\subsection{Predicting yields with the Convergence Gap}

As formalized by Duffee (2011), hidden factors in the cross-section of yields shall affect the expectation of future interest rates and risk premia in opposite directions, thereby leaving

\footnotetext{
${ }^{13}$ For example, Table 4 in Joslin et al. (2014a) document that the effects of economic growth on forward term premia declines markedly as the contract horizon increases; on the other hand, the effects of inflation on the forward term premium remain large and of the same sign for maturities up to ten years.

${ }^{14}$ See Appendix A.3 for details on the data.
} 
the current yield curve unchanged. In the previous section, we show that the convergence gap helps forecasting returns and uncovers a countercyclical component of bond risk premia. As a further indication of the genuine importance of $\mathrm{CG}$, we now ask if it also helps forecasting future rates. To this end, we conduct an out-of-sample forecasting exercise where we predict changes in one-year yield at forecast horizons of $H=\{1,2,3,4\}$ years. Specifically, the first regression is estimated using data from January 1964 through December 1989. Using only information until the end of this period, we regress $H$-year changes in the one-year yield, $y_{t+H}^{(1)}-y_{t}^{(1)}$, on a constant and a set of predictors:

$$
y_{t+H}^{(1)}-y_{t}^{(1)}=a+b X_{t}+\varepsilon_{t+H}
$$

We consider three different models: $X_{t}=\{$ Slope $\}$, or $X_{t}=\{$ Convergence Gap $\}$, or $X_{t}=$ $\left\{\right.$ Slope, Convergence Gap\}. We proxy for the slope using $s_{t}^{(5)}=y_{t}^{(5)}-y_{t}^{(1)}$. Using the resultant coefficients and the value of the slope and CG on December 1989 we then produce out-ofsample forecasts of the $H$-year ahead one-year yield. The first forecast error obtains by comparing $y_{t}^{(1)}$ on $t=$ December 1990, and its forecast made on December 1989. We then include the January 1990 information and follow the same procedure to produce forecasts for the January 1991 1-year yield, and so on until the end of 2017.

We follow Duffee (2002) and take the random walk (RW) model as our benchmark. Thus, we compare the forecasts from predictive regressions of the $H$-year ahead one-year yield on the term spread, the convergence gap, and their combination to the RW forecast. Table 4 shows the out-of-sample $\mathrm{R}^{2}$ statistic, $\mathrm{R}_{\text {OoS }}^{2}$, used by Campbell and Thompson (2008) among others. Testing whether the predictive regression model has a significantly lower mean square prediction error (MSPE) than the random walk benchmark forecast is tantamount to testing the null hypothesis that $\mathrm{R}_{O o S}^{2} \leq 0$ against the alternative hypothesis that $\mathrm{R}_{O o S}^{2}>0$. Therefore, we use the Clark and West (2007) adjusted version of the Diebold and Mariano (1995) and West (1996) statistic, which is suitable in our case to compare forecasts from nested linear 
models. Table 4 collects the results.

The first model (column (2)) forecasts the one-year yield changes using the slope $s_{t}^{(5)}$. This specification generates positive and significant $\mathrm{R}_{O o S}^{2}$ for $H=3$ and $H=4$. On the other hand, forecast at shorter horizons are statistically indistinguishable from those obtained by the RW model. These results are in line with those in Duffee (2002), who shows that the random walk model is a hard-to-beat benchmark for yield predictions.

The second model (column (3)) forecasts one-year yield changes using the convergence gap. Compared with the model based on the slope, conditioning on CG substantially improves the $\mathrm{R}_{O o S}^{2}$ at short horizons. Indeed, we observe out-of-sample $\mathrm{R}^{2} \mathrm{~s}$ that are large at about $15 \%$ for $H=1$ and $H=2$. The predictive ability of $\mathrm{CG}$ decreases at longer horizons, but continues to be statistically significant at standard confidence levels.

Finally, the third model (column (4)) predicts yield changes with both the slope and CG. With respect to the previous model, the $\mathrm{R}_{O o S}^{2} \mathrm{~s}$ increase at all horizons, the sole exception being at the one year horizon where the performance is basically at par. The $p$-value of the Clark and West (2007) test against the RW model confirms that the improvements of the joint model at all forecasting horizons are significantly different from zero.

As an additional piece of evidence, we use the estimated 1- to 5-year short rate expectations from Adrian, Crump and Moench (2013)'s model. ${ }^{15}$ We then subtract expected inflation, and construct the corresponding estimated term structure of real forward rates. The regression of $\mathrm{CG}$ onto these 1- to 5-year expected real rates attains an $\mathrm{R}$-squared of 0.64. Thus, CG strongly relates to expectations of future real rates generated by a FED's reference model like Adrian et al. (2013), despite the fact that the two approaches use different input information. Overall, these results show that the gap between the level of the real (short-term) interest rate and the natural rate of interest brings additional forecasting power about future interest rates.

\footnotetext{
${ }^{15}$ The data is available at https://www.newyorkfed.org/research/data_indicators/term_premia. html.
} 


\section{Economic Drivers of the Convergence Gap}

Our analysis so far shows that the convergence gap contains valuable information for bond return predictability. In this section, we ask what are the economic channels that are behind this evidence. Our empirical design is inspired by recent work by Lunsford and West (2019), who explore the potential drivers of the long run safe interest rate in a reduced-form setting. We complement their work along several important dimensions. First, we do not investigate the drivers of the long-run rate but rather of the convergence gap, which reflects deviations from the natural rate induced by monetary policy actions. Therefore, our analysis is informative about which shocks induce revisions in the policy rate relative to its equilibrium level. Second, we ask which of the drivers in turn capture a predictable component of bond risk premia, which is the novel finding of our paper. Finally, while Lunsford and West (2019) use annual data and look at long-term correlations, our CG is constructed at the monthly frequency. High-frequency fluctuations can contain valuable information as they reveal a widening of the gap (in either direction), which is then closed in the long run. Therefore, we augment the relevant variables from their list with monthly indicators.

We classify the determinants into three, possibly co-existent, groups. The first group of variables captures demographic conditions, which may induce imbalances aggregate in savings and investment. We use the ratio of employment to population, the middle-to-young ratio proposed by Geanakoplos et al. (2004), life expectancy, and the dependency ratio (constructed as percentage of population younger than 20 or older than 64 ). The second group collects measures of productivity growth, namely the Arouba-Diebold-Scotti (2009) index, capacity utilization, labor force hours growth, and total factor productivity in the private, non-farm business sector. Finally, we use the ratio of federal debt to GDP and current account to GDP to capture capital flows and government (dis)saving. Details on the variables are provided in Appendix A.4.

Armed with these candidate factors, we regress them onto the convergence gap, and use the fitted value from this regression as a predictor of average bond excess returns together 
with forward rates. That is, we run specification (3) in Panel A of Table 1 where the fitted value is used in place of CG. Columns 1-3 of Table 5 report the coefficient, $t$-statistic and $\mathrm{R}^{2}$ for the regression of a given variable on $\mathrm{CG}$, while columns 4-6 report coefficient and $t$-statistic for the fitted value in the bond regression with forward rates (whose estimates are omitted for brevity) and the corresponding increment in $\mathrm{R}^{2}$ compared to predicting bond returns with forward rates only.

Looking at the first group of variables, we find that changes in demographics play a key role, which resonates with the evidence in Lunsford and West (2019) that they strongly correlate with the natural rate. For example, the employment to population ratio explains CG with a positive and marginally significant coefficient of 0.97 ; its loading in the bond return regression with forward rates is a negative -1.74 , highly significant with a $t$-stat of -3.06, and captures an additional 0.02 of the variance in bond risk premia. The MiddleYoung ratio (also used by Favero et al., 2016), Life Expectancy, and the Dependency Ratio are either significant drivers of $\mathrm{CG}$, valid predictors of bond returns, or both. ${ }^{16}$

Turning to productivity growth measures, we observe that they also help explaining variations in CG and bond risk premia, although the second-stage $t$-statistics are generally lower than for demographic measures. Among the growth variables, the Arouba-DieboldScotti index (capturing $6 \%$ of the variance of CG and adding $4 \%$ to the $\mathrm{R}^{2}$ of the bond return regression) and total factor productivity (figures at $16 \%$ and $2 \%$, respectively) stand out as useful drivers. Finally, we find very limited role for flow-related variables - namely, Fed debt to GDP and Current accounts to GDP - as they are insignificant in either regressions, and the associated $\mathrm{R}^{2}$ never exceeds 0.03 .

We thus conclude that variations in the gap can be traced to fundamental economic drivers, in particular demographic and productivity shocks. At the same time, we also note that the increment in $\mathrm{R}^{2}$ to the return regression is significantly lower than the 0.12

\footnotetext{
${ }^{16}$ The lack of correspondence in significance between the two regressions may also come from lack of power as some of the variables are available only at the quarterly or annual frequency.
} 
increment that we found in Table 1 when we compared specification CPG versus CP. ${ }^{17}$ Thus, the unexplained component, capturing the (unobservable) drivers of FED's decision to manoeuvre the real policy rate, still plays a key role in enhancing bond predictability. We interpret this as evidence that the convergence gap acts as the right summary statistic to capture how various economic determinants, such as those discussed in this section as well as other shocks, influence monetary policy decisions and, in turn, the future path of interest rates.

\section{Economic Significance of Bond Predictability}

Does the statistical significance of our results also translate into economic significance? We address this question by looking at the impact of our conditioning variables in the context of a dynamic portfolio strategy. Specifically, we consider the optimization problem of a quadratic utility agent who allocates her funds between a risk-free investment and a risky asset. In the fixed income literature, this approach has been previously applied by Della Corte et al. (2008) to quantify the economic significance of violations of the Expectations Hypothesis at the short-end of the maturity spectrum using daily data. Our focus, instead, is on the performance of portfolio allocation to long-term bonds at monthly and annual horizons. In our analysis, the risk-free asset is a bond with maturity equal to the investment horizon. For monthly holding-period returns, the risky asset is the monthly series of a portfolio of bonds with two to three years to maturity (the source is the CRSP Fama Bond Portfolio Returns tape). For one-year holding period returns, we use the average excess return $\overline{r x}_{t+1}$, representing the return to an equally weighted portfolio of two- to five-year maturity bonds, sampled at annual frequency.

To determine the optimal conditional allocation strategy, we adopt the parametric portfolio choice approach of Brandt and Santa-Clara (2006). In their setup, the time-varying

\footnotetext{
${ }^{17}$ As in Lunsford and West (2019), we look at univariate relations in order to preserve the interpretation of the results. However, this conclusions hold true also in the multivariate setting, and the residual in the first regression is statistically significant in the bond regression across all variables.
} 
vector of relative weights $w_{t}$ allocated to $N$ risky assets is expressed as a linear function of $K$ conditioning variables $z_{t}$, or $w_{t}=\theta^{\prime} z_{t}$. In the benchmark case considered here, $N=1$ as the only risky asset is the bond portfolio. The $K \times 1$ vector of parameters $\theta$, to be estimated, captures the marginal impact of each variable on the portfolio weight. Brandt and Santa-Clara (2006) show that the dynamic optimization problem can be reduced to solving the static problem:

$$
\max _{\theta} E_{t}\left[\theta^{\prime} \widetilde{r}_{t+1}-\frac{\gamma}{2} \theta^{\prime} \widetilde{r}_{t+1} \widetilde{r}_{t+1} \theta\right]
$$

where $\gamma$ is a risk aversion parameter and $\widetilde{r}_{t+1} \equiv z_{t} \otimes r_{t+1}$ replaces the base asset with managed portfolios. Following their work, we set $\gamma=5$. In practice, the estimates of $\theta$ are obtained by OLS in the regression of a constant term on $\widetilde{r}_{t+1}$, which allows us to use standard testing procedures for evaluating statistical significance. ${ }^{18}$

The smallest conditioning set is $z_{t}=1$, which corresponds to the static Markowitz portfolio choice problem. The conditioning variables we include next are standardized to have mean zero and unity standard deviation, so that the coefficient on the constant can be interpreted as the time-series average allocation in the risky asset. A positive coefficient is associated to variables which either forecast higher expected returns, lower volatility, or both. The opposite is true for variables entering with a negative $\theta$. The economic impact of the variables in $z_{t}$ is then summarized by the Sharpe Ratio of the resultant optimal portfolio, and by the corresponding equalization fee, defined as the annual fee an investor is willing to pay to have access to $z_{t} \cdot{ }^{19}$

The first specification of Table 6 reports the estimates for the two-asset unconditional

\footnotetext{
${ }^{18}$ We work within a constant volatility setting since Thornton and Valente (2012) provide evidence that models with time-varying volatility do not yield significant improvement in economic value relative to the constant volatility alternative. Similarly, Duffee (2002) and Cheridito et al. (2007) find that bond excess returns are best captured by constant volatility models, in spite of the fact that such models cannot match the time-series variation in interest rate volatility. However, Gargano et al. (2019) find that controlling for stochastic volatility and unspanned macro factors enhances the economic value of bond predictability.

${ }^{19}$ Specifically, the equalization fee is computed as the difference in the certainty equivalent of the dynamic allocation and that of the constant (unconditional) case, as also done in Brandt and Santa-Clara (2006), Della Corte et al. (2008), Thornton and Valente (2012), and Ghysels et al. (2016). Similar results, omitted for brevity, obtain if we use Modigliani and Modigliani (1997) performance measure.
} 
portfolio allocation, or $z_{t}=1(K=1)$. At monthly horizon, the average return $\left(E\left(r_{p}\right)\right)$ and standard deviation $\left(\sigma_{p}\right)$ of the resultant optimal portfolio are about 0.07 , leading to a Sharpe Ratio of 0.33 . These statistics are comparable at annual frequency.

In specification (2) of the Table, the portfolio allocation is conditioned on the one- to five-year forward rates, or $z_{t}=\left[1 \boldsymbol{f}_{t}\right]^{\prime}(K=6)$. The average return and standard deviation of the managed portfolio both increase to about 0.11 , with a corresponding Sharpe Ratio of about 0.58 . The dynamic strategy yields an equalization fee of about $2 \%$ both at the monthly and annual horizon.

In specification (3), the set of conditioning variables is augmented by the convergence gap,

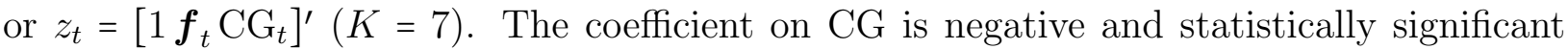
at both the monthly $(-2.59, t$-statistic of -1.95$)$ and annual horizon $(-1.71, t$-statistic of -3.14). The negative sign is consistent with the evidence in the previous sections. The inclusion of $\mathrm{CG}$ changes substantially the loadings on forward rates and the performance of the allocation. The in-sample Sharpe Ratio raises to about 0.60 at both horizons and the equalization fee is now about 70-90bps higher than in specification (2). Furthermore, rolling analysis reveals (see Appendix Table C.1 and Figure C.1) that the difference in the Sharpe Ratio of the optimal portfolio with and without CG varies with economic conditions. This is consistent with the evidence in Panel B of Table 1 that CG helps capturing countercyclical variation in risk premia.

To quantify the impact of transaction costs, row "Eq. fee TC-adj" reports the equalization fee when adjusting the optimal portfolio return by a one-way transaction cost of 10 basis points, as in Gargano et al. (2019). The transaction cost is computed based on turnover, i.e. the absolute value in the change in optimal weight, as in Brandt et al. (2009). Accounting for transaction costs reduces the equalization fee by about $1 \%$ for both model (2) (forward rates only; from $2.2 \%$ to $1.2 \%$ ) and model (3) (forward rates plus CG; from $3.1 \%$ to $2.1 \%$ ). Hence, the difference between the two models remains unchanged at 90bps. At the annual frequency, turnover is much smaller and the adjustment only affects the fee in its fourth 
decimal.

We also report equalization fees for other specifications. In row "Eq. fee OOS", we report the equalization from a full out-of-sample exercise at the monthly frequency over the 1990-2017 sample period, where the portfolio coefficients are recursively estimated to generate proper out-of-sample allocations. ${ }^{20}$ Adding $\mathrm{CG}$ to the conditioning vector increases the fee by $1.4 \%$, from $0.5 \%$ (column (2)) to $1.9 \%$ (column (3)). Row "Eq. fee Power utility" reports the fee for an investor who is endowed with a power utility function with $\gamma=5$, as in Brandt et al. (2009) and Ghysels et al. (2016). We note that conditioning on CG still leads to a significant increase in the equalization fee of $1.0 \%$ at the monthly horizon (from $1.8 \%$ in column (2) to $2.7 \%$ in column (3)), and a somewhat higher $3 \%$ at the annual frequency. Finally, in row "Eq. fee N assets" we compute the equalization fee for the dynamic allocation when the investor optimizes across $N$ bonds, where $N=3$ assets in the case of monthly returns (corresponding to the three CRSP bond portfolios) and $N=4$ assets in the case of annual returns (corresponding to the individual bond Fama-Bliss returns, sampled at non-overlapping frequencies). ${ }^{21}$ Again, the addition of $\mathrm{CG}$ again raises the equalization fee at both frequencies, respectively by $2.7 \%$ and $1 \%$.

In Figure 3, we display the time-varying weight $w_{t}$ implied by the monthly (top plot) and annual (bottom plot) estimates of Table 6. In the plots, the horizontal solid line represents the unconditional allocation corresponding to specification (1), the red solid line with circles corresponds to the policy that conditions on forward rates only as in specification (2), and the blue solid line tracks the portfolio weight implied by specification (3) where we condition on forward rates and the convergence gap. Several differences between the two dynamic strategies emerge. The correlation between the two weights is just 0.41 at the monthly horizon and 0.47 at the annual horizon. Both optimal policies, however, often imply taking substantial short $\left(w_{t}<0\right)$ or leveraged $\left(w_{t}>1\right)$ positions. To study their impact on

\footnotetext{
${ }^{20}$ At the annual (non-overlapping) frequency we do not have a sufficient number of observations to carry a proper analysis.

${ }^{21}$ In this latter case, however, the results should be taken with caution as the number of parameters $(N \times K)$ becomes quite large compared to the number of (non-overlapping, annual) observations.
} 
performance, we follow Della Corte et al. (2008) and winsorize the weight between -1 and 2. The equalization fee from this constrained policy, reported in the last row of Table 6, is again significantly larger when CG is included, confirming that its economic relevance does not arise from taking extreme positions. In sum, after accounting for the monetary policy stance as proxied by the convergence gap, we find the time-varying component of bond risk premia to play an economically prominent role in dynamic portfolio choice. Our findings also show that departures from the Expectations Hypothesis at long maturities are indeed economically relevant.

\section{Additional Analysis}

This section collects additional analyses that extend our main set of results along several dimensions. Section 6.1 documents that the convergence gap forecasts bond excess returns in countries other than the U.S. Section 6.2 shows that the ability of the gap to forecast U.S. returns persists out-of-sample. Finally, Section 6.3 presents a battery of checks that confirm the robustness of our results to various definitions of the convergence gap, sampling frequency, and other concerns.

\subsection{International evidence}

So far, our analysis has relied on Fama-Bliss yield data for the U.S. Treasury market. One would expect the importance of the gap to extend also to other countries whose central banks follow explicit targeting policies.

We investigate whether our results hold internationally by estimating the regression on future average excess returns for three other countries, namely Canada, the UK, and Germany. We take the corresponding one- to five-year artificial zero coupon bond yields at the monthly frequency from the Bank of Canada, Bank of England, and Bundesbank, respectively. We construct the convergence gap as the difference between the natural rate of interest and the 
real interest rate. To proxy for the natural rate of interest we use the estimates from Holston et al. (2017). The short-term interest rate is: the Bank of Canada's target for the overnight rate for Canada; the Bank of England's Official Lending Rate, published by the Bank of England, for the U.K.; and the three-month rate from the Area Wide Model (Fagan et al., 2001) for Germany (Eurozone from 1999 onward). For all countries, the inflation series is constructed by splicing the core price index with an all-items price index. ${ }^{22}$

Table 7 collects the slope coefficients from predicting annual average bond returns for these countries using the same format as Panel A of Table 1. In specification (1), we observe that forward rates alone explain $17 \%$ of bond return variability in Canada and the UK, and as much as $28 \%$ in Germany. In specification (2), we note that the convergence gap alone enters the regression with a negative coefficient. However, it does not meet statistical significance and the associated $\mathrm{R}^{2}$ is quite modest. As it was the case for the U.S., including both forward rates and CG leads to a sharp increase in goodness of fit and statistical significance. Indeed, the gap enters the regression with a significantly (at the $5 \%$ level or better) negative coefficient in all three countries. The in-sample $\mathrm{R}^{2}$ increases by $30 \%$ (from 0.28 to 0.36 ) for Germany, by $50 \%$ (from 0.17 to 0.26 ) for the U.K., and by $100 \%$ (from 0.17 to 0.34 ) for Canada. The last column reports the equalization fee for models (1) and (3) from the corresponding mean-variance dynamic optimization exercise as in Table 6. For all three countries, the inclusion of CG leads to an increase in the equalization fee in the order of $1.5 \%-$ $2 \%$. Overall, we find this evidence that the convergence gap enhances return predictability and retains economic value in countries (and over different sample periods) other than the U.S. rather reassuring of the robustness of our findings.

It is also natural to ask to what extent the convergence gaps co-move in the cross-section of countries. Figure E.1 in the Appendix displays the time series over the common 19912017 period. We observe several instances of co-movements, in particular in the period from

\footnotetext{
${ }^{22}$ As above, we use a four-quarter moving average of past inflation as a proxy for inflation expectations in constructing the ex ante real interest rate. Unlike the U.S., however, we note that the CG for these countries exhibits a discernible trend. We therefore use a linearly detrended convergence gap in the regressions to prevent this trend from contaminating our results.
} 
the late 1990s to mid-2000s. Table 8 reports the correlation matrix of these series at the monthly and annual frequency, with underneath the corresponding fraction of overall variance accounted for by the principal components. Correlations are mostly positive but never exceed 0.50, with the U.S. featuring positive correlation up to 0.40 with U.K. and Canada, and a slightly negative correlation with Germany/Eurozone. The first principal component accounts for more than $40 \%$ of overall variance at both frequencies. This fact reveals the presence of sizable co-movements in CG across countries, and implies commonalities in the above-mentioned drivers and monetary policies. On the other hand, idiosyncratic (i.e., country-specific) movements also play a non-negligible role, as reflected by the importance of the other principal components.

\subsection{Out-of-sample analysis}

We conduct a recursive experiment to investigate whether our results also hold in an out-of-sample environment. ${ }^{23}$ We consider as a burn-in sample the first 25-year period from 1964:1 to 1989:12. Using only information until the end of this period, we construct the CP and CPG factors following the methodology described in Section 3.1. Next, we regress each individual bond excess return on the lagged factors to determine their individual loadings, similarly to what reported in Table 2 for the full sample. Due to the predictive nature of the regression, the last observation in the right-hand-side variables is that of December 1988. We use the resultant coefficients and the value of the CP and CPG factors on December 1989 to produce out-of-sample forecasts of one-year ahead excess returns for each maturity. The first forecast error obtains by comparing the excess holding period realized return during the January 1990 through December 1990 period and its forecast made on December 1989. We then include the January 1990 information and follow the same procedure to produce forecasts of the February 1990 through January 1991 returns, and so on until the end of 2017. Since

\footnotetext{
${ }^{23}$ Out-of-sample tests are usually viewed as important tools to detect spurious, sample-specific evidence. However, as Cochrane (2008) points out poor out-of-sample predictability may arise even when the true data-generating-process is characterized by time-varying, persistent risk premia.
} 
the GDP information is available only on a quarterly basis, we keep the filtered permanent growth GDP component constant throughout the three months following a quarter's end.

In Table 9, we summarize the results of this exercise for the four individual bond returns. We contrast the forecasting accuracy of Model 1, which includes the convergence gap, with that of Model 2, which excludes it. Both models incorporate a constant term. The ratio of the mean squared forecast errors $M S F E_{1} / M S F E_{2}$, reported in the third column, tells us whether the model with CG features lower (ratios less than one) or higher (ratios above one) forecast errors than the competing model. To gauge statistical significance, the column "DM test" reports the $p$-values for the Diebold and Mariano (1995) test on the difference in MSFEs.

In the first row of each panel, Model 2 consists of a constant term only, i.e. we benchmark the gap against the naive historical mean estimator. The inclusion of CG leads to a decline in MSFE of about $8 \%$ across the maturity spectrum, statistically significant at the $2 \%$ level at all maturities.

In the second row, Model 2 consists of the CP factor, and, thus, it exploits information in forward rates only. Adding CG in the conditioning set leads to a surge in out-of-sample prediction accuracy across all bonds, with MSFEs declining by about $25 \%$. This improvement is economically large, and strongly statistically significant.

In the third row, we contrast the model with $\mathrm{CPG}$ with a model that combines $\mathrm{CP}$ with the Cieslak and Povala (2015)'s cyclical factor. Conditioning on the convergence gap improves the forecasting ability of forward rates in an out-of-sample fashion even after controlling for the inflation-driven cycle, $c f_{t}$. Indeed, the inclusion of CG reduces the MSFE by about $25 \%$ across maturities. However, as we discussed in Section 3.2 and 3.3, the evidence points to substantial predictive content of CPG for short-term and intermediate maturities, while the contribution of $c f_{t}$ becomes more sizable as we increase the maturity of the bonds. In line with this analysis, we find that the MSFE improvement obtained by using the convergence gap is statistically significant at standard confidence levels for short- and 
medium-term bonds but it becomes insignificant at the longest 5-year maturity.

Hence, the third row confirms the maturity-dependence of the impact of CPG and $c f_{t}$ factors on bond risk premium. It is natural to postulate that the two cycles together should deliver good performance across the term structure. To this end, in the last row we add the $c f_{t}$ factor to either $\mathrm{CPG}$ or $\mathrm{CP}$. In line with our hypothesis, we observe that the specification including $\mathrm{CPG}_{t}$ and $c f_{t}$ leads to a reduction in MSFE that is statistically significant for all bond maturities. Taken together, the evidence in rows three and four clarifies that CG provides complementary information on bond risk premia compared to that in $c f_{t}$.

In order to further explore the provenance of these results, we investigate whether the improvements arise from a reduction in the bias or in the variance of the forecast errors through Ashley et al. (1980)'s test. ${ }^{24}$ The $p$-values of these tests are reported in columns "Bias" and "Variance", respectively. It is clear that the improvement from adding CG to the model comes from a reduction in the bias of the forecast errors and, to a lesser extent, from a variance reduction.

\subsection{Robustness checks and other concerns}

Alternative Measures of Convergence Gap: In Tables E.1-E.4, we experiment several alternatives to the construction of CG. Details are provided in Appendix E.

In Table E.1, we replace the one-sided HP filtered trend component of real GDP with the potential GDP series obtained by Laubach and Williams (2003) using a Kalman filter. In Table E.2, we instead replace the one-sided HP filtered trend component of real GDP with the Kalman filter natural-rate estimates - denoted $r_{t}^{*}$ - by Holston et al. (2017). In Table E.3 we follow Laubach and Williams (2003) and use the forecast of the twelve-monthahead percentage change in core PCE generated from a univariate $\mathrm{AR}(9)$ estimated over

\footnotetext{
${ }^{24}$ Let $\widehat{e}_{1 t}$ and $\widehat{e}_{2 t}$ denote the forecast errors for Model 1 and 2, respectively. Define $\Delta_{t}=\widehat{e}_{1, t}-\widehat{e}_{2, t}$, $\Sigma_{t}=\widehat{e}_{1, t}+\widehat{e}_{2, t}$ and $\bar{\Sigma}$ its time-series average. We estimate regression: $\Delta_{t}=\beta_{0}+\beta_{1}\left(\Sigma_{t}-\bar{\Sigma}\right)+u_{t}$. The $t$-statistic for $\beta_{0}$ measures the bias improvement of Model 1 versus Model 2, while the $t$-statistic for $\beta_{1}$ captures reduction in the error variance. See Berardi and Torous (2005) for a paper using this test in term structure modeling.
} 
the prior 120 months as a proxy for inflation expectations in constructing the ex ante real interest rate. Survey data is an appealing alternative to model-based expectations, but at the cost of reduced sample size as it starts only in 1981. In Table E.4 we use CPI inflation forecasts from the Survey of Professional Forecasters (SPF) to construct the real rate from 1981 onwards, and we splice it with a four quarter moving average of past CPI inflation. ${ }^{25}$ We use such proxy for inflation expectations in constructing the ex-ante real interest rate. We find that all these variations generally produce comparable, or even stronger, results than those reported in Table 1.

Alternative sampling frequencies, period, and vintage data: In Panel A of Table 10, we report the results for average excess returns $\overline{r x}_{t+1}$ when data are sampled at the quarterly and annual frequency. The quarterly series does not require GDP data to be interpolated in the construction of CG. The yearly frequency addresses econometric concerns arising from the use of overlapping returns (see Bauer and Hamilton, 2017, for a discussion) by relying on non-overlapping observations, at the cost of a much smaller sample size. For comparison, we report in the table the R-squared $\left(R_{f w d}^{2}\right)$ when using forward rates only as regressors. In both specifications, the coefficient on $\mathrm{CG}$ is again negative at about -8 , and statistically significant with reverse regressions $t$-statistics below -3 . The associated $R^{2}$ confirms that forward rates conditional on the gap capture substantial incremental time-variation in bond risk premia.

In Panel B, we verify the robustness of our findings to excluding the zero-lower-bound period. To this end, we re-estimate our baseline model when ending the sample in November, 2008. As we can see, the results mimic quite closely those from Table 1, which indicates that our conclusions also hold when excluding the period of unconventional monetary policy.

In Panel C, we report analogous results when constructing the convergence gap using vintage data for GDP and inflation. ${ }^{26}$ Vintage series for inflation start being available in

\footnotetext{
${ }^{25}$ In the fixed-income literature, Chun (2011) includes survey expectations in the estimation of an arbitragefree affine term structure model, and shows that GDP growth forecasts play a crucial role in tracking bond risk premia.

${ }^{26}$ Ghysels et al. (2018) provide evidence that bond risk premia predictability using macroeconomic infor-
} 
1996. Starting on January 1996, we construct CG based on recursive estimations that use the vintage data available until that calendar quarter end. ${ }^{27}$ Panel $\mathrm{B}$ reports the corresponding results. The coefficient on CG remains negative and significant, although its magnitude is smaller than that in Panel, and the increments in R-squared compared to the forward-only specification remain large.

Additional risk factors: It is natural to ask whether the convergence gap merely captures macroeconomic conditions. To this end, Appendix Table E.5 displays results for individual bonds predictive regressions when we control for the Ludvigson and Ng (2009)'s F5 macro factor. This factor is obtained as a linear combination (from a subset) of the first eight principal components formed from more than 130 macroeconomic and financial time series. ${ }^{28}$ Importantly, specification (3) shows that both CG and F5 are significant predictors of bond excess returns across all maturities. We conclude that the convergence gap increases the forecasting ability of forward rates over and beyond macroeconomic risk.

We also investigate whether empirically interest rate volatility and CG provide different information on monetary policy stance. In particular, we predict average excess returns (as in Table 1) employing both forward rates and $\mathrm{CG}_{t}$ as predictors, but also controlling for three alternative measures of realized volatility. The first two measures are monthly realized volatility computed from daily data of 1-year yield, and 3-month T-Bill, respectively. ${ }^{29}$ The third measure is based on a 12-month rolling standard deviation of FFR. Table E.6 reports the results. In all three cases we observe that our conclusion continues to hold: The convergence gap enters the regression with a negative sign and its statistical significance is hardly affected. On the contrary, interest rates volatility is never significant independently from the mation is largely attenuated when taking into account the actual data release.

${ }^{27}$ To fix ideas, on a given quarter, say 1998:Q3, we construct the convergence gap using the most recent GDP release as of the end of that calendar quarter (that is, September 1998), which refers to real GDP in the previous quarter (namely, 1998:Q2). For inflation, we take the one-year moving average of the vintage data, which is again lagged by one month and ignores subsequent revisions. We then move forward by one quarter, and add the last observation for CG (1998:Q4) to the series obtained using data until 1998:Q3.

${ }^{28}$ We kindly thank Sydney Ludvigson for making the principal components available on her website.

${ }^{29}$ We also replace T-bill by the FFR but we found that in this case the monthly realized volatility was essentially flat for quite long periods, at times several months. 
measure employed.

A Term Structure Model with the Convergence Gap: In Appendix F we cast our CPG risk factor in the context of a standard affine term structure model, where yields and risk premia are jointly determined. We show that CPG plays the role of an unspanned factor, and raises the cyclicality of the model-implied expected excess returns, consistent with our regression-based evidence.

Fama-Bliss Present-Value Restrictions: To further trace the role of the gap, we rely on univariate Fama-Bliss regressions that use the forward spread corresponding to the bond maturity, instead of the full spectrum of rates. In Appendix G, we review the Fama and Bliss (1987) accounting identity, and extend it to the case of regressors other than yields, forward rates, or combinations thereof. Consistent with the previous (multivariate) evidence, we show that the success of the convergence gap (or better, of its orthogonal component with respect to forward spreads) to enhance bond predictability stems from its ability to significantly forecast bond returns and future yields with the opposite sign, see Table G.1.

\section{Concluding Remarks}

We study the ability of the Convergence Gap (CG), i.e. the difference between the natural rate of interest and the ex-ante real Fed funds rate, to improve our understanding of bond risk premia. This variable appears as a natural candidate to capture correlated cyclical variations in yields and risk premia, given that, over our sample, positive values of CG are recorded in periods that anticipate an increase in future yields and economic activity, i.e. periods when risk premia are likely to decline. We find strong support for the role of CG in the context of return and yield predictive regressions. On the one hand, a linear combination of forward rates and the convergence gap explains $33 \%$ of the variability in average and individual bond returns during the 1964-2017 period.

The information embedded in CG is not only statistically, but also economically relevant. 
While risk premia solely based on forward rates tend to miss cyclical patterns, controlling for CG delivers forecast errors that are virtually uncorrelated with the business cycle. In addition, CG brings significant economic gains when used as a conditioning variable in a dynamic fixed-income asset allocation problem. The importance of the gap extends to countries other than the U.S., persists out-of-sample and is not subsumed by a wide array of other factors. Overall, our results shed new light on the link between the conduct of monetary policy, bond prices, and risk premia. 


\section{References}

Adrian, Tobias, Richard Crump, and Emmanuel Moench (2013) "Pricing the term structure with linear regressions," Journal of Financial Economics, Vol. 110, pp. 110-138.

Amato, Jeffery D. (2005) "The Role of the Natural Rate of Interest in Monetary Policy," CESifo Economic Studies, Vol. 51, No. 4, pp. 729-755.

Anderson, Nicola and John Sleath (2001) "New estimates of the UK real and nominal yield curves," bank of england working papers, Bank of England.

Aruoba, S. Borayan, Francis X. Diebold, and Chiara Scotti (2009) "Real-Time Measurement of Business Conditions," Journal of Business 83 Economic Statistics, Vol. 27, No. 4, pp. 417-427.

Ashley, R., C. W. J. Granger, and R. Schmalensee (1980) "Advertising and Aggregate Consumption: An Analysis of Causality," Econometrica, Vol. 48, pp. 1149-1167.

Bandi, Federico and Andrea Tamoni (2018) "Long-run Economic Uncertainty." Working Paper.

Barsky, Robert, Alejandro Justiniano, and Leonardo Melosi (2014) "The Natural Rate of Interest and Its Usefulness for Monetary Policy," American Economic Review, Vol. 104, No. 5, pp. 37-43, May.

Bauer, Michael D. and James D. Hamilton (2017) "Robust Bond Risk Premia," The Review of Financial Studies, Vol. 31, No. 2, pp. 399-448, 09.

Bauer, Michael and Glenn Rudebusch (2017) "Interest Rates Under Falling Stars," Working Paper Series 2017-16, Federal Reserve Bank of San Francisco.

Berardi, Andrea and Walter Torous (2005) "Term Structure Forecasts of Long-Term Consumption Growth," Journal of Financial and Quantitative Analysis, Vol. 40, No. 2, pp. 241-258.

Bliss, Robert R. (1997) "Movements in the term structure of interest rates," Economic Review, Vol. 82, No. Q 4, pp. 16-33.

Bomfim, Antulio N. (1997) "The Equilibrium Fed Funds Rate and the Indicator Properties of the Term-Structure Spreads," Economic Inquiry, Vol. 35, No. 4, pp. 830-846.

Brandt, Michael W. and Pedro Santa-Clara (2006) "Dynamic Portfolio Selection by Augmenting the Asset Space," Journal of Finance, Vol. 61, p. 5.

Brandt, Michael, Pedro Santa-Clara, and Rossen Valkanov (2009) "Parametric portfolio policies: Exploiting characteristics in the cross section of equity returns," Review of Financial Studies, Vol. 22, pp. 3411-3447.

Campbell, John Y. and Robert J. Shiller (1988) "The Dividend-Price Ratio and Expectations of Future Dividends and Discount Factors," Review of Financial Studies, Vol. 1, No. 3, pp. 195-228.

Campbell, John Y. and R. J. Shiller (1991) "Yield Spreads and Interest Rate Movements: A Bird's Eye View," Review of Economic Studies, Vol. 58, No. 3, pp. 495-514. 
Campbell, John and Samuel B. Thompson (2008) "Predicting Excess Stock Returns Out of Sample: Can Anything Beat the Historical Average?" Review of Financial Studies, Vol. 21, No. 4, pp. $1509-1531$.

Cheridito, Patrick, Damir Filipovic, and Robert L. Kimmel (2007) "Market price of risk specifications for affine models: Theory and evidence," Journal of Financial Economics, Vol. 83, No. 1, pp. $123-170$.

Chun, Albert Lee (2011) "Expectations, Bond Yields, and Monetary Policy," Review of Financial Studies, Vol. 24, No. 1, pp. 208-247.

Cieslak, Anna and Pavol Povala (2015) "Expected Returns in Treasury Bonds," Review of Financial Studies, Vol. 28, No. 10, pp. 2859-2901.

Clark, Todd E. and Kenneth D. West (2007) "Approximately normal tests for equal predictive accuracy in nested models," Journal of Econometrics, Vol. 138, No. 1, pp. 291 - 311.

Cochrane, John H. (2008) "The Dog That Did Not Bark: A Defense of Return Predictability," Review of Financial Studies, Vol. 21, No. 4, pp. 1533-1575, July.

Cochrane, John (2011) "Presidential Address: Discount Rates," Journal of Finance, Vol. 66, No. 4, pp. $1047-1108$.

Cochrane, John H. and Monika Piazzesi (2005) "Bond Risk Premia," American Economic Review, Vol. 95, No. 1, pp. 138-160.

Cochrane, John and Monika Piazzesi (2008) "Decomposing the Yield Curve." Working paper, University of Chicago.

Cogley, Timothy, Giorgio E. Primiceri, and Thomas J. Sargent (2010) "Inflation-Gap Persistence in the US," American Economic Journal: Macroeconomics, Vol. 2, No. 1, pp. 43-69, January.

Cooper, Ilan and Richard Priestley (2009) "Time-Varying Risk Premiums and the Output Gap," The Review of Financial Studies, Vol. 22, No. 7, pp. 2801-2833.

Curdia, Vasco, Andrea Ferrero, Ging Cee Ng, and Andrea Tambalotti (2015) "Has U.S. monetary policy tracked the efficient interest rate?," Journal of Monetary Economics, Vol. 70, No. C, pp. $72-83$.

Della Corte, Pasquale, Lucio Sarno, and Daniel L. Thornton (2008) "The expectation hypothesis of the term structure of very short-term rates: Statistical tests and economic value," Journal of Financial Economics, Vol. 89, No. 1, pp. 158 - 174.

Diebold, F. X. and R. S. Mariano (1995) "Comparing Predictive Accuracy," Journal of Business and Economic Statistics, Vol. 13, pp. 253-263.

Duffee, Gregory R. (2002) "Term Premia and Interest Rate Forecasts in Affine Models," Journal of Finance, Vol. 57, No. 1, pp. pp. 405-443.

(2011) "Information in (and not in) the Term Structure," Review of Financial Studies, Vol. 24, pp. 2895-2934. 
Fagan, Gabriel, Jerome Henry, and Ricardo Mestre (2001) "An area-wide model (AWM) for the euro area," Working Paper Series 0042, European Central Bank.

Fama, Eugene F. and Robert R. Bliss (1987) "The Information in Long-Maturity Forward Rates," American Economic Review, Vol. 77, No. 4, pp. 680-692.

Favero, Carlo, Arie E. Gozluklu, and Haoxi Yang (2016) "Demographics and the Behavior of Interest Rates," IMF Economic Review, Vol. 64, No. 4, pp. 732-776.

Gargano, Antonio, Davide Pettenuzzo, and Allan Timmermann (2019) "Bond Return Predictability: Economic Value and Links to the Macroeconomy," Management Science, Vol. 65, No. 2, pp. 508-540.

Garnier, Julien and Bjørn-Roger Wilhelmsen (2009) "The natural rate of interest and the output gap in the euro area: a joint estimation," Empirical Economics, Vol. 36, No. 2, pp. 297-319, May.

Geanakoplos, John, Michael Magill, and Martine Quinzii (2004) "Demography and the Long-Run Predictability of the Stock Market," Brookings Papers on Economic Activity, Vol. 1, pp. 241-352.

Ghysels, Eric, Casidhe Horan, and Emanuel Moench (2018) "Forecasting through the Rearview Mirror: Data Revisions and Bond Return Predictability," The Review of Financial Studies, Vol. 31, No. 2, pp. 678-714.

Ghysels, Eric, Alberto Plazzi, and Rossen Valkanov (2016) "Why Invest in Emerging Markets? The Role of Conditional Return Asymmetry," Journal of Finance, Vol. 71, pp. 2145-2192.

Giammarioli, Nicola and Natacha Valla (2004) "The natural real interest rate and monetary policy: a review," Journal of Policy Modeling, Vol. 26, No. 5, pp. 641-660.

Greenspan, A. (2005) "Federal Reserve Board's semiannual Monetary Policy Report to the Congress,"Technical report, Board of the Governors of the Federal Reserve System.

Gürkaynak, Refet, Brian Sack, and Jonathan Wright (2007) "The U.S. Treasury yield curve: 1961 to the present," Journal of Monetary Economics, Vol. 54, No. 8, pp. 2291-2304.

Gurkaynak, Refet S., Brian Sack, and Jonathan H. Wright (2010) "The TIPS Yield Curve and Inflation Compensation," American Economic Journal: Macroeconomics, Vol. 2, No. 1, pp. 7092, January.

Hodrick, Robert J. (1992) "Dividend Yields and Expected Stock Returns: Alternative Procedures for Inference and Measurement," The Review of Financial Studies, Vol. 5, No. 3, pp. 357-386, 05 .

Hodrick, Robert J. and Edward C. Prescott (1997) "Postwar U.S. Business Cycles: An Empirical Investigation," Journal of Money, Credit and Banking, Vol. 29, No. 1, pp. 1-16.

Holston, Kathryn, Thomas Laubach, and John C. Williams (2017) "Measuring the natural rate of interest: International trends and determinants," Journal of International Economics, Vol. 108, No. S1, pp. 59-75. 
Joslin, Scott and Anh Le (2016) "Interest Rate Volatility and No-Arbitrage Affine Term Structure Models," Working Paper Series 0042, University of Southern California, Los Angeles.

Joslin, Scott, Marcel Priebsch, and Kenneth J. Singleton (2014a) "Risk Premiums in Dynamic Term Structure Models with Unspanned Macro Risks," The Journal of Finance, Vol. 69, No. 3, pp. 1197-1233.

(2014b) "Risk Premiums in Dynamic Term Structure Models with Unspanned Macro Risks," Journal of Finance, Vol. 69, No. 3, pp. 1197-1233, June.

Kaplan, Robert S. (2018) "The Neutral Rate of Interest," essays and speeches by president robert s. kaplan, 2018. Federal Reserve Bank of Dallas.

Kiefer, Nicholas M. and Timothy J. Vogelsang (2005) "A New Asymptotic Theory For Heteroskedasticity-Autocorrelation Robust Tests," Econometric Theory, Vol. 21, No. 06, pp. 1130-1164, December.

Kiley, Michael T. (2015) "What Can the Data Tell Us About the Equilibrium Real Interest Rate?," Finance and Economics Discussion Series 2015-77, Board of Governors of the Federal Reserve System (U.S.).

Kozicki, Sharon and P. A. Tinsley (2001) "Shifting endpoints in the term structure of interest rates," Journal of Monetary Economics, Vol. 47, No. 3, pp. 613-652, June.

Laubach, Thomas and John C. Williams (2003) "Measuring the natural rate," The Review of Economics and Statistics, Vol. 85, pp. 1063-1070.

Le, Anh and Kenneth J. Singleton (2013) "The Structure of Risks in Equilibrium Affine Models of Bond Yields," working paper series, Stanford GSB.

Ludvigson, Sydney C. and Serena Ng (2009) "Macro Factors in Bond Risk Premia," Review of Financial Studies, Vol. 22, No. 12, pp. 5027-5067, December.

Lunsford, Kurt G. and Kenneth D. West (2019) "Some Evidence on Secular Drivers of US Safe Real Rates," American Economic Journal: Macroeconomics, Vol. 11, No. 4, pp. 113-139.

Markovich, Michael and Alberto Plazzi (2013) "Predicting Yields for Predicting Returns." Working paper, USI Lugano.

Mesonnier, Jean-Stephane and Jean-Paul Renne (2007) "A time-varying natural rate of interest for the euro area," European Economic Review, Vol. 51, No. 7, pp. 1768-1784, October.

Modigliani, F. and L. Modigliani (1997) "Risk-adjusted performance," Journal of Portfolio Management, Vol. 23, pp. 45-54.

Neiss, Katharine S. and Edward Nelson (2003) "The Real-Interest-Rate Gap As An Inflation Indicator," Macroeconomic Dynamics, Vol. 7, No. 02, pp. 239-262, April.

Newey, Whitney K. and Kenneth D. West (1987) "A Simple Positive Semi-Definite, Heteroskedasticity and Autocorrelation Consistent Covariance Matrix," Econometrica, Vol. 55, pp. 703-708.

Orphanides, Athanasios and John C. Williams (2002) "Robust Monetary Policy Rules with Unknown Natural Rates," Brookings Papers on Economic Activity, Vol. 2002, No. 2, pp. 63-118. 
Romer, Christina and David Romer (1989) "Does Monetary Policy Matter? A New Test in the Spirit of Friedman and Schwartz," in NBER Macroeconomics Annual 1989, Volume 4: National Bureau of Economic Research, Inc, pp. 121-184.

Thornton, Daniel L. and Giorgio Valente (2012) "Out-of-Sample Predictions of Bond Excess Returns and Forward Rates: An Asset Allocation Perspective," Review of Financial Studies, Vol. 25, No. 10, pp. 3141-3168.

Waggoner, Daniel F. (1997) "Spline methods for extracting interest rate curves from coupon bond prices," FRB Atlanta Working Paper 97-10, Federal Reserve Bank of Atlanta.

Wei, Min and Jonathan H. Wright (2013) "Reverse Regressions and Long-Horizon Forecasting," Journal of Applied Econometrics, Vol. 28, No. 3, pp. 353-371.

West, Kenneth (1996) "Asymptotic Inference about Predictive Ability," Econometrica, Vol. 64, No. 5, pp. 1067-84.

Wicksell, K. (1936) Interest and Prices, London: Macmillan.

Williams, John C. (2016) "Monetary Policy in a Low R-star World," FRBSF Economic Letter, Vol. 23, pp. 1-5.

Woodford, M. (2003) Interest and Prices, Foundations of a Theory of Monetary Policy, Princeton: Princeton University Press.

Wright, Jonathan H. (2011) "Term Premia and Inflation Uncertainty: Empirical Evidence from an International Panel Dataset," American Economic Review, Vol. 101, No. 4, pp. 1514-34, June.

Yellen, Janet L. (2015) "Normalizing Monetary Policy: Prospects and Perspectives," speech delivered at the "the new normal monetary policy," san francisco, california march 27. Federal Reserve Bank of San Francisco. 


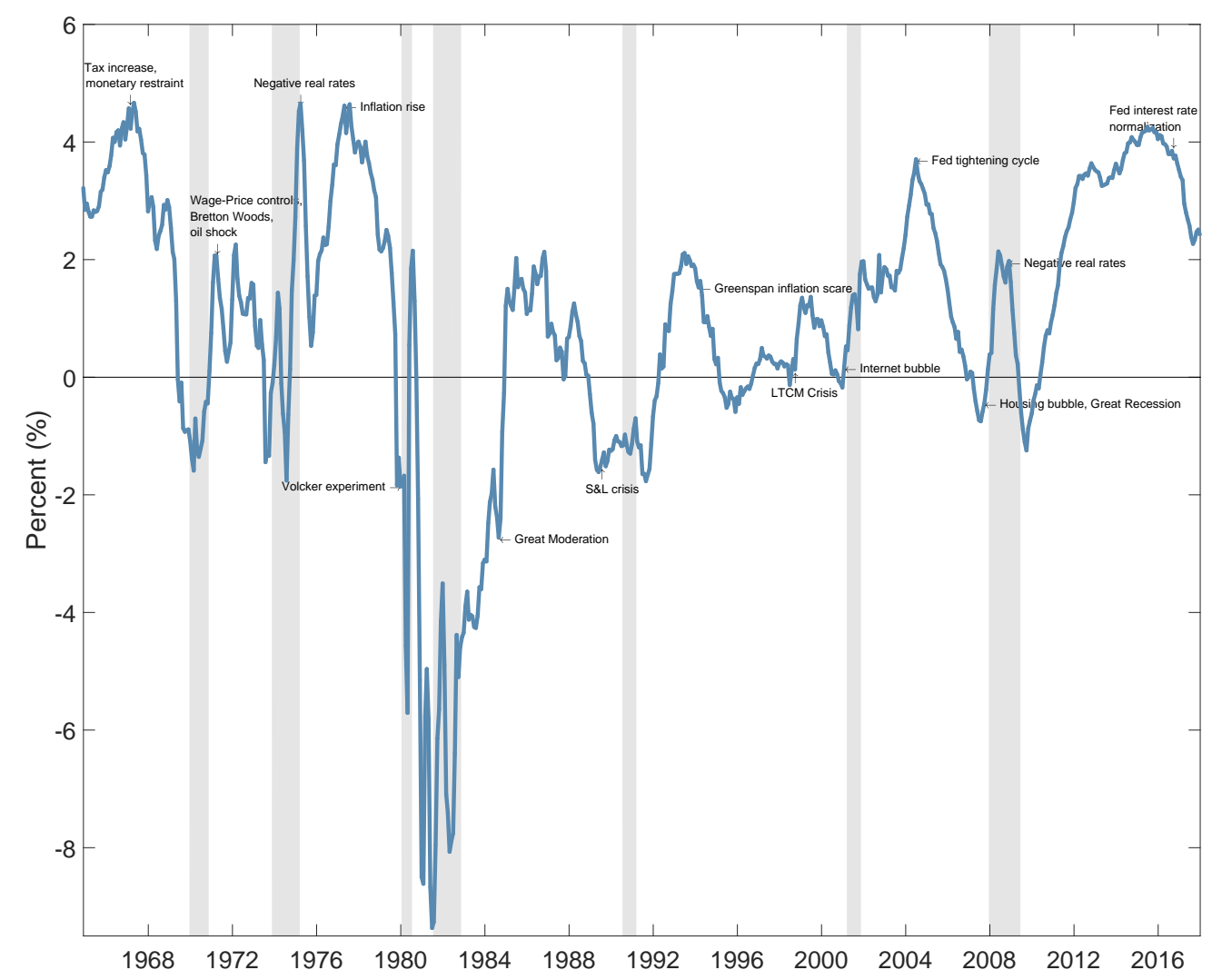

Figure 1: The convergence gap: This figure plots the time series of the convergence gap, CG. The sample period is $1964 / 01$ to $2017 / 12$.

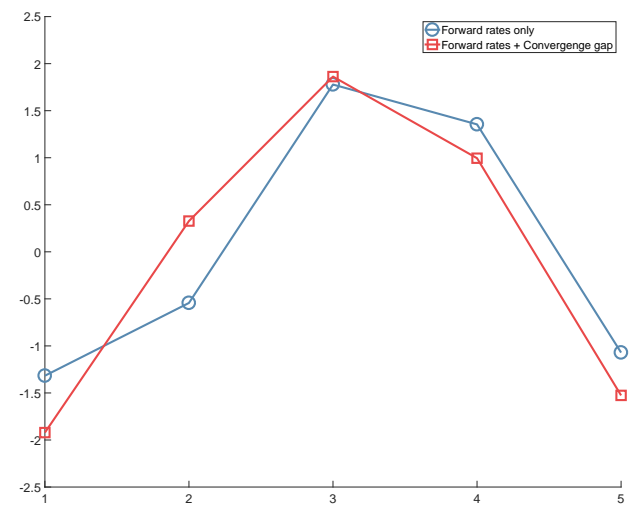

A: Regression coefficients on forward rates

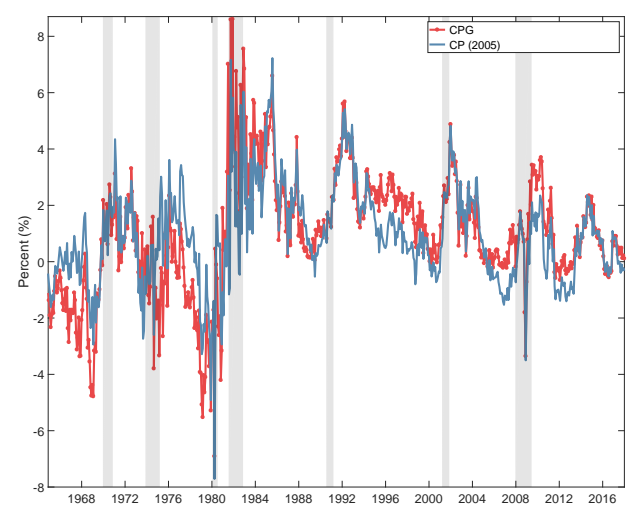

B: Bond risk factors

FIGURE 2: Estimating the return forecasting factor: This figure plots the unrestricted coefficients from a regression of bond excess returns on all forward rates, and from a regression of bond excess returns on all forward rates and the convergence gap (Panel A), and the bond risk factors (Panel B), namely the Cochrane and Piazzesi (2005) factor CP (solid line) and the CPG factor obtained by conditioning the forward rates on the convergence gap (dotted line). The sample period is 1964/01 to 2017/12. 


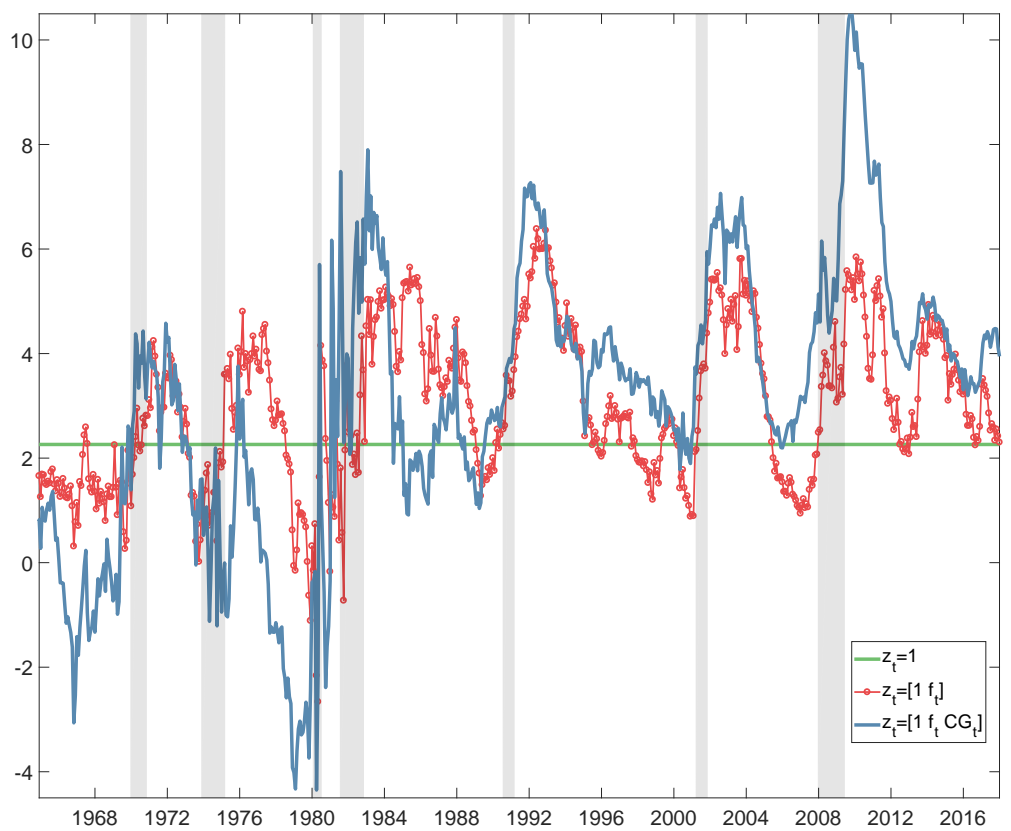

A: Monthly horizon

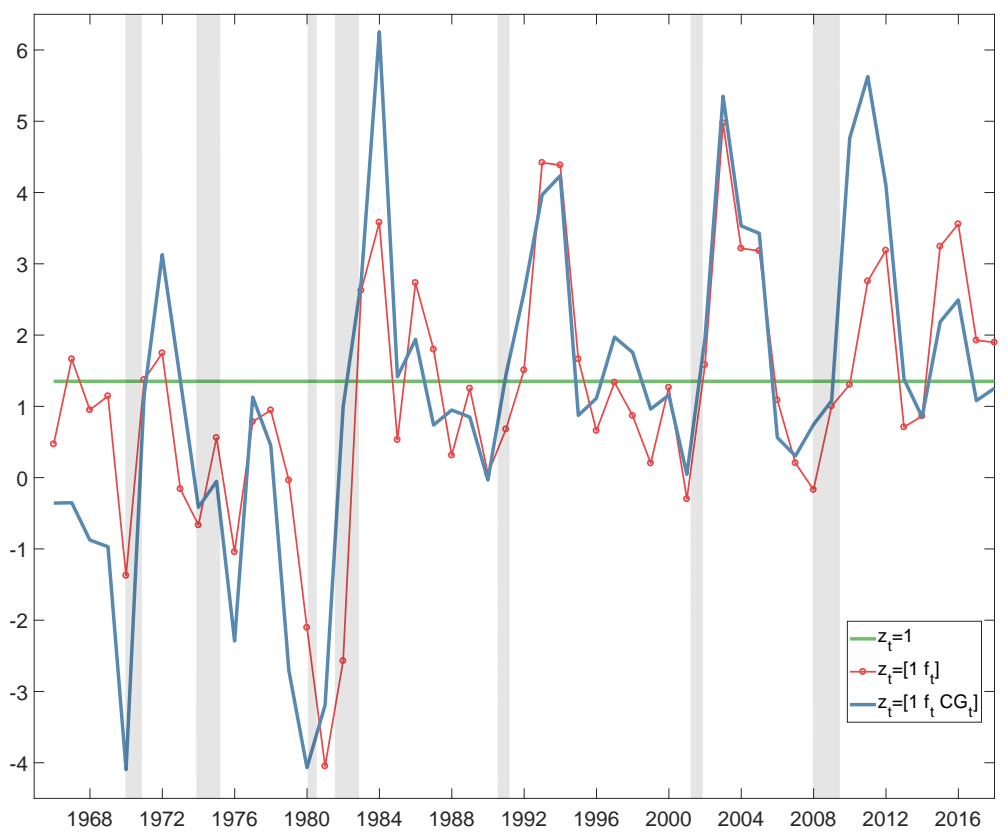

B: Annual horizon

Figure 3: Portfolio weight on bond portfolio: Time-series of the weight in the risky asset (bond portfolio) implied by the estimates of Table 6 at the monthly (top panel) and annual (bottom panel) horizon. The green solid line represents the unconditional allocation (specification (1) of Table 6), the solid line with circles corresponds to the policy conditional of forward rates (specification (2)), and the thick solid line tracks the portfolio weight implied by specification (3) which conditions on the forward rates and the convergence gap $C G_{t}$. The sample period is $1964 / 01$ to $2017 / 12$. 


\section{TABLE 1: Forecasting average (across maturity) bond excess returns}

Panel A of this table reports OLS slope coefficients and $R^{2}$ in the regression of future average (across maturities) annual excess returns $\overline{r x}_{t+1}$ on a constant and various combinations of lagged one- to five-year forward rates and the convergence gap, $\mathrm{CG}_{t}$. In parentheses, below the estimates, we report $t$-statistics computed using the reverse regression delta method by Wei and Wright (2013). The convergence gap, $C G_{t}$, is defined as the difference between the year-to-year log change in potential GDP and the real interest rate. To proxy for potential GDP we use the trend component of quarterly real GDP obtained from a one-sided Hodrick and Prescott (1997) filter. We linearly interpolate the resultant trend series to obtain monthly observations. The short-term interest rate is the annualized nominal funds rate, available from the Board of Governors. We use a four-quarter moving average of past inflation as a proxy for inflation expectations in constructing the ex ante real interest rate. Panel B reports the OLS slope coefficients and $R^{2}$ in the regression of the residuals from specifications $(\mathrm{CP})$ and $(\mathrm{CPG})$ of Panel $\mathrm{A}$. The residuals are projected on a constant and the following variables: inflation (CPI), the Chicago Fed National Activity Index (CFNAI), and the NBER recession dummy. In parentheses below the estimates we report $t$-statistics based on Newey and West (1987) standard errors with 60 lags. Significance: ${ }^{*} p<0.10,{ }^{* *} p<0.05,{ }^{* *} p<0.01$. The intercept estimates are omitted. The sample period is 1964/01 to 2017/12.

\begin{tabular}{|c|c|c|c|c|c|c|c|}
\hline \multicolumn{8}{|c|}{ Panel A: Forecasting average excess bond returns } \\
\hline Spec. & $f_{t}^{(1)}$ & $f_{t}^{(2)}$ & $f_{t}^{(3)}$ & $f_{t}^{(4)}$ & $f_{t}^{(5)}$ & $\mathrm{CG}_{t}$ & $R^{2}$ \\
\hline$(\mathrm{CP})$ & $\begin{array}{l}-1.46^{*} \\
(-1.67)\end{array}$ & $\begin{array}{c}-0.23 \\
(-0.54)\end{array}$ & $\begin{array}{c}1.61^{*} \\
(1.72)\end{array}$ & $\begin{array}{c}1.11^{*} \\
(1.88)\end{array}$ & $\begin{array}{c}-0.84^{*} \\
(-1.80)\end{array}$ & & 0.21 \\
\hline$(\mathrm{CG})$ & & & & & & $\begin{array}{l}-0.42^{* *} \\
(-2.16)\end{array}$ & 0.08 \\
\hline$(\mathrm{CPG})$ & $\begin{array}{l}-2.16^{* * *} \\
(-2.74)\end{array}$ & $\begin{array}{c}0.85 \\
(0.61)\end{array}$ & $\begin{array}{c}1.40^{*} \\
(1.79)\end{array}$ & $\begin{array}{c}1.07^{*} \\
(1.79)\end{array}$ & $\begin{array}{l}-1.46^{* * *} \\
(-3.12)\end{array}$ & $\begin{array}{l}-0.74^{* * *} \\
(-3.17)\end{array}$ & 0.33 \\
\hline \multicolumn{8}{|c|}{ Panel B: Forecasting residuals } \\
\hline Spec. & & $C P I_{t}$ & $C F N A I_{t}$ & $N B E R_{t}$ & & & $R^{2}$ \\
\hline$(\mathrm{CP})$ & & $\begin{array}{l}-0.33^{*} \\
(-2.24)\end{array}$ & $\begin{array}{l}-0.05^{* * *} \\
(-3.03)\end{array}$ & $\begin{array}{l}0.02^{* *} \\
(2.28)\end{array}$ & & & 0.13 \\
\hline$(\mathrm{CPG})$ & & $\begin{array}{c}-0.19 \\
(-1.12)\end{array}$ & $\begin{array}{c}-0.03 \\
(-1.53)\end{array}$ & $\begin{array}{c}0.01^{*} \\
(1.72)\end{array}$ & & & 0.06 \\
\hline
\end{tabular}




\section{TABLE 2: Forecasting individual bond excess returns}

This table reports OLS slope coefficients and $R^{2}$ in the regressions of future annual excess returns for bonds with maturities of two years (Panel A), three years (Panel B), four years (Panel C), and five years (Panel D). The table shows (1) to (4) specifications of the regressors. CP denotes Cochrane and Piazzesi (2005) forward rates factors. CPG denotes the fitted value from specification (3) in Panel A of Table 1, where forward rates are augmented with the convergence gap. The convergence gap, $\mathrm{CG}_{t}$, is defined as in Table 1 . cf denotes the cyclical factor of Cieslak and Povala (2015). In parentheses, below the estimates, we report $t$-statistics computed using the reverse regression delta method by Wei and Wright (2013). Significance: ${ }^{*} p<0.10$, ${ }^{* *} p<0.05,{ }^{* *} p<0.01$. All regressions include a constant term, whose coefficient is omitted. The sample period is $1964 / 01$ to $2017 / 12$.

\begin{tabular}{|c|c|c|c|c|c|c|c|c|c|}
\hline \multirow[b]{2}{*}{ Spec. } & \multicolumn{3}{|c|}{ Panel A: $r x_{t+1}^{(2)}$} & \multirow[b]{2}{*}{$R^{2}$} & \multicolumn{5}{|c|}{ Panel B: $r x_{t+1}^{(3)}$} \\
\hline & $\mathrm{CP}_{t}$ & $\mathrm{CPG}_{t}$ & $c f_{t}$ & & Spec. & $\mathrm{CP}_{t}$ & $\mathrm{CPG}_{t}$ & $c f_{t}$ & $R^{2}$ \\
\hline (1) & $\begin{array}{l}0.42^{*} \\
(1.89)\end{array}$ & & & 0.17 & (1) & $\begin{array}{c}0.81^{* * *} \\
(3.30)\end{array}$ & & & 0.19 \\
\hline (2) & & $\begin{array}{c}0.46^{* * *} \\
(3.36)\end{array}$ & & 0.32 & (2) & & $\begin{array}{c}0.85^{* * *} \\
(4.71)\end{array}$ & & 0.32 \\
\hline (3) & & & $\begin{array}{c}1.48^{* * *} \\
(3.14)\end{array}$ & 0.25 & (3) & & & $\begin{array}{c}2.88 * * * \\
(4.26)\end{array}$ & 0.29 \\
\hline (4) & $\begin{array}{l}-0.11 \\
(-0.45)\end{array}$ & & $\begin{array}{c}1.25^{* * *} \\
(2.81)\end{array}$ & 0.26 & (4) & $\begin{array}{c}0.19 \\
(0.68)\end{array}$ & & $\begin{array}{c}2.49 * * * \\
(2.73)\end{array}$ & 0.29 \\
\hline \multirow[t]{2}{*}{ (5) } & & $\begin{array}{l}0.34^{*} \\
(1.91)\end{array}$ & $\begin{array}{c}0.71 \\
(1.29)\end{array}$ & 0.35 & $(5)$ & & $\begin{array}{c}0.57^{* * *} \\
(2.74)\end{array}$ & $\begin{array}{c}1.57 \\
(1.62)\end{array}$ & 0.37 \\
\hline & \multicolumn{3}{|c|}{ Panel C: $r x_{t+1}^{(4)}$} & & \multicolumn{5}{|c|}{ Panel D: $r x_{t+1}^{(5)}$} \\
\hline Spec. & $\mathrm{CP}_{t}$ & $\mathrm{CPG}_{t}$ & $c f_{t}$ & $R^{2}$ & Spec. & $\mathrm{CP}_{t}$ & $\mathrm{CPG}_{t}$ & $c f_{t}$ & $R^{2}$ \\
\hline (1) & $\begin{array}{c}1.24^{* * *} \\
(3.67)\end{array}$ & & & 0.22 & (1) & $\begin{array}{c}1.52^{* * *} \\
(3.53)\end{array}$ & & & 0.22 \\
\hline (2) & & $\begin{array}{c}1.22^{* * *} \\
(5.02)\end{array}$ & & 0.34 & (2) & & $\begin{array}{c}1.47 * * * \\
(4.47)\end{array}$ & & 0.32 \\
\hline (3) & & & $\begin{array}{c}4.21^{* * *} \\
(4.78)\end{array}$ & 0.31 & (3) & & & $\begin{array}{c}5.40^{* * *} \\
(5.12)\end{array}$ & 0.33 \\
\hline (4) & $\begin{array}{c}0.39 \\
(0.79)\end{array}$ & & $\begin{array}{c}3.42^{* * *} \\
(2.92)\end{array}$ & 0.32 & (4) & $\begin{array}{c}0.36 \\
(0.28)\end{array}$ & & $\begin{array}{c}4.66 * * * \\
(3.60)\end{array}$ & 0.34 \\
\hline (5) & & $\begin{array}{c}0.79 * * * \\
(2.63)\end{array}$ & $\begin{array}{c}2.40^{* * *} \\
(2.14)\end{array}$ & 0.40 & $(5)$ & & $\begin{array}{l}0.86^{*} \\
(1.91)\end{array}$ & $\begin{array}{c}3.43^{* * *} \\
(2.79)\end{array}$ & 0.39 \\
\hline
\end{tabular}




\section{TABLE 3: Forecasting individual real bond excess returns}

This table reports OLS slope coefficients and $R^{2}$ in the regressions of future annual excess returns for real bonds with maturities of two years (Panel A), three years (Panel B), four years (Panel C), and five years (Panel D). The table shows (1) to (4) specifications of the regressors. CP denotes Cochrane and Piazzesi (2005) forward rates factors. CPG denotes the fitted value from specification (3) in Panel A of Table 1, where forward rates are augmented with the convergence gap. $c f$ denotes the cyclical factor of Cieslak and Povala (2015). In parentheses, below the estimates, we report $t$-statistics computed using the reverse regression delta method by Wei and Wright (2013). Significance: ${ }^{*} p<0.10,{ }^{* *} p<0.05,{ }^{* *} p<0.01$. All regressions include a constant term, whose coefficient is omitted. The sample period is 1999/01 to 2017/12.

\begin{tabular}{|c|c|c|c|c|c|c|c|c|c|}
\hline \multirow[b]{2}{*}{ Spec. } & \multicolumn{3}{|c|}{ Panel A: $r x_{t+1}^{(2)}$} & \multirow[b]{2}{*}{$R^{2}$} & \multicolumn{5}{|c|}{ Panel B: $r x_{t+1}^{(3)}$} \\
\hline & $\mathrm{CP}_{t}$ & $\mathrm{CPG}_{t}$ & $c f_{t}$ & & Spec. & $\mathrm{CP}_{t}$ & $\mathrm{CPG}_{t}$ & $c f_{t}$ & $R^{2}$ \\
\hline (1) & $\begin{array}{c}0.91^{* * *} \\
(2.67)\end{array}$ & & & 0.54 & (1) & $\begin{array}{c}0.86^{* * *} \\
(2.84)\end{array}$ & & & 0.37 \\
\hline (2) & & $\begin{array}{c}0.85^{* * *} \\
(2.91)\end{array}$ & & 0.53 & $(2)$ & & $\begin{array}{c}0.85^{* * *} \\
(3.09)\end{array}$ & & 0.40 \\
\hline (3) & & & $\begin{array}{c}1.42 \\
(1.21)\end{array}$ & 0.13 & (3) & & & $\begin{array}{c}1.84 \\
(1.59)\end{array}$ & 0.17 \\
\hline (4) & $\begin{array}{c}0.95 \\
(3.29)\end{array}$ & & $\begin{array}{c}-0.27 \\
(-0.45)\end{array}$ & 0.55 & (4) & $\begin{array}{c}0.78 \\
(2.91)\end{array}$ & & $\begin{array}{c}0.46 \\
(0.26)\end{array}$ & 0.37 \\
\hline \multirow[t]{2}{*}{ (5) } & & $\begin{array}{c}0.87 * * * \\
(3.30)\end{array}$ & $\begin{array}{c}-0.11 \\
(-0.33)\end{array}$ & 0.53 & $(5)$ & & $\begin{array}{c}0.78^{* * * *} \\
(3.01)\end{array}$ & $\begin{array}{c}0.48 \\
(0.22)\end{array}$ & 0.40 \\
\hline & \multicolumn{3}{|c|}{ Panel C: $r x_{t+1}^{(4)}$} & & \multicolumn{5}{|c|}{ Panel D: $r x_{t+1}^{(5)}$} \\
\hline Spec. & $\mathrm{CP}_{t}$ & $\mathrm{CPG}_{t}$ & $c f_{t}$ & $R^{2}$ & Spec. & $\mathrm{CP}_{t}$ & $\mathrm{CPG}_{t}$ & $c f_{t}$ & $R^{2}$ \\
\hline (1) & $\begin{array}{c}1.08^{* * *} \\
(2.98)\end{array}$ & & & 0.34 & (1) & $\begin{array}{c}1.16^{* * *} \\
(2.96)\end{array}$ & & & 0.28 \\
\hline (2) & & $\begin{array}{c}1.09 * * * \\
(3.24)\end{array}$ & & 0.38 & $(2)$ & & $\begin{array}{c}1.20^{* * *} \\
(3.24)\end{array}$ & & 0.33 \\
\hline (3) & & & $\begin{array}{c}2.73^{* * *} \\
(2.00)\end{array}$ & 0.22 & (3) & & & $\begin{array}{c}3.37^{* * *} \\
(2.30)\end{array}$ & 0.24 \\
\hline (4) & $\begin{array}{c}0.86^{* * *} \\
(2.59)\end{array}$ & & $\begin{array}{c}1.21 \\
(0.88)\end{array}$ & 0.37 & $(4)$ & $\begin{array}{c}0.82^{* * *} \\
(2.29)\end{array}$ & & $\begin{array}{c}1.93 \\
(1.33)\end{array}$ & 0.34 \\
\hline (5) & & $\begin{array}{c}0.91^{* * *} \\
(2.77)\end{array}$ & $\begin{array}{c}1.14 \\
(0.77)\end{array}$ & 0.41 & (5) & & $\begin{array}{c}0.92^{* * * *} \\
(2.53)\end{array}$ & $\begin{array}{c}1.77 \\
(1.20)\end{array}$ & 0.38 \\
\hline
\end{tabular}




\section{TABLE 4: Predicting yield changes}

This table reports the out-of-sample $\mathrm{R}^{2}$ statistic, $\mathrm{R}_{\text {OoS }}^{2}$, of Campbell and Thompson (2008) from predicting $H$-year ahead one-year yields using three different models. Statistical significance for the $\mathrm{R}_{O o S}^{2}$ statistic is based on the $p$-value for the Clark and West (2007) out-of-sample MSPE-adjusted statistic; the statistic corresponds to a one-sided test of the null hypothesis that the competing forecasting model given in Column (1), (2), or (3) has equal expected square prediction error relative to the random walk (RW) forecasting model against the alternative hypothesis that the competing forecasting model has a lower expected square prediction error than the RW model. The specification "RW" (random walk) uses the current yield as best estimate of future yields. In the columns $s_{t}^{(5)}, \mathrm{CG}_{t}$, and $\left[s_{t}^{(5)} \mathrm{CG}_{t}\right]$ either the slope $\left(s_{t}^{(5)}=y_{t}^{(5)}-y_{t}^{(1)}\right)$, the convergence gap, or both, are used to predict future $H$-year changes in one-year yields. The estimates are then used to form one-year yields forecast. All predictive regressions include a constant term, whose estimate is omitted. The convergence gap, $\mathrm{CG}_{t}$, is defined as in Table 1 . The first forecast is made in $1989 / 12$, and the last forecast in 2016/12. The full sample period is $1964 / 01$ to $2017 / 12$.

\begin{tabular}{cccc}
\hline \hline Horizon $H$ (years) & $s_{t}^{(5)}$ & $\mathrm{CG}_{t}$ & {$\left[s_{t}^{(5)} \mathrm{CG}_{t}\right]$} \\
\hline 1 & -0.05 & 0.14 & 0.13 \\
& $(0.99)$ & $(0.00)$ & $(0.00)$ \\
2 & 0.03 & 0.15 & 0.20 \\
& $(0.16)$ & $(0.00)$ & $(0.00)$ \\
3 & 0.19 & 0.10 & 0.25 \\
& $(0.00)$ & $(0.01)$ & $(0.04)$ \\
4 & 0.22 & 0.02 & 0.18 \\
& $(0.00)$ & $(0.05)$ & $(0.00)$ \\
\hline \hline
\end{tabular}




\section{TABle 5: Economic Drivers of Convergence Gap}

This table explores the potential drivers of the convergence gap (see columns (1) to (3)), as well as drivers of the predictable component of bond risk premia (see columns (4) to (6)). Specifically, in columns (1) to (3) we report coefficient, $t$-statistic, and R-squared in the regression of CG onto a given driver, while columns (4) to (6) report analogous statistics for the fitted value from the previous regression as a predictor of bond returns (together with forward rates) in place of the raw CG. We collect the drivers into demographic measures (employment to population ratio; middle-to-young ratio proposed by Geanakoplos et al. (2004), life expectancy; and dependency ratio constructed as percent population younger than 20 or older than 64), variables related to economic growth (Arouba-Diebold-Scotti business conditions index; capacity utilization; labor force hours growth; and total factor productivity in the private, non-farm business sector), and capital flows (federal debt to GDP and current account to GDP). The convergence gap, $\mathrm{CG}_{t}$, is defined as in Table 1. The full sample period is $1964 / 01$ to $2017 / 12$.

\begin{tabular}{lcrrrrr}
\hline \hline & \multicolumn{3}{c}{ Regression on CG } & \multicolumn{3}{c}{ Regression on $\overline{r x}_{t+1}$} \\
& \multicolumn{1}{c}{$(1)$} & $(2)$ & $(3)$ & $(4)$ & $(5)$ & $(6)$ \\
& Coeff. & $t$-stat & $R^{2}$ & Coeff. & $t$-stat & $R^{2}-R_{f w d}^{2}$ \\
\hline & & & & & & \\
Demographic & & & & & & \\
Employment to Population & $0.97^{*}$ & 1.65 & 0.01 & $-1.74^{* * *}$ & -3.06 & 0.02 \\
Middle-Young & $-0.18^{* * *}$ & -2.93 & 0.07 & -0.38 & -0.80 & 0.00 \\
Life Expectancy & -0.95 & -0.84 & 0.01 & $2.38^{*}$ & -1.70 & 0.03 \\
Dependency Ratio & 0.11 & 0.88 & 0.02 & $-2.78^{* * *}$ & -2.97 & 0.06 \\
& & & & & & \\
Growth & & & & & & \\
Arouba-Diebold-Scotti & $0.07^{*}$ & 1.76 & 0.06 & $-1.14^{* *}$ & -2.19 & 0.04 \\
Capacity utilization & 0.08 & 1.15 & 0.02 & $-1.52^{*}$ & -1.90 & 0.01 \\
Labour hours & $0.24^{*}$ & 1.72 & 0.06 & $-0.92^{*}$ & -1.85 & 0.03 \\
TFP & $0.59^{*}$ & 1.85 & 0.16 & $-0.77^{* *}$ & -2.20 & 0.02 \\
& & & & & & \\
Flows & & & & & & \\
Fed debt/GDP & -0.16 & -1.41 & 0.03 & -0.71 & -0.75 & 0.01 \\
Current account/GDP & -0.02 & -0.96 & 0.01 & -1.46 & -1.11 & 0.00 \\
\hline \hline
\end{tabular}




\section{TABLE 6: Dynamic portfolio policies}

This table reports estimates of the portfolio policies for a quadratic utility investor with $\gamma=5$ at the monthly and annual horizon. For each horizon, three columns are displayed corresponding to different sets of conditioning variables: (1) includes a constant term; (2) adds one- to five- year forward rates; (3) adds the convergence gap CG. All conditioning variables except the constant are standardized. The first block of the Table reports the OLS coefficient $\theta$ associated to each variable, with $t$-statistics in parentheses below the estimates. $F$-test is the $p$-value for the test that all slope coefficients are jointly equal to zero. The annualized mean $\left(E\left(r_{p}\right)\right)$, annualized standard deviation $\left(\sigma_{p}\right)$, and annual Sharpe Ratio $\left(S R_{p}\right)$ of the corresponding optimal portfolio are displayed next. The last six rows report in order: (1) the equalization fee, i.e. the annual fee that the investor would pay to have access to the conditioning information; (2) the equalization fee when adjusting the optimal portfolio return by a one-way transaction cost of 10 basis points, as in Gargano et al. (2019); (3) the fee for a full out-of-sample exercise; (4) the equalization fee for an investor who is endowed with a power utility function with $\gamma=5$; (5) the equalization fee for the dynamic allocation when the investor optimizes across $N$ assets; (6) the equalization fee when weights are constrained between -1 and 2. The convergence gap, $\mathrm{CG}_{t}$, is defined as in Table 1 . The sample period is 1964/01 to 2017/12.

\begin{tabular}{|c|c|c|c|c|c|c|}
\hline & \multicolumn{3}{|c|}{ Monthly Returns } & \multicolumn{3}{|c|}{ Annual Returns } \\
\hline & (1) & $(2)$ & (3) & (4) & $(5)$ & $(6)$ \\
\hline \multirow[t]{2}{*}{ Const } & 2.261 & 2.891 & 3.039 & 1.305 & 1.183 & 1.146 \\
\hline & $(2.446)$ & $(2.389)$ & (2.798) & $(1.870)$ & $(1.745)$ & $(2.716)$ \\
\hline \multirow[t]{2}{*}{$f^{(1)}$} & & -6.006 & -8.465 & & -0.239 & -3.622 \\
\hline & & $(-2.234)$ & $(-2.951)$ & & $(-0.053)$ & $(-0.687)$ \\
\hline \multirow[t]{2}{*}{$f^{(2)}$} & & 3.549 & 6.745 & & -8.978 & -4.106 \\
\hline & & $(0.559)$ & $(0.970)$ & & $(-1.041)$ & $(-0.430)$ \\
\hline \multirow[t]{2}{*}{$f^{(3)}$} & & -7.761 & -8.484 & & 8.510 & 8.163 \\
\hline & & $(-2.337)$ & $(-2.761)$ & & $(1.838)$ & $(1.842)$ \\
\hline \multirow[t]{2}{*}{$f^{(4)}$} & & 3.483 & 2.831 & & 2.407 & 0.642 \\
\hline & & $(0.984)$ & $(0.737)$ & & $(0.781)$ & $(0.244)$ \\
\hline \multirow[t]{2}{*}{$f^{(5)}$} & & 6.505 & 4.651 & & -2.500 & -3.023 \\
\hline & & $(2.113)$ & $(1.319)$ & & $(-1.873)$ & $(-1.769)$ \\
\hline \multirow[t]{2}{*}{ CG } & & & -2.592 & & & -1.710 \\
\hline & & & $(-1.949)$ & & & $(-3.145)$ \\
\hline$F$-test & & 0.001 & 0.000 & & 0.000 & 0.000 \\
\hline$E\left(r_{p}\right)$ & 0.073 & 0.116 & 0.133 & 0.064 & 0.094 & 0.104 \\
\hline$\sigma_{p}$ & 0.067 & 0.114 & 0.128 & 0.059 & 0.095 & 0.099 \\
\hline$S R_{p}$ & 0.333 & 0.578 & 0.651 & 0.257 & 0.513 & 0.592 \\
\hline Eq. fee & & 0.022 & 0.031 & & 0.019 & 0.026 \\
\hline Eq. fee TC-adj & & 0.012 & 0.021 & & 0.019 & 0.026 \\
\hline Eq. fee OOS & & 0.005 & 0.019 & & - & - \\
\hline Eq. fee Power utility & & 0.018 & 0.027 & & 0.058 & 0.092 \\
\hline Eq. fee $\mathrm{N}$ assets & & 0.068 & 0.095 & & 0.092 & 0.102 \\
\hline Eq. fee $\left(w_{t} \in[-1,2]\right)$ & & 0.006 & 0.015 & & 0.013 & 0.017 \\
\hline
\end{tabular}




\section{TABLE 7: Forecasting average (across maturity) excess bond returns, international evidence}

This table reports the OLS slope coefficients and $R^{2}$ in the regression of future average annual excess returns $\overline{r x}_{t+1}$ on a constant and various combinations of lagged one- to five-year forward rates and the convergence gap, $\mathrm{CG}_{t}$. Panel A shows results for Canada, Panel B for UK, and Panel C for Germany (Eurozone from 1999 onward). The convergence gap, CG, is defined as the difference between the natural rate of interest and the real interest rate. To proxy for the natural rate of interest we use the estimates from Holston et al. (2017). Finally, the convergence gap has been linearly detrended. The short-term interest rate is: the Bank of Canada's target for the overnight rate in Panel A; the Bank of England's Official Lending Rate, published by the Bank of England, in Panel B; and the three-month rate from the Area Wide Model for the euro area (Fagan et al., 2001) in Panel C. For all countries, the inflation series is constructed by splicing the core price index with an all-items price index. We use a four-quarter moving average of past inflation as a proxy for inflation expectations in constructing the ex ante real interest rate. In parentheses below the estimates we report $t$-statistics based on Newey and West (1987) standard errors with 18 lags. Significance: ${ }^{*} p<0.10$, ${ }^{* *} p<0.05,{ }^{* *} p<0.01$. Significance is computed using the asymptotic theory of Kiefer and Vogelsang (2005). All regressions include a constant term, whose coefficient is omitted. The last column reports the equalization fee for models (1) and (3) from the corresponding mean-variance dynamic optimization exercise as in Table 6. The sample period is 1986/01 to 2017/12 for Canada and the UK, and 1991/01 to 2017/12 for Germany.

\begin{tabular}{ccccccccc}
\hline \hline \multicolumn{7}{c}{ Panel A: Forecasting $\overline{r x}_{t+1}$, Canada: $1986 / 01-2017 / 12$} \\
& $f_{t}^{(1)}$ & $f_{t}^{(2)}$ & $f_{t}^{(3)}$ & $f_{t}^{(4)}$ & $f_{t}^{(5)}$ & $\mathrm{CG}_{t}$ & $R^{2}$ & Eq. fee \\
\hline$(1)$ & -1.22 & 0.93 & -3.13 & $9.55^{*}$ & $-6.04^{* *}$ & & 0.17 & 0.006 \\
& $(-1.71)$ & $(0.44)$ & $(-0.74)$ & $(1.88)$ & $(-2.36)$ & & & \\
$(2)$ & & & & & & -0.28 & 0.03 & \\
& & & & & & $(-1.10)$ & & \\
$(3)$ & $-2.16^{* * *}$ & 0.15 & 2.60 & 0.59 & -1.09 & $-0.97^{* * *}$ & 0.34 & 0.019 \\
& $(-2.73)$ & $(0.07)$ & $(0.62)$ & $(0.12)$ & $(-0.46)$ & $(-5.41)$ & &
\end{tabular}

Panel B: Forecasting $\overline{r x}_{t+1}$, United Kingdom: 1986/01 - 2017/12

\begin{tabular}{ccccccccc} 
& $f_{t}^{(1)}$ & $f_{t}^{(2)}$ & $f_{t}^{(3)}$ & $f_{t}^{(4)}$ & $f_{t}^{(5)}$ & $\mathrm{CG}_{t}$ & $R^{2}$ & Eq. fee \\
\hline$(1)$ & -0.52 & 0.88 & -11.70 & 24.29 & -12.89 & & 0.17 & 0.023 \\
& $(-0.49)$ & $(0.15)$ & $(-0.67)$ & $(1.09)$ & $(-1.33)$ & & & \\
$(2)$ & & & & & & -0.24 & 0.01 & \\
& & & & & & $(-0.69)$ & & \\
$(3)$ & -1.54 & 2.02 & -8.10 & 12.26 & -4.35 & $-1.06^{* * *}$ & 0.26 & 0.043 \\
& $(-1.58)$ & $(0.38)$ & $(-0.54)$ & $(0.68)$ & $(-0.58)$ & $(-2.75)$ & &
\end{tabular}

Panel C: Forecasting $\overline{r x}_{t+1}$, Germany and Euro Area: 1991/01-2017/12

\begin{tabular}{ccccccccc} 
& $f_{t}^{(1)}$ & $f_{t}^{(2)}$ & $f_{t}^{(3)}$ & $f_{t}^{(4)}$ & $f_{t}^{(5)}$ & $\mathrm{CG}_{t}$ & $R^{2}$ & Eq. fee \\
\hline$(1)$ & -2.65 & -0.25 & 18.34 & -28.87 & 13.87 & & 0.28 & 0.078 \\
& $(-2.97)$ & $(-0.05)$ & $(1.34)$ & $(-1.67)$ & $(1.72)$ & & & \\
$(2)$ & & & & & & -0.20 & 0.01 & \\
& & & & & & $(-0.95)$ & & \\
$(3)$ & $-3.38^{* *}$ & 0.87 & 15.26 & -23.95 & 11.57 & $-0.66^{*}$ & 0.36 & 0.096 \\
& $(-2.81)$ & $(0.14)$ & $(1.07)$ & $(-1.46)$ & $(1.59)$ & $(-2.17)$ & & \\
\hline \hline
\end{tabular}




\section{TABLE 8: International co-movements}

This table reports the correlation matrix of the convergence gap series in the cross-section of countries at the monthly (left quadrant) and annual frequency (right quadrant), with underneath the corresponding fraction of overall variance accounted for by the fourth principal components $(\mathrm{PC} 1, \ldots, \mathrm{PC} 4)$. The convergence gap, $\mathrm{CG}$, is the difference between the natural rate of interest and the real interest rate. To proxy for the natural rate of interest we use the estimates from Holston et al. (2017). Finally, the convergence gap has been linearly detrended. The short-term interest rate is: the Bank of Canada's target for the overnight rate; the Bank of England's Official Lending Rate, published by the Bank of England; and the three-month rate from the Area Wide Model for the euro area (Fagan et al., 2001). For all countries, the inflation series is constructed by splicing the core price index with an all-items price index. We use a four-quarter moving average of past inflation as a proxy for inflation expectations in constructing the ex ante real interest rate. The sample period is $1991 / 01$ to $2017 / 12$.

\begin{tabular}{|c|c|c|c|c|c|c|c|c|c|}
\hline \multicolumn{5}{|c|}{ Correlation matrix, monthly freq. } & \multicolumn{5}{|c|}{ Correlation matrix, annual freq. } \\
\hline & US & CAN & UK & $\mathrm{DE} / \mathrm{EA}$ & & US & CAN & UK & $\mathrm{DE} / \mathrm{EA}$ \\
\hline US & 1.00 & 0.27 & 0.32 & -0.02 & US & 1.00 & 0.13 & 0.41 & -0.13 \\
\hline CAN & 0.27 & 1.00 & 0.32 & 0.46 & CAN & 0.13 & 1.00 & 0.41 & 0.50 \\
\hline UK & 0.32 & 0.32 & 1.00 & 0.03 & UK & 0.41 & 0.41 & 1.00 & -0.01 \\
\hline $\mathrm{DE} / \mathrm{EA}$ & -0.02 & 0.46 & 0.03 & 1.00 & $\mathrm{DE} / \mathrm{EA}$ & -0.13 & 0.50 & -0.01 & 1.00 \\
\hline \multicolumn{5}{|c|}{ PCA, monthly freq. } & \multicolumn{5}{|c|}{ PCA, annual freq. } \\
\hline & $\mathrm{PC} 1$ & $\mathrm{PC} 2$ & PC3 & $\mathrm{PC} 4$ & & $\mathrm{PC} 1$ & $\mathrm{PC} 2$ & PC3 & $\mathrm{PC} 4$ \\
\hline Fract. (\%) & 43.1 & 29.1 & 16.9 & 11.0 & Fract. (\%) & 43.1 & 33.6 & 14.7 & 8.6 \\
\hline
\end{tabular}




\section{TABLE 9: Forecasting individual bond excess returns, out-of-sample analysis}

This table reports the out-of-sample accuracy in forecasting individual bond excess returns of Model 1, which includes the CPG factor, defined as in Table 2, in the first, second and third rows, and the CPG factor and the the cyclical factor of Cieslak and Povala (2015), $c f$, in the fourth row; and Model 2, which includes the constant in the first row, the CP factor in the second row, and the $\mathrm{CP}$ and the $c f$ factor from Cieslak and Povala (2015) in the third and fourth rows. All models also include a constant term. The CP and $c f$ factors are re-estimated whenever a new observation is added to the sample. The first forecast is made in 1989/12, and the last forecast is in $2016 / 12$, for a total of 325 (overlapping) observations. $M S F E_{1} / M S F E_{2}$ denotes the ratio between the mean squared forecast error of Model 1 to Model 2. DM reports the $p$-value of the Diebold and Mariano (1995) test for the null hypothesis of zero difference in MSE between the models. Bias and Variance report, respectively, the $p$-value of the $t$-statistic for the intercept and slope in the regression of the difference in forecast errors on the demeaned sum of forecast errors of the two models. The convergence gap, $\mathrm{CG}_{t}$, is defined as in Table 1 , but is re-estimated whenever a new observation is added to the sample. The full sample period is $1964 / 01$ to $2017 / 12$.

\begin{tabular}{|c|c|c|c|c|c|}
\hline Model 1 & Model 2 & $M S F E_{1} / M S F E_{2}$ & DM test & Bias & Variance \\
\hline \multicolumn{6}{|c|}{ Panel A: $r x_{t+1}^{(2)}$} \\
\hline $\mathrm{CPG}$ & Constant & 0.927 & 0.013 & 0.266 & 0.342 \\
\hline $\mathrm{CPG}$ & $\mathrm{CP}$ & 0.759 & 0.002 & 0.000 & 0.038 \\
\hline $\mathrm{CPG}$ & {$[\mathrm{CP} c f]$} & 0.765 & 0.054 & 0.008 & 0.359 \\
\hline$[\mathrm{CPG} c f]$ & {$[\mathrm{CP} c f]$} & 0.833 & 0.000 & 0.000 & 0.004 \\
\hline \multicolumn{6}{|c|}{ Panel B: $r x_{t+1}^{(3)}$} \\
\hline $\mathrm{CPG}$ & Constant & 0.932 & 0.015 & 0.261 & 0.321 \\
\hline $\mathrm{CPG}$ & $\mathrm{CP}$ & 0.748 & 0.003 & 0.000 & 0.014 \\
\hline CPG & {$[\mathrm{CP} c f]$} & 0.765 & 0.077 & 0.009 & 0.418 \\
\hline$[\mathrm{CPG} c f]$ & {$[\mathrm{CP} c f]$} & 0.838 & 0.001 & 0.000 & 0.001 \\
\hline \multicolumn{6}{|c|}{ Panel C: $r x_{t+1}^{(4)}$} \\
\hline $\mathrm{CPG}$ & Constant & 0.915 & 0.013 & 0.253 & 0.200 \\
\hline $\mathrm{CPG}$ & CP & 0.729 & 0.002 & 0.000 & 0.013 \\
\hline $\mathrm{CPG}$ & {$[\mathrm{CP} c f]$} & 0.756 & 0.087 & 0.008 & 0.554 \\
\hline$[\mathrm{CPG} c f]$ & {$[\mathrm{CP} \quad c f]$} & 0.831 & 0.001 & 0.000 & 0.000 \\
\hline \multicolumn{6}{|c|}{ Panel D: $r x_{t+1}^{(5)}$} \\
\hline $\mathrm{CPG}$ & Constant & 0.926 & 0.017 & 0.251 & 0.202 \\
\hline $\mathrm{CPG}$ & $\mathrm{CP}$ & 0.732 & 0.003 & 0.000 & 0.018 \\
\hline $\mathrm{CPG}$ & {$[\mathrm{CP} c f]$} & 0.774 & 0.128 & 0.010 & 0.814 \\
\hline$[\mathrm{CPG} c f]$ & {$[\mathrm{CP} c f]$} & 0.840 & 0.001 & 0.000 & 0.001 \\
\hline
\end{tabular}




\section{TABLE 10: Robustness analysis}

This table reports OLS slope estimates and associated $t$-statistics (in parentheses) for the regression of excess bond returns on a constant, lagged one- to five-year forward rates, and various specifications of the additional regressors and sampling frequency. In Panel A the dependent variable is the average annual excess return $\overline{r x}_{t+1}$ and the estimates are for quarterly and yearly sampled observations. $R_{f w d}^{2}$ is the R-squared statistics for the specification with forward rates only. In Panel B, we re-estimate our baseline model but end the sample in November, 2008. In Panel $\mathrm{C}$, analogous results are reported when $C G$ is constructed using real-time vintage data. In Panel $\mathrm{D}$, the dependent variable is the monthly excess return on a portfolio of bonds with two to three years to maturity. RP denotes Duffee (2011)'s hidden factor. In parentheses, below the estimates, we report $t$-statistics computed using the reverse regression delta method by Wei and Wright (2013). Significance: ${ }^{*} p<0.10,{ }^{* *} p<0.05,{ }^{* * *} p<0.01$. All regressions include a constant term, whose coefficient is omitted. The sample period is 1964/01 to 2017/12, except for the last regression for which the sample ends on $2007 / 12$.

\begin{tabular}{lcccccccc}
\hline \hline \multicolumn{7}{c}{ Panel A: Quarterly and Annual Regressions } & & \\
Frequency & $f_{t}^{(1)}$ & $f_{t}^{(2)}$ & $f_{t}^{(3)}$ & $f_{t}^{(4)}$ & $f_{t}^{(5)}$ & $\mathrm{CG}_{t}$ & $R^{2}$ & $R_{f w d}^{2}$ \\
\hline Quarterly & $-2.16^{* * *}$ & 0.12 & $2.84^{* * *}$ & 0.62 & $-1.71^{* * *}$ & $-0.79^{* * *}$ & 0.36 & 0.24 \\
& $(-2.75)$ & $(0.10)$ & $(2.73)$ & $(0.87)$ & $(-3.57)$ & $(-3.37)$ & & \\
Annual & $-2.17^{*}$ & -0.45 & $3.73^{*}$ & 0.65 & $-1.80^{* *}$ & $-0.83^{* * *}$ & 0.42 & 0.27 \\
& $(-1.74)$ & $(-0.32)$ & $(1.78)$ & $(0.63)$ & $(-2.16)$ & $(-3.27)$ & &
\end{tabular}

Panel B: Excluding the zero-lower-bound period

\begin{tabular}{lcccccccc} 
Sample period & $f_{t}^{(1)}$ & $f_{t}^{(2)}$ & $f_{t}^{(3)}$ & $f_{t}^{(4)}$ & $f_{t}^{(5)}$ & $\mathrm{CG}_{t}$ & $R^{2}$ & $R_{\text {fwd }}^{2}$ \\
\hline $1964 / 01$ to $2008 / 11$ & $-2.45^{* * *}$ & 1.49 & $1.74^{*}$ & 0.84 & $-1.82^{* * *}$ & $-0.70^{* *}$ & 0.34 & 0.25 \\
& $(-2.83)$ & $(0.84)$ & $(1.91)$ & $(1.53)$ & $(-3.50)$ & $(-2.82)$ & &
\end{tabular}

Panel C: Quarterly and Annual Regressions, Vintage Data

\begin{tabular}{lllllllll} 
Frequency & $f_{t}^{(1)}$ & $f_{t}^{(2)}$ & $f_{t}^{(3)}$ & $f_{t}^{(4)}$ & $f_{t}^{(5)}$ & $\mathrm{CG}_{t}$ & $R^{2}$ & $R_{f w d}^{2}$ \\
\hline Quarterly vintage & -1.67 & -1.03 & 3.87 & 0.63 & -1.89 & -0.50 & 0.34 & 0.28 \\
& $(-3.27)$ & $(-1.09)$ & $(3.08)$ & $(1.00)$ & $(-4.58)$ & $(-3.81)$ & & \\
Annual vintage & -1.55 & -0.68 & 4.10 & 1.19 & -2.15 & -0.68 & 0.40 & 0.33 \\
& $(-4.12)$ & $(-0.65)$ & $(5.88)$ & $(3.38)$ & $(-7.26)$ & $(-6.91)$ & &
\end{tabular}

Panel D: Forecasting Monthly Excess Returns

\begin{tabular}{lcccccccc} 
Spec. & $f_{t}^{(1)}$ & $f_{t}^{(2)}$ & $f_{t}^{(3)}$ & $f_{t}^{(4)}$ & $f_{t}^{(5)}$ & $\mathrm{CG}_{t}$ & $\mathrm{RP}_{t}$ & $R^{2}$ \\
\hline$(1)$ & -0.06 & -0.06 & 0.09 & 0.09 & -0.04 & & & 0.02 \\
& $(-1.17)$ & $(-0.53)$ & $(0.70)$ & $(0.70)$ & $(-0.47)$ & & & \\
$(2)$ & & & & & & & & \\
& $-0.11^{*}$ & -0.00 & 0.09 & 0.07 & -0.07 & $-0.05^{*}$ & & \\
$(-1.91)$ & $(-0.01)$ & $(0.74)$ & $(0.49)$ & $(-0.97)$ & $(-1.93)$ & & \\
$(3)$ & & & & & & & \\
& $-0.11^{*}$ & 0.23 & -0.28 & 0.02 & 0.10 & $-0.06^{* *}$ & $2.56^{* * *}$ & 0.06 \\
\hline \hline
\end{tabular}




\section{A Data and variable construction}

\section{A.1 Convergence Gap}

We require data for real GDP, inflation, and the short-term nominal interest rate, as well as a procedure to compute inflation expectations to calculate the ex ante real short term interest rate. The real GDP data is obtained from the St. Louis Fed's FRED database (mnemonic GDPC1). We use observations starting in 1957 to allow for a burn-in seven-year period to estimate the 1964 trend component. Using longer burn-in periods - in particular starting in 1947 - does not affect our results. The inflation measure is the growth rate of the price index for personal consumption expenditure (PCE) excluding food and energy, referred to as core PCE inflation (mnemonic PCEPILFE). We look at core PCE because this is the measure that monetary policy makers focus on. ${ }^{30}$ The short-term interest rate is the annualized nominal funds rate, available from the Board of Governors. Because the federal funds rate frequently fell below the discount rate prior to 1965, we use the Federal Reserve Bank of New York's discount rate prior to 1965, reported by the IMF. For our benchmark measure we use a four-quarter moving average of past inflation as a proxy for inflation expectations in constructing the ex ante real interest rate. This is the same approach used in Holston et al. (2017). Canadian, UK, and Euro Area data is from Holston et al. (2017). We refer the reader to their detailed data appendix.

\section{A.2 Cieslak and Povala (2015) factor}

To construct the Cieslak-Povala factor we use bonds with maturities of $1,2,3,4,5,7$, and 10 years. $^{31}$ We then run a regression of yields with different maturities on the trend inflation $\tau_{t}^{C P I}$ :

$$
y_{t}^{(n)}=a_{n}+b_{n} \tau_{t}^{C P I}+\varepsilon_{t}, \quad n=1,2,3,4,5,7,10
$$

\footnotetext{
${ }^{30}$ See e.g. discussion in Cogley, Primiceri and Sargent (2010), and in particular their footnote 12.

${ }^{31}$ Cieslak and Povala (2015) use also a 20 years bonds. However such maturity is not available in the Le and Singleton (2013) dataset.
} 
We define the residual from regression (A.1) as the maturity-specific cycle:

$$
c_{t}^{(n)}=y_{t}^{(n)}-\hat{a}_{n}-\hat{b}_{n} \tau_{t}^{C P I} .
$$

We then take an average of duration-standardized excess returns across maturities, denoted

by ${\overline{r x^{D}}}_{t+1}=\frac{1}{6} \sum_{n=2}^{10} \frac{r x_{t+1}^{(n)}}{n}$. We then predict the average return $\overline{r x}_{t+1}^{D}$ with the cycles defined in Equation A.2:

$$
\overline{r x}_{t+1}^{D}=\gamma_{0}+\gamma_{1} \bar{c}_{t}+\gamma_{2} c_{t}^{(1)}+\varepsilon_{t},
$$

where $\bar{c}_{t}=\frac{c_{t}^{(2)}+c_{t}^{(3)}+c_{t}^{(4)}+c_{t}^{(5)}+c_{t}^{(7)}+c_{t}^{(10)}}{6}$. We estimate a value of $\gamma_{1}=1.28(t$-stat=8.24) and $\gamma_{2}=-0.87(t$-stat $=-7.99)$, which is close to the original point estimates of 1.45 and -0.61 reported by Cieslak and Povala (2015) in their original paper.

Finally, the fitted value from Regression (A.3) delivers the Cieslak-Povala cycle factor, $\widehat{c f}_{t}$ :

$$
\widehat{c f_{t}}=\hat{\gamma}_{0}+\hat{\gamma}_{1} \bar{c}_{t}+\hat{\gamma}_{2} c_{t}^{(1)}
$$

\section{A.3 Real bond returns}

U.S. data. The data on U.S. TIPS (Treasury inflation-protected securities) are obtained from Gurkaynak, Sack and Wright (GSW, 2010). GSW estimate the real yield curve by fitting observed prices of TIPS with a Nelson-Siegel-Svensson (NSS) model. As GSW point out, the second hump in the Svensson curve is not well identified unless there are enough long-term securities. Therefore, for the TIPS yield curve GSW use the more restricted functional form (Nelson-Siegel allowing for only one hump) up to the end of 2003, and then switch to the Svensson parameterization after that point as the issuance of 20 -year TIPS improved the estimation. Moreover, TIPS with less than 18 months to maturity are dropped from the estimation of the TIPS yield curve, because the effect of the indexation lag makes the prices of these securities erratic. This implies that the shortest observed maturity is five years before January 2004 and two years afterward. We reconstruct the yields for the 2- to 4-year maturities over the January 1999 to December 2003 sample period using the estimated parameters of the Nelson-Siegel model published by GSW. With regard to the 
1-year maturity, for the period January 2004 to December 2017 we reconstruct the series using the parameters of the Svensson model estimated by GSW. For the period January 1999 to December 2003, the application of the estimated Nelson-Siegel parameters generates a very erratic series, as stated by GSW. Therefore, we construct a smoother series for that variable by taking the difference between the 1-year nominal yield estimated in GSW (2007), again using the Svensson model, and the SPF 1-year ahead CPI inflation rate.

U.K. data. Data for yields on the UK Index-Linked Gilts are available from the Bank of England website. These data are based on the estimation of a modified version of a splinebased variable roughness penalty model (see Waggoner, 1997; Anderson and Sleath, 2001). The data starts in January 1985. However, as in the case of TIPS, short-term yields (yields with maturity below 4 years) are not available for all the dates in the sample. We thus build a 1- to 10-year term structure for Index-Linked Gilts yields by fitting the Svensson model to the yields observable at the end of each month (from the shortest maturity available up to 10 years) for the period January 1985 to December 2017. The fit to actual data is very good, with an average yield error equal to zero and a standard deviation of yield errors around 0.17 bps for all maturities.

Using these data, we recompute the Cochrane-Piazzesi factor and our CPG factor by running the regressions (1) and (2) in the paper, reported here for reader's convenience:

$$
\begin{gathered}
\overline{r x}_{t+1}=\delta_{0}+\delta_{1}^{\prime} \boldsymbol{f}_{t}+\epsilon_{t+1}, \\
\overline{r x}_{t+1}=\delta_{0}^{C G}+\delta_{1}^{C G^{\prime}} \boldsymbol{f}_{t}+\delta_{2}^{C G} \mathrm{CG}_{t}+\epsilon_{t+1}^{C G}
\end{gathered}
$$

where now $\boldsymbol{f}_{t}$ are real Treasury forward rates and $\overline{r x}_{t+1}$ is an average (across maturities) holding period returns on real Treasury bonds. Along the lines of the original study by Cochrane and Piazzesi (2005) we use only maturities from one through five-year.

\section{A.4 Economic drivers of CG}

In Section 4, we study the following economic determinants of CG and bond risk premia, which are available at either the Monthly (M), Quarterly (Q), or Annual (frequency). We 
use the year-on-year growth rate in Middle-Young ratio (A), Life Expectancy (A), Labour hours (A), TFP (A), Fed debt/GDP (Q), Current account/GDP (Q), and the Dependency Ratio (A), all from Lunsford and West (2019) (see their data source details). We also obtain the Employment to Population growth rate (from FRED, EMRATIO; M), the year-on-year growth rate in the Arouba-Diebold-Scotti index (from FED Philadelphia; M) and Capacity utilization (from FRED, TCU; M).

\section{B Predicting real bond returns: UK evidence}

\section{TABLE B.1: Forecasting individual real bond excess returns: UK evidence}

This table reports OLS slope coefficients and $R^{2}$ in the regressions of future annual excess returns for real bonds with maturities of two years (Panel A), three years (Panel B), four years (Panel C), and five years (Panel D). The table shows (1) to (4) specifications of the regressors. CP denotes Cochrane and Piazzesi (2005) forward rates factors. CPG denotes the fitted value from a regression of average (across maturities) bond returns on forward rates and CG. The convergence gap, $\mathrm{CG}_{t}$, is defined as in Table 1. In parentheses, below the estimates, we report $t$-statistics computed using the reverse regression delta method by Wei and Wright (2013). Significance: ${ }^{*} p<0.10,{ }^{* *} p<0.05,{ }^{* *} p<0.01$. All regressions include a constant term, whose coefficient is omitted. The sample period is 1985/01 to 2017/12.

\begin{tabular}{|c|c|c|c|c|c|c|c|}
\hline \multirow[b]{2}{*}{ Spec. } & \multicolumn{3}{|c|}{ Panel A: $r x_{t+1}^{(2)}$} & \multicolumn{4}{|c|}{ Panel B: $r x_{t+1}^{(3)}$} \\
\hline & $\mathrm{CP}_{t}$ & $\mathrm{CPG}_{t}$ & $R^{2}$ & Spec. & $\mathrm{CP}_{t}$ & $\mathrm{CPG}_{t}$ & $R^{2}$ \\
\hline (1) & $\begin{array}{c}0.48 \\
(1.16)\end{array}$ & & 0.21 & (1) & $\begin{array}{l}0.88^{* * *} \\
(2.35)\end{array}$ & & 0.29 \\
\hline \multirow[t]{2}{*}{ (2) } & & $\begin{array}{c}0.50 \\
(1.49)\end{array}$ & 0.25 & $(2)$ & & $\begin{array}{l}0.87^{* * *} \\
(2.55)\end{array}$ & 0.33 \\
\hline & \multicolumn{2}{|c|}{ Panel C: $r x_{t+1}^{(4)}$} & & \multicolumn{4}{|c|}{ Panel D: $r x_{t+1}^{(5)}$} \\
\hline Spec. & $\mathrm{CP}_{t}$ & $\mathrm{CPG}_{t}$ & $R^{2}$ & Spec. & $\mathrm{CP}_{t}$ & $\mathrm{CPG}_{t}$ & $R^{2}$ \\
\hline (1) & $\begin{array}{l}1.19^{* * * *} \\
(3.08)\end{array}$ & & 0.33 & (1) & $\begin{array}{l}1.45^{* * * *} \\
(3.57)\end{array}$ & & 0.34 \\
\hline (2) & & $\begin{array}{l}1.19^{* * *} \\
(3.27)\end{array}$ & 0.37 & $(2)$ & & $\begin{array}{l}1.43^{* * *} \\
(3.79)\end{array}$ & 0.38 \\
\hline
\end{tabular}




\section{Economic Significance of Bond Predictability}

\section{TABle C.1: Optimal Sharpe Ratios and Economic Conditions}

This table reports the OLS slope coefficients and $R^{2}$ in the regression of the difference in annualized Sharpe ratios on economic indicators. The difference in annualized Sharpe ratios between specifications (3) and (2) in Table 6 (for monthly returns) is projected on a constant and the following variables: inflation (CPI), the Chicago Fed National Activity Index (CFNAI), and the NBER recession dummy. In parentheses below the estimates we report $t$-statistics based on Newey-West standard errors with 60 lags. Significance: ${ }^{*} p<0.10$, ${ }^{* *} p<0.05,{ }^{* *} p<0.01$. The intercept estimates are omitted. The sample period is 1964/01 to 2017/12.

\begin{tabular}{lcccc}
\hline \hline \multicolumn{4}{c}{ Sharpe ratio and Economic Determinants } \\
Spec. & $C P I_{t}$ & $C F N A I_{t}$ & $N B E R_{t}$ & $R^{2}$ \\
\hline$(1)$ & -1.33 & & 0.02 \\
& $(-0.79)$ & & \\
$(2)$ & & $-0.12^{* * *}$ & \\
& & $(-3.59)$ & \\
$(3)$ & & & $0.05^{* * *}$ & 0.09 \\
& & & $(3.11)$ & \\
$(4)$ & -1.82 & 0.03 & $0.06^{* * *}$ & 0.12 \\
& $(-1.24)$ & $(0.50)$ & $(2.46)$ & \\
\hline \hline
\end{tabular}

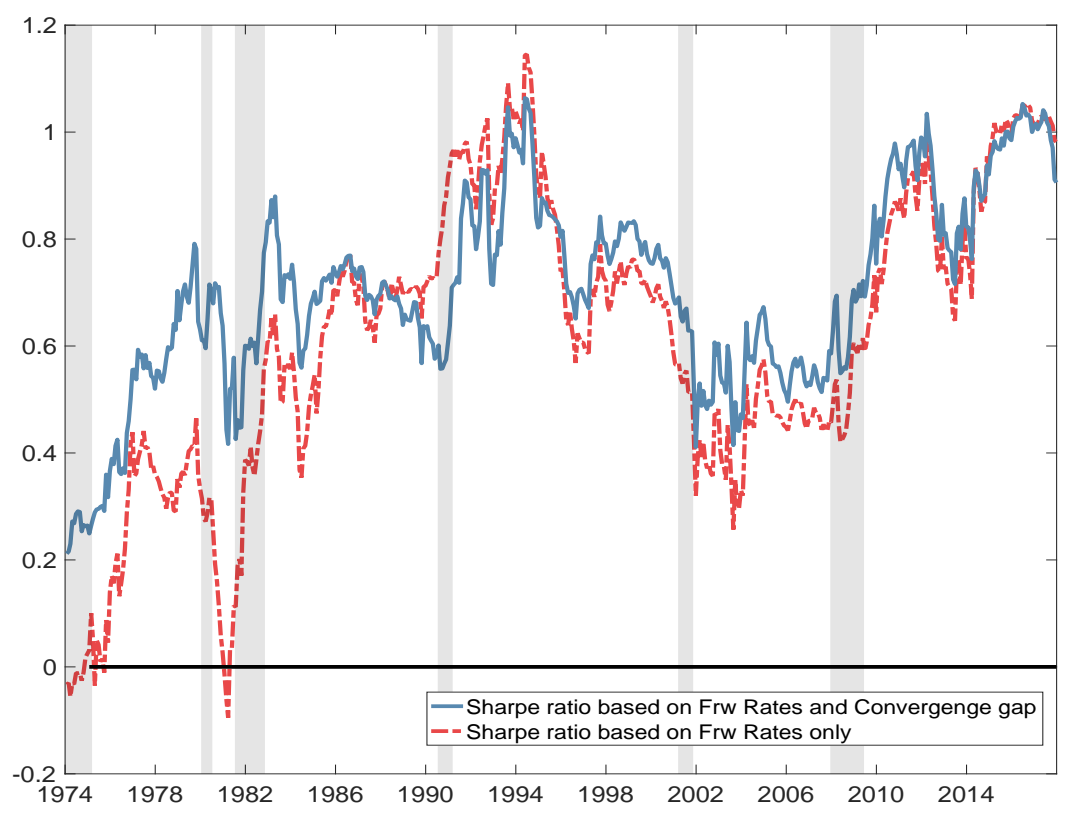

Figure C.1: Sharpe Ratios: This figure plots the time series of the 10-year rolling Sharpe Ratio for the monthly optimal dynamic portfolio strategy based on forward rates only (i.e. column (2) of Table 6) and for that based on forward rates plus CG (i.e. column (3) of Table 6). The gray bars denote NBER recession months. 


\section{International evidence}

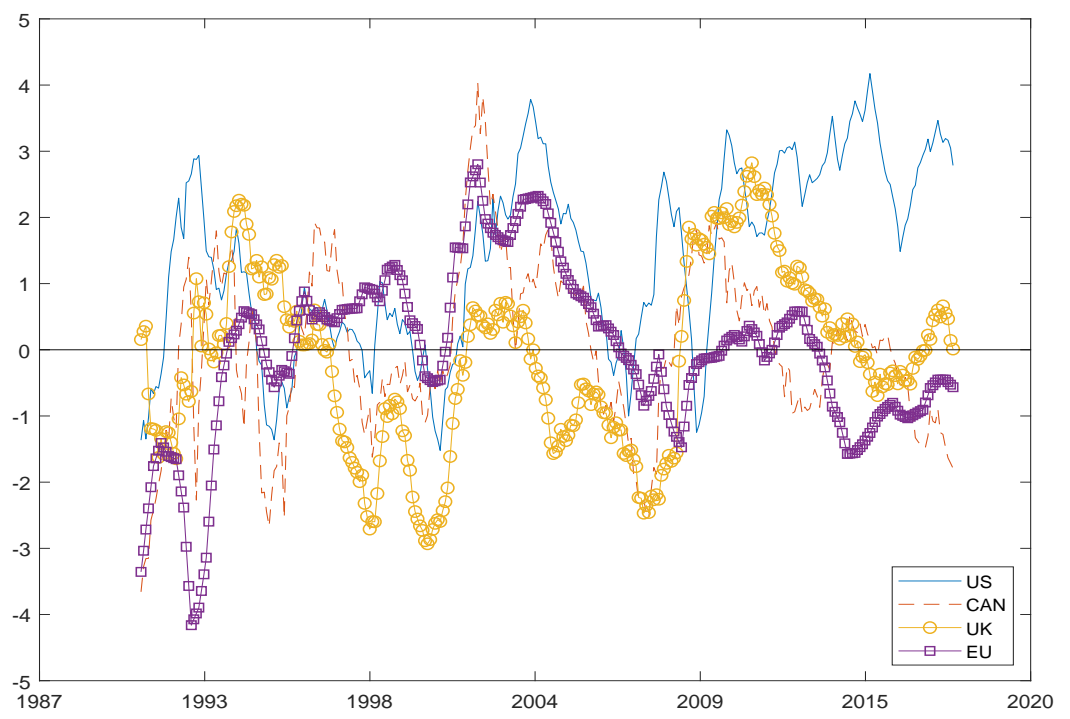

Figure E.1: The convergence gap: This figure plots the time series of the convergence gap, $C G$, for the US, Canada, UK, and Germany/EuroArea using the natural rate of interest estimates from Holston et al. (2017) over the common $1991 / 01$ to $2017 / 12$ period. 


\section{E Robustness}

We study the robustness of our results to alternative formulation of the convergence gap, such as changing the measure of the equilibrium rate of interest (c.f. Tables E.1 and E.2), or using alternative proxies for the real short-rate (c.f. Tables E.3 and E.4).

In Figure E.1, we plot the convergence gap series obtained when we proxy for the natural rate with: (1) an HP-filtered measure of output gap (benchmark measure used in the main body of the paper); (2) the measure of potential output by Laubach and Williams (2003); (3) the Kalman filter natural-rate estimates by Holston et al. (2017). We observe that all convergence gap series are highly correlated. This prima facie evidence suggests that our results are robust to alternative proxies for the natural rate, with the correlation between various CG series being in the tune of 0.80 .

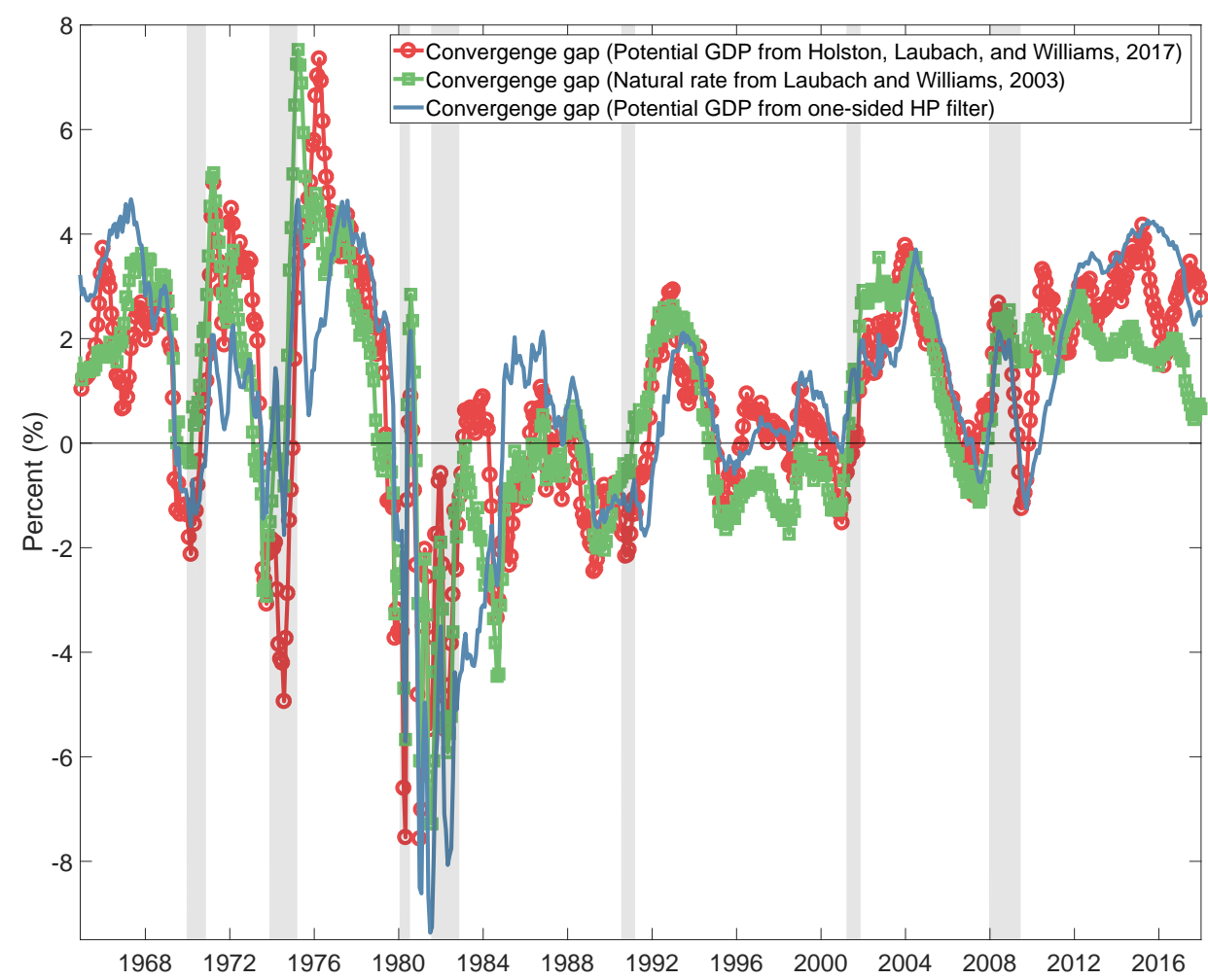

Figure E.1: The convergence gap: This figure plots the time series of the convergence gap, $C G$, using alternative proxies for the natural rate. The sample period is 1964/01 to 2017/12.

Table E.1 carries out the same analysis of Table 1 when replacing the one-sided HP filtered trend component of real GDP with the potential GDP series obtained by Laubach 
and Williams (2003) using a Kalman filter. Table E.2 report analogous results when instead we replace the one-sided HP filtered trend component of real GDP with the Kalman filter natural-rate estimates - denoted $r_{t}^{*}$ - by Holston et al. (2017). The Holston et al. (2017) natural rate of interest is composed of the trend growth rate of the natural rate of output and a component that captures the households' rate of time preference as well as other determinants of $r^{*}$ unrelated to trend growth.

Tables E.3 and E.4 repeat the analysis of Table 1 using alternative measure of the exante real interest rate. In particular, in Table E.3 we proxy inflation expectations with the forecast of the twelve-month-ahead percentage change in the price index for personal consumption expenditures excluding food and energy ("core PCE prices") generated from a univariate $\mathrm{AR}(9)$ of inflation estimated over the prior 120 months. This measure is similar to the measure of inflation expectations used by Laubach and Williams (2003). In Table E.4 we instead use CPI inflation forecasts from the Survey of Professional Forecasters (SPF) to construct the real rate. The SPF data are quarterly beginning in 1981Q2. ${ }^{32}$ We use the median across the respondents, but our conclusions are unaffected if we instead use the average. A survey at quarter $t$ reports $k$ quarter ahead consensus predictions of CPI inflation for $k=1, \ldots, 4$. We use these forecasts to calculate predictions of inflation over the next year. To go further back in time, we splice this series with the four-quarter moving average of past CPI inflation, in order to obtain a final series spanning the period 1964-2017.

\section{F A Term Structure Model with the Convergence Gap}

The evidence that the convergence gap plays a significant role for bond return predictability begs the question how to interpret our findings from a term structure modeling perspective, where yields and risk premia are jointly determined. We address this point by evaluating the effect of CG within a no-arbitrage bond pricing framework. To be precise we assume a conditionally log-normal pricing kernel:

$$
M_{t+1}=\exp \left(-r_{t}-\frac{1}{2} \Lambda_{t}^{\prime} \Lambda_{t}-\Lambda_{t}^{\prime} \varepsilon_{t+1}\right),
$$

\footnotetext{
${ }^{32}$ PCE forecasts are available only starting from 2007:Q1, hence we switch to CPI as our inflation proxy despite the fact that the Fed pays more attention to the PCE for policy purposes.
} 
where the market price of risk $\Lambda_{t}=\Lambda_{0}+\Lambda_{1} X_{t}$ and the short rate $r_{t}=\delta_{0}+\delta_{1}^{\prime} X_{t}$ are affine in the $m \times 1$ vector of state variables $X_{t}$ (see Duffee, 2002), and $\varepsilon_{t+1}$ is i.i.d. $\mathrm{N}(0, I)$. We further assume that the vector of state variables follows a first-order vector autoregression (VAR) model with homoskedastic shocks: ${ }^{33}$

$$
X_{t+1}=\mu+\Phi X_{t}+\Sigma \varepsilon_{t+1}
$$

It then follows that the no-arbitrage price of a $n$-period zero coupon bond is an exponentially affine function of the state vector:

$$
P_{t}^{(n)}=\exp \left\{A_{n}+B_{n}^{\prime} X_{t}\right\}
$$

where the coefficients $A_{n}$ and $B_{n}$ solve a system of ODEs (see e.g. Wright, 2011).

In our analysis we employ three factors, i.e. $m=3$. The first two variables in $X_{t}$ are the first two principal components (PCs) of the yield curve. The third variable is alternatively $\mathrm{CP}$ or $\mathrm{CPG}$, each of them orthogonalized with respect to the two PCs.

We estimate the two models on our sample of 1- to 5-year Fama and Bliss yields using a two-step procedure, similar to Cochrane and Piazzesi (2008) and Adrian et al. (2013). In a first step, we obtain the risk-adjusted parameters by minimizing the distance between the coefficients from regressing yields onto the factors and their model counterpart. Next, we find estimates of the risk premia parameters $\left(\Lambda_{0}\right.$ and $\left.\Lambda_{1}\right)$ by minimizing the distance between the coefficients from regressing individual bond excess yields onto the factors and their model counterpart, keeping the first-step parameters fixed. We collect the resulting parameter estimates in Table F.1.

Based on the implied coefficients from the model, two important conclusions emerge. First, the CPG factor loading on the short rate (i.e., the third element of $\delta_{1}$ ) is small and statistically indistinguishable from zero, and so are the corresponding loadings on CPG for the yield curve. However, we can reject the null hypothesis that the risk premia coefficients on CPG (i.e. the third row of $\Lambda_{1}$ ) are zero. These results imply that we can interpret CPG

\footnotetext{
${ }^{33}$ Joslin and Le (2016) find that no-arbitrage term structure models that incorporate stochastic volatility face difficulties in matching yield dynamics under both the physical and risk-neutral probability measures.
} 
as an unspanned factor that affects risk premia but not the level of yields, consistent with the arguments in, e.g., Duffee (2011) and Joslin et al. (2014b). Second, conditioning on the convergence gap changes the cyclicality of the model-implied expected excess returns. When using $\mathrm{CP}$ as a third factor in the model, the $\mathrm{R}^{2}$ from regressing the model-implied average (across maturities) expected excess bond return on the CPI, CFNAI, and NBER dummy is nearly zero (0.006, or a correlation of 0.08). In contrast, when using the CPG factor, the $\mathrm{R}^{2}$ jumps to 0.057 (or, a correlation of 0.24 ), and the three macro variables enters with the same signs as in Panel B of Table 1 - i.e. bond risk premia become more countercyclical. Overall, these results confirm that the reduced-form findings of Table 1 hold in a more general structural estimation setting.

\section{G Fama-Bliss Identity and the Convergence Gap}

The Fama and Bliss (1987) accounting identity implies that, algebraically, the price $P_{t}^{(n)}$ of an $n$-year bond is the present value of the $\$ 1$ payoff discounted at the expected values of the future 1-year returns on the bond:

$$
P_{t}^{(n)}=\exp \left(-E_{t}\left[r_{t+1}^{(n)}\right]-E_{t}\left[r_{t+2}^{(n-1)}\right]-\ldots-E_{t}\left[y_{t+n-1}^{(1)}\right]\right)
$$

Fama and Bliss (1987) show that summing the last $n-1$ expected returns in Eq. (G.1), and substituting the resulting expression for prices in the definition of a forward contract, gives:

$$
f_{t}^{(n)}-y_{t}^{(1)}=\underbrace{\left(E_{t}\left[r_{t+1}^{(n)}\right]-y_{t}^{(1)}\right)}_{E_{t}\left[r x_{t+1}^{(n)}\right]}+(n-1) \times\left(E_{t}\left[y_{t+1}^{(n-1)}\right]-y_{t}^{(n-1)}\right) .
$$

The above Fama and Bliss (1987) identity says that the forward-spot spread contains information about either the premium for a 1-year return on an $n$-year bond over the 1-year spot rate, or the expected change over the next year of the yield on $n-1$ year bonds, or both. In terms of regression coefficients, Eq. (G.2) implies that the slope coefficients in the following 
system:

$$
\begin{aligned}
r_{t+1}^{(n)}-y_{t}^{(1)} & =a_{r}+b_{r}\left(f_{t}^{(n)}-y_{t}^{(1)}\right)+e_{t+1} \\
(n-1) \times\left(y_{t+1}^{(n-1)}-y_{t}^{(n-1)}\right) & =a_{y}+b_{y}\left(f_{t}^{(n)}-y_{t}^{(1)}\right)+u_{t+1}
\end{aligned}
$$

obey the present-value restriction $b_{r}+b_{y}=1 .^{34}$

Panel A of Table G.1 shows results from estimating regressions (G.3)-(G.4) on the Fama and Bliss data. The table re-establishes what documented by other authors, namely that all the variation in the forward-spot spread is attributable to the 1-year expected premium $\left(\hat{b}_{r}=1\right)$, and none to expected yield changes $\left(\hat{b}_{y}=0\right)$.

The Fama-Bliss identity (G.2) also applies to other, potentially non-yield related predictors. To see this, consider a variable $x_{t}$ that is orthogonal to the forward spread. Exploiting (G.2) we obtain:

$$
\operatorname{Cov}\left(x_{t}, f_{t}^{(n)}-y_{t}^{(1)}\right)=\operatorname{Cov}\left(x_{t}, r_{t+1}^{(n)}-y_{t}^{(1)}\right)+\operatorname{Cov}\left(x_{t},(n-1) \times\left(y_{t+1}^{(n-1)}-y_{t}^{(n-1)}\right)\right)
$$

where the left-hand side is zero by construction. In words, if the variable $x_{t}$ predicts interest rates changes, then it ought to predict bond returns. In terms of regression coefficients we have that:

$$
\begin{aligned}
r_{t+1}^{(n)}-y_{t}^{(1)} & =a_{r, x}+b_{r, x} x_{t}+e_{t+1} \\
(n-1) \times\left(y_{t+1}^{(n-1)}-y_{t}^{(n-1)}\right) & =a_{y, x}+b_{y, x} x_{t}+u_{t+1}
\end{aligned}
$$

and, importantly, Eq. (G.2) now imposes that $b_{r, x}+b_{y, x}=0.35,36$

\footnotetext{
${ }^{34}$ This restriction is remindful of the Campbell and Shiller (1988) identity which implies that the dividendprice must forecast dividend growth and/or returns. See Cochrane (2008) for a thorough discussion of the Campbell-Shiller identity, and its implications for long-horizon regressions. Despite the similarities, two important distinctions between the Fama-Bliss and Campbell-Shiller identities are that the former: (1) is exact, whereas the latter requires a log-linear expansion, and (2) does not rely on long-horizon regressions which typically are plagued by econometric small-sample biases.

${ }^{35}$ Analogously, the Campbell-Shiller identity also imposes restrictions on predictors other than the pricedividend ratio. These restrictions have been exploited by Cochrane (2011) to examine the predictive ability of the consumption-wealth ratio for short-run market returns, and by Bandi and Tamoni (2018) to investigate the ability of long-run uncertainty to predict long-run market returns.

${ }^{36}$ The restriction is also reminiscent of "hidden factor models" introduced by Duffee (2011) and Joslin, Priebsch and Singleton (2014b). Our derivation based on Fama-Bliss is new, and complementary to that
} 
Panel B of Table G.1 reports the results from regressions (G.5) (leftmost part) and (G.6) (rightmost part) when we use as predictor $x_{t}$ the component of the convergence gap that is orthogonal to the forward spread, denoted $\mathrm{CG}_{t}^{\perp}$. Panel $\mathrm{C}$ collects analogous results when the forward spread is added to the convergence gap. Panel B shows that the convergence gap has an impressive ability to forecast future changes in yields of different maturities: the $R^{2}$ s are all above $10 \%$, and the coefficients are strongly significant with $t$-statistic greater than three. The predictive ability of the convergence gap is decreasing in the maturity of the bond. This is intuitive since the effect of monetary policy is likely to be stronger at the short-end of the yield curve. Finally, the ability of $\mathrm{CG}_{t}^{\perp}$ to forecast interest rates is mirrored by its ability to forecast bond excess returns. Importantly, the sign of the coefficients is in line with the economic intuition: a positive convergence gap predicts an increase in shortand long-term rates $\left(b_{y, C G^{\perp}}>0\right)$ and, at the same time, lower prices (hence, returns) going forward $\left(b_{r, C G^{\perp}}<0\right)$. By construction, the $R^{2}$ attained by the convergence gap in forecasting excess returns adds to the $R^{2}$ achieved by forward rates in standard Fama-Bliss regressions. The leftmost part in Panel $\mathrm{C}$ shows this result: the convergence gap raises the $R^{2}$ for bonds with 2 - and 3 -year maturity by about $15 \%$.

typically found in Gaussian no-arbitrage models of the Term Structure. 
TABLE E.1: Forecasting average (across maturity) bond excess returns using Laubach and Williams (2003)'s potential GDP series into CG

Panel A of this table reports OLS slope coefficients and $R^{2}$ in the regression of average (across maturities) annual excess returns $\overline{r x}_{t+1}$ on a constant and various combinations of lagged one- to five-year forward rates and the convergence gap, $\mathrm{CG}_{t}$. Panel $\mathrm{B}$ reports the OLS slope coefficients and $R^{2}$ in the regression of the residuals from specifications $(\mathrm{CP})$ and $(\mathrm{CPG})$ of Panel A. The residuals are projected on a constant and the following variables: inflation (CPI), the Chicago Fed National Activity Index (CFNAI), and the NBER recession dummy. In parentheses, below the estimates, we report $t$-statistics computed using the reverse regression delta method by Wei and Wright (2013). Significance: ${ }^{*} p<0.10,{ }^{* *} p<0.05,{ }^{* *} p<0.01$. The intercept estimates are omitted. The convergence gap, $C G_{t}$, is defined as the difference between the year-toyear log change in potential GDP and the real interest rate. To proxy for potential GDP we use the Laubach and Williams (2003) estimates obtained by Kalman filter. We linearly interpolate the Laubach and Williams (2003) series to obtain monthly observations. The short-term interest rate is the annualized nominal funds rate, available from the Board of Governors. We use a four quarter moving average of past inflation as a proxy for inflation expectations in constructing the ex ante real interest rate. The sample period is 1964/01 to $2017 / 12$.

\begin{tabular}{|c|c|c|c|c|c|c|c|}
\hline \multicolumn{8}{|c|}{ Panel A: Forecasting average excess bond returns } \\
\hline Spec. & $f_{t}^{(1)}$ & $f_{t}^{(2)}$ & $f_{t}^{(3)}$ & $f_{t}^{(4)}$ & $f_{t}^{(5)}$ & $\mathrm{CG}_{t}$ & $R^{2}$ \\
\hline$(\mathrm{CP})$ & $\begin{array}{l}-1.46^{*} \\
(-1.67)\end{array}$ & $\begin{array}{c}-0.23 \\
(-0.54)\end{array}$ & $\begin{array}{l}1.61^{*} \\
(1.72)\end{array}$ & $\begin{array}{l}1.11^{*} \\
(1.88)\end{array}$ & $\begin{array}{l}-0.84^{*} \\
(-1.80)\end{array}$ & & 0.21 \\
\hline$(\mathrm{CG})$ & & & & & & $\begin{array}{l}-0.28 \\
(-1.40)\end{array}$ & 0.03 \\
\hline$(\mathrm{CPG})$ & $\begin{array}{c}-2.47^{* * * *} \\
(-3.23)\end{array}$ & $\begin{array}{c}0.76 \\
(0.56)\end{array}$ & $\begin{array}{c}1.88^{* *} \\
(2.21)\end{array}$ & $\begin{array}{c}0.75 \\
(1.31)\end{array}$ & $\begin{array}{c}-1.08^{* *} \\
(-2.31)\end{array}$ & $\begin{array}{c}-0.73^{* * *} \\
(-3.35)\end{array}$ & 0.31 \\
\hline \multicolumn{8}{|c|}{ Panel B: Forecasting residuals } \\
\hline Spec. & & $C P I_{t}$ & $C F N A I_{t}$ & $N B E R_{t}$ & & & $R^{2}$ \\
\hline$(\mathrm{CP})$ & & $\begin{array}{l}-0.33^{*} \\
(-2.24)\end{array}$ & $\begin{array}{c}-0.05 * * * \\
(-3.03)\end{array}$ & $\begin{array}{c}0.02 * * \\
(2.28)\end{array}$ & & & 0.13 \\
\hline$(\mathrm{CPG})$ & & $\begin{array}{c}-0.20 \\
(-1.23)\end{array}$ & $\begin{array}{c}-0.02 \\
(-1.05)\end{array}$ & $\begin{array}{c}0.01 \\
(1.56)\end{array}$ & & & 0.04 \\
\hline
\end{tabular}


TABLE E.2: Forecasting average (across maturity) bond excess returns using the natural rate of interest estimates from Holston et al. (2017) into CG

Panel A of this table reports OLS slope coefficients and $R^{2}$ in the regression of average (across maturities) annual excess returns $\overline{r x}_{t+1}$ on a constant and various combinations of lagged one- to five-year forward rates and the convergence gap, $\mathrm{CG}_{t}$. Panel $\mathrm{B}$ reports the OLS slope coefficients and $R^{2}$ in the regression of the residuals from specifications $(\mathrm{CP})$ and $(\mathrm{CPG})$ of Panel $\mathrm{A}$. The residuals are projected on a constant and the following variables: inflation (CPI), the Chicago Fed National Activity Index (CFNAI), and the NBER recession dummy. In parentheses, below the estimates, we report $t$-statistics computed using the reverse regression delta method by Wei and Wright (2013). Significance: ${ }^{*} p<0.10,{ }^{* *} p<0.05,{ }^{* * *} p<0.01$. The intercept estimates are omitted. The convergence gap, $C G_{t}$, is defined as the difference between the natural rate of interest and the real interest rate. To proxy for the natural rate of interest we use the Holston et al. (2017) estimates obtained by Kalman filter. We linearly interpolate the Holston et al. (2017) series to obtain monthly observations. The short-term interest rate is the annualized nominal funds rate, available from the Board of Governors. We use a four quarter moving average of past inflation as a proxy for inflation expectations in constructing the ex ante real interest rate. The sample period is 1964/01 to 2017/12.

\begin{tabular}{|c|c|c|c|c|c|c|c|}
\hline \multicolumn{8}{|c|}{ Panel A: Forecasting average bond excess returns } \\
\hline Spec. & $f_{t}^{(1)}$ & $f_{t}^{(2)}$ & $f_{t}^{(3)}$ & $f_{t}^{(4)}$ & $f_{t}^{(5)}$ & $\mathrm{CG}_{t}$ & $R^{2}$ \\
\hline$(\mathrm{CP})$ & $\begin{array}{l}-1.46^{*} \\
(-1.67)\end{array}$ & $\begin{array}{c}-0.23 \\
(-0.54)\end{array}$ & $\begin{array}{l}1.61^{*} \\
(1.72)\end{array}$ & $\begin{array}{l}1.11^{*} \\
(1.88)\end{array}$ & $\begin{array}{l}-0.84^{*} \\
(-1.80)\end{array}$ & & 0.21 \\
\hline$(\mathrm{CG})$ & & & & & & $\begin{array}{c}-0.29 \\
(-1.49)\end{array}$ & 0.03 \\
\hline$(\mathrm{CPG})$ & $\begin{array}{c}-2.20^{* * *} \\
(-2.68)\end{array}$ & $\begin{array}{c}-0.20 \\
(-0.08)\end{array}$ & $\begin{array}{c}2.03^{* *} \\
(2.38)\end{array}$ & $\begin{array}{c}0.83 \\
(1.44)\end{array}$ & $\begin{array}{c}-0.97^{* *} \\
(-2.09)\end{array}$ & $\begin{array}{c}-0.69 * * * \\
(-2.78)\end{array}$ & 0.30 \\
\hline \multicolumn{8}{|c|}{ Panel B: Forecasting residuals } \\
\hline Spec. & & $C P I_{t}$ & $C F N A I_{t}$ & $N B E R_{t}$ & & & $R^{2}$ \\
\hline$(\mathrm{CP})$ & & $\begin{array}{l}-0.33^{*} \\
(-2.24)\end{array}$ & $\begin{array}{c}-0.05^{* * *} \\
(-3.03)\end{array}$ & $\begin{array}{c}0.02^{* *} \\
(2.28)\end{array}$ & & & 0.13 \\
\hline$(\mathrm{CPG})$ & & $\begin{array}{c}-0.14 \\
(-0.73)\end{array}$ & $\begin{array}{l}-0.04^{*} \\
(-1.73)\end{array}$ & $\begin{array}{c}0.02^{* *} \\
(2.38)\end{array}$ & & & 0.08 \\
\hline
\end{tabular}


TABLE E.3: Forecasting average (across maturity) bond excess returns using an AR(9) model to construct inflation expectations into $\mathrm{CG}$

Panel A of this table reports OLS slope coefficients and $R^{2}$ in the regression of average (across maturities) annual excess returns $\overline{r x}_{t+1}$ on a constant and various combinations of lagged one- to five-year forward rates and the convergence gap, $\mathrm{CG}_{t}$. Panel $\mathrm{B}$ reports the OLS slope coefficients and $R^{2}$ in the regression of the residuals from specifications $(\mathrm{CP})$ and $(\mathrm{CPG})$ of Panel A. The residuals are projected on a constant and the following variables: inflation (CPI), the Chicago Fed National Activity Index (CFNAI), and the NBER recession dummy. In parentheses, below the estimates, we report $t$-statistics computed using the reverse regression delta method by Wei and Wright (2013). Significance: ${ }^{*} p<0.10,{ }^{* *} p<0.05,{ }^{* *} p<0.01$. The intercept estimates are omitted. The convergence gap, $C G_{t}$, is defined as the difference between the yearto-year log change in potential GDP and the real interest rate. To proxy for potential GDP we use the trend component of quarterly real GDP obtained from a one-sided Hodrick and Prescott (1997) filter. We linearly interpolate the resultant trend series to obtain monthly observations. The short-term interest rate is the annualized nominal funds rate, available from the Board of Governors. We use the forecast of the twelve-month-ahead percentage change in core PCE generated from a univariate AR(9) estimated over the prior 120 months as a proxy for inflation expectations in constructing the ex-ante real interest rate. The sample period is $1964 / 01$ to $2017 / 12$.

\begin{tabular}{|c|c|c|c|c|c|c|c|}
\hline \multicolumn{8}{|c|}{ Panel A: Forecasting average bond excess returns } \\
\hline Spec. & $f_{t}^{(1)}$ & $f_{t}^{(2)}$ & $f_{t}^{(3)}$ & $f_{t}^{(4)}$ & $f_{t}^{(5)}$ & $\mathrm{CG}_{t}$ & $R^{2}$ \\
\hline$(\mathrm{CP})$ & $\begin{array}{l}-1.46^{*} \\
(-1.67)\end{array}$ & $\begin{array}{c}-0.23 \\
(-0.54)\end{array}$ & $\begin{array}{l}1.61^{*} \\
(1.72)\end{array}$ & $\begin{array}{l}1.11^{*} \\
(1.88)\end{array}$ & $\begin{array}{l}-0.84^{*} \\
(-1.80)\end{array}$ & & 0.21 \\
\hline$(\mathrm{CG})$ & & & & & & $\begin{array}{c}-0.42^{* *} \\
(-2.12)\end{array}$ & 0.08 \\
\hline (CPG) & $\begin{array}{c}-2.23^{* * *} \\
(-2.84)\end{array}$ & $\begin{array}{c}0.91 \\
(0.68)\end{array}$ & $\begin{array}{l}1.41^{*} \\
(1.80)\end{array}$ & $\begin{array}{l}1.06^{*} \\
(1.75)\end{array}$ & $\begin{array}{c}-1.46^{* * *} \\
(-3.10)\end{array}$ & $\begin{array}{c}-0.77^{* * * *} \\
(-3.26)\end{array}$ & 0.33 \\
\hline \multicolumn{8}{|c|}{ Panel B: Forecasting residuals } \\
\hline Spec. & & $C P I_{t}$ & $C F N A I_{t}$ & $N B E R_{t}$ & & & $R^{2}$ \\
\hline$(\mathrm{CP})$ & & $\begin{array}{l}-0.33^{*} \\
(-2.24)\end{array}$ & $\begin{array}{c}-0.05 * * * \\
(-3.03)\end{array}$ & $\begin{array}{c}0.02^{* *} \\
(2.28)\end{array}$ & & & 0.13 \\
\hline$(\mathrm{CPG})$ & & $\begin{array}{c}-0.18 \\
(-1.08)\end{array}$ & $\begin{array}{l}-0.04^{*} \\
(-1.66)\end{array}$ & $\begin{array}{c}0.01 \\
(1.64)\end{array}$ & & & 0.06 \\
\hline
\end{tabular}


TABLE E.4: Forecasting average (across maturity) bond excess returns SPF inflation forecasts into CG

Panel A of this table reports OLS slope coefficients and $R^{2}$ in the regression of average (across maturities) annual excess returns $\overline{r x}_{t+1}$ on a constant and various combinations of lagged one- to five-year forward rates and the convergence gap, $\mathrm{CG}_{t}$. Panel $\mathrm{B}$ reports the OLS slope coefficients and $R^{2}$ in the regression of the residuals from specifications $(\mathrm{CP})$ and $(\mathrm{CPG})$ of Panel $\mathrm{A}$. The residuals are projected on a constant and the following variables: inflation (CPI), the Chicago Fed National Activity Index (CFNAI), and the NBER recession dummy. In parentheses, below the estimates, we report $t$-statistics computed using the reverse regression delta method by Wei and Wright (2013). Significance: ${ }^{*} p<0.10,{ }^{* *} p<0.05,{ }^{* *} p<0.01$. The intercept estimates are omitted. The convergence gap, $C G_{t}$, is defined as the difference between the year-toyear log change in potential GDP and the real interest rate. To proxy for potential GDP we use the trend component of quarterly real GDP obtained from a one-sided Hodrick and Prescott (1997) filter. We linearly interpolate the resultant trend series to obtain monthly observations. The short-term interest rate is the annualized nominal funds rate, available from the Board of Governors. We use CPI inflation forecasts from the Survey of Professional Forecasters (SPF) to construct the real rate from 1981 onwards, and we splice it with a four quarter moving average of past CPI inflation. We use such proxy for inflation expectations in constructing the ex ante real interest rate. The sample period is 1964/01 to 2017/12.

\begin{tabular}{|c|c|c|c|c|c|c|c|}
\hline \multicolumn{8}{|c|}{ Panel A: Forecasting average bond excess returns } \\
\hline Spec. & $f_{t}^{(1)}$ & $f_{t}^{(2)}$ & $f_{t}^{(3)}$ & $f_{t}^{(4)}$ & $f_{t}^{(5)}$ & $\mathrm{CG}_{t}$ & $R^{2}$ \\
\hline$(\mathrm{CP})$ & $\begin{array}{l}-1.46^{*} \\
(-1.67)\end{array}$ & $\begin{array}{c}-0.23 \\
(-0.54)\end{array}$ & $\begin{array}{l}1.61^{*} \\
(1.72)\end{array}$ & $\begin{array}{l}1.11^{*} \\
(1.88)\end{array}$ & $\begin{array}{l}-0.84^{*} \\
(-1.80)\end{array}$ & & 0.21 \\
\hline$(\mathrm{CG})$ & & & & & & $\begin{array}{c}-0.42^{* *} \\
(-2.06)\end{array}$ & 0.08 \\
\hline$(\mathrm{CPG})$ & $\begin{array}{c}-2.29 * * * \\
(-2.74)\end{array}$ & $\begin{array}{c}1.08 \\
(0.83)\end{array}$ & $\begin{array}{l}1.35^{*} \\
(1.66)\end{array}$ & $\begin{array}{l}1.03^{*} \\
(1.66)\end{array}$ & $\begin{array}{c}-1.47^{* * *} \\
(-3.04)\end{array}$ & $\begin{array}{c}-0.76^{* * *} \\
(-2.61)\end{array}$ & 0.33 \\
\hline \multicolumn{8}{|c|}{ Panel B: Forecasting residuals } \\
\hline Spec. & & $C P I_{t}$ & $C F N A I_{t}$ & $N B E R_{t}$ & & & $R^{2}$ \\
\hline$(\mathrm{CP})$ & & $\begin{array}{l}-0.33^{*} \\
(-2.24)\end{array}$ & $\begin{array}{c}-0.05^{* * *} \\
(-3.03)\end{array}$ & $\begin{array}{c}0.02^{* *} \\
(2.28)\end{array}$ & & & 0.13 \\
\hline$(\mathrm{CPG})$ & & $\begin{array}{l}-0.15 \\
(-1.10)\end{array}$ & $\begin{array}{c}-0.04^{* *} \\
(-2.15)\end{array}$ & $\begin{array}{c}0.01 \\
(0.86)\end{array}$ & & & 0.04 \\
\hline
\end{tabular}




\section{TABLE E.5: Forecasting individual bond excess returns controlling for F5 factor}

This table reports OLS slope coefficients and $R^{2}$ in the regressions of future annual excess returns for bonds with maturities of two years (Panel A), three years (Panel B), four years (Panel C), and five years (Panel D) on lagged one- to five-year forward rates (specification (1)), on lagged one- to five-year forward rates and the convergence gap, $\mathrm{CG}_{t}$ (specification (2)), and on lagged one- to five-year forward rates, the convergence gap, $\mathrm{CG}_{t}$, and the Ludvigson and $\mathrm{Ng}$ (2009) macro factor, $F 5$. The convergence gap, $\mathrm{CG}_{t}$, is defined as in Table 1. In parentheses, below the estimates, we report $t$-statistics computed using the reverse regression delta method by Wei and Wright (2013). Significance: ${ }^{*} p<0.10,{ }^{* *} p<0.05,{ }^{* *} p<0.01$. All regressions include a constant term, whose coefficient is omitted. The sample period is 1964/01 to 2017/12.

\begin{tabular}{|c|c|c|c|c|c|c|c|c|c|c|c|c|c|c|c|c|c|}
\hline \multicolumn{8}{|c|}{ Panel A: $r x_{t+1}^{(2)}$} & \multicolumn{10}{|c|}{ Panel B: $r x_{t+1}^{(3)}$} \\
\hline Spec. & $f_{t}^{(1)}$ & $f_{t}^{(2)}$ & $f_{t}^{(3)}$ & $f_{t}^{(4)}$ & $f_{t}^{(5)}$ & $\mathrm{CG}_{t}$ & $F 5_{t}$ & $R^{2}$ & Spec. & $f_{t}^{(1)}$ & $f_{t}^{(2)}$ & $f_{t}^{(3)}$ & $f_{t}^{(4)}$ & $f_{t}^{(5)}$ & $\mathrm{CG}_{t}$ & $F 5_{t}$ & $R^{2}$ \\
\hline (1) & $\begin{array}{c}-0.70 \\
(-0.71)\end{array}$ & $\begin{array}{c}0.22 \\
(-0.40)\end{array}$ & $\begin{array}{c}0.58 \\
(1.23)\end{array}$ & $\begin{array}{c}0.34 \\
(1.35)\end{array}$ & $\begin{array}{c}-0.32 \\
(-1.83)\end{array}$ & & & 0.18 & (1) & $\begin{array}{c}-1.21 \\
(-1.58)\end{array}$ & $\begin{array}{c}-0.24 \\
(-0.78)\end{array}$ & $\begin{array}{c}1.82 \\
(2.01)\end{array}$ & $\begin{array}{c}0.60 \\
(1.48)\end{array}$ & $\begin{array}{c}-0.80 \\
(-1.75)\end{array}$ & & & 0.19 \\
\hline (2) & $\begin{array}{c}-1.07 \\
(-1.78)\end{array}$ & $\begin{array}{c}0.79 \\
(0.88)\end{array}$ & $\begin{array}{c}0.47 \\
(1.14)\end{array}$ & $\begin{array}{c}0.33 \\
(1.24)\end{array}$ & $\begin{array}{c}-0.66 \\
(-3.15)\end{array}$ & $\begin{array}{c}-0.39 \\
(-3.34)\end{array}$ & & 0.33 & (2) & $\begin{array}{c}-1.86 \\
(-2.79)\end{array}$ & $\begin{array}{c}0.75 \\
(0.59)\end{array}$ & $\begin{array}{c}1.63 \\
(2.14)\end{array}$ & $\begin{array}{c}0.57 \\
(1.40)\end{array}$ & $\begin{array}{c}-1.37 \\
(-3.20)\end{array}$ & $\begin{array}{c}-0.68 \\
(-3.53)\end{array}$ & & 0.33 \\
\hline (3) & $\begin{array}{c}-1.02 \\
(-1.60)\end{array}$ & $\begin{array}{c}0.89 \\
(1.11)\end{array}$ & $\begin{array}{c}0.47 \\
(1.12)\end{array}$ & $\begin{array}{c}0.21 \\
(0.82)\end{array}$ & $\begin{array}{c}-0.62 \\
(-2.83)\end{array}$ & $\begin{array}{c}-0.27 \\
(-2.38)\end{array}$ & $\begin{array}{c}0.39 \\
(3.32)\end{array}$ & 0.41 & (3) & $\begin{array}{c}-1.76 \\
(-2.59)\end{array}$ & $\begin{array}{c}0.92 \\
(0.83)\end{array}$ & $\begin{array}{c}1.62 \\
(2.14)\end{array}$ & $\begin{array}{c}0.38 \\
(1.00)\end{array}$ & $\begin{array}{c}-1.31 \\
(-2.89)\end{array}$ & $\begin{array}{c}-0.47 \\
(-2.61)\end{array}$ & $\begin{array}{c}0.65 \\
(3.32)\end{array}$ & 0.40 \\
\hline & & & Panel & C: $r x_{t+1}^{(4)}$ & & & & & & Pan & el D: $r x_{t}^{(}$ & & & & & & \\
\hline Spec. & $f_{t}^{(1)}$ & $f_{t}^{(2)}$ & $f_{t}^{(3)}$ & $f_{t}^{(4)}$ & $f_{t}^{(5)}$ & $\mathrm{CG}_{t}$ & $F 5_{t}$ & $R^{2}$ & Spec. & $f_{t}^{(1)}$ & $f_{t}^{(2)}$ & $f_{t}^{(3)}$ & $f_{t}^{(4)}$ & $f_{t}^{(5)}$ & $\mathrm{CG}_{t}$ & $F 5_{t}$ & $R^{2}$ \\
\hline (1) & $\begin{array}{c}-1.76 \\
(-1.93)\end{array}$ & $\begin{array}{c}-0.37 \\
(-0.43)\end{array}$ & $\begin{array}{c}1.91 \\
(1.82)\end{array}$ & $\begin{array}{c}1.70 \\
(2.13)\end{array}$ & $\begin{array}{l}-1.27 \\
(-2.01)\end{array}$ & & & 0.22 & (1) & $\begin{array}{c}-2.17 \\
(-1.84)\end{array}$ & $\begin{array}{c}-0.53 \\
(-0.53)\end{array}$ & $\begin{array}{c}2.14 \\
(1.59)\end{array}$ & $\begin{array}{c}1.80 \\
(2.07)\end{array}$ & $\begin{array}{c}-0.96 \\
(-1.53)\end{array}$ & & & 0.22 \\
\hline (2) & $\begin{array}{c}-2.58 \\
(-3.01)\end{array}$ & $\begin{array}{c}0.90 \\
(0.68)\end{array}$ & $\begin{array}{c}1.66 \\
(1.95)\end{array}$ & $\begin{array}{c}1.65 \\
(2.04)\end{array}$ & $\begin{array}{c}-2.01 \\
(-3.24)\end{array}$ & $\begin{array}{c}-0.87 \\
(-3.16)\end{array}$ & & 0.34 & (2) & $\begin{array}{c}-3.13 \\
(-2.79)\end{array}$ & $\begin{array}{c}0.95 \\
(0.42)\end{array}$ & $\begin{array}{c}1.85 \\
(1.61)\end{array}$ & $\begin{array}{c}1.75 \\
(1.98)\end{array}$ & $\begin{array}{l}-1.82 \\
(-2.75)\end{array}$ & $\begin{array}{l}-1.02 \\
(-2.78)\end{array}$ & & 0.32 \\
\hline (3) & $\begin{array}{c}-2.46 \\
(-2.81)\end{array}$ & $\begin{array}{c}1.11 \\
(0.88)\end{array}$ & $\begin{array}{c}1.66 \\
(1.93)\end{array}$ & $\begin{array}{c}1.41 \\
(1.73)\end{array}$ & $\begin{array}{c}-1.92 \\
(-2.98)\end{array}$ & $\begin{array}{c}-0.61 \\
(-2.33)\end{array}$ & $\begin{array}{c}0.83 \\
(3.13)\end{array}$ & 0.39 & (3) & $\begin{array}{c}-2.99 \\
(-2.58)\end{array}$ & $\begin{array}{c}1.21 \\
(0.61)\end{array}$ & $\begin{array}{c}1.84 \\
(1.65)\end{array}$ & $\begin{array}{c}1.46 \\
(1.64)\end{array}$ & $\begin{array}{c}-1.72 \\
(-2.52)\end{array}$ & $\begin{array}{c}-0.70 \\
(-1.99)\end{array}$ & $\begin{array}{c}1.00 \\
(3.24)\end{array}$ & 0.37 \\
\hline
\end{tabular}




\section{TABLE E.6: Forecasting average bond excess returns controlling for volatility}

This table reports OLS slope coefficients and $R^{2}$ in the regression of future average (across maturities) annual excess returns $\overline{r x}_{t+1}$ on a constant, lagged one- to five-year forward rates, the convergence gap, $\mathrm{CG}_{t}$, and various measures of realized volatility (denoted RV). The first two measures are monthly realized volatility computed from daily data of 1-year yield, and 3-month T-Bill, respectively. The third measure is based on a 12-month rolling standard deviation of FFR. The convergence gap, $C G_{t}$, is defined as the difference between the year-to-year log change in potential GDP and the real interest rate. To proxy for potential GDP we use the trend component of quarterly real GDP obtained from a one-sided Hodrick and Prescott (1997) filter. We linearly interpolate the resultant trend series to obtain monthly observations. The short-term interest rate is the annualized nominal funds rate, available from the Board of Governors. We use a four-quarter moving average of past inflation as a proxy for inflation expectations in constructing the ex ante real interest rate. In parentheses, below the estimates, we report $t$-statistics computed using the reverse regression delta method by Wei and Wright (2013). Significance: ${ }^{*} p<0.10,{ }^{* *} p<0.05,{ }^{* * *} p<0.01$. The intercept estimates are omitted. The sample period is 1964/01 to 2017/12.

\begin{tabular}{|c|c|c|c|c|c|c|c|c|}
\hline \multicolumn{9}{|c|}{ Forecasting average excess bond returns } \\
\hline Spec. & $f_{t}^{(1)}$ & $f_{t}^{(2)}$ & $f_{t}^{(3)}$ & $f_{t}^{(4)}$ & $f_{t}^{(5)}$ & $\mathrm{CG}_{t}$ & $\mathrm{RV}_{t}$ & $R^{2}$ \\
\hline$(\mathrm{CPG}+\mathrm{RV}(1 \mathrm{y}$ yield $))$ & $\begin{array}{l}-2.04^{* *} \\
(-2.74)\end{array}$ & $\begin{array}{c}0.59 \\
(0.37)\end{array}$ & $\begin{array}{l}1.59^{* *} \\
(2.07)\end{array}$ & $\begin{array}{l}1.04^{*} \\
(1.74)\end{array}$ & $\begin{array}{c}-1.44^{* * *} \\
(-3.13)\end{array}$ & $\begin{array}{c}-0.79 * * * \\
(-3.22)\end{array}$ & $\begin{array}{l}-60.00 \\
(-0.80)\end{array}$ & 0.33 \\
\hline$(\mathrm{CPG}+\mathrm{RV}(3 \mathrm{mTbill}))$ & $\begin{array}{c}-1.86^{* * *} \\
(-2.49)\end{array}$ & $\begin{array}{c}0.45 \\
(0.21)\end{array}$ & $\begin{array}{l}1.55^{* *} \\
(1.99)\end{array}$ & $\begin{array}{l}1.07^{*} \\
(1.79)\end{array}$ & $\begin{array}{c}-1.40^{* * *} \\
(-3.08)\end{array}$ & $\begin{array}{c}-0.79 * * * \\
(-3.24)\end{array}$ & $\begin{array}{l}-48.33 \\
(-1.01)\end{array}$ & 0.34 \\
\hline$(\mathrm{CPG}+\operatorname{StdDev}(\mathrm{FFR}))$ & $\begin{array}{l}-1.94^{* *} \\
(-2.50)\end{array}$ & $\begin{array}{c}0.41 \\
(0.12)\end{array}$ & $\begin{array}{l}1.83^{* *} \\
(2.35)\end{array}$ & $\begin{array}{c}0.96 \\
(1.52)\end{array}$ & $\begin{array}{c}-1.42^{* * *} \\
(-3.07)\end{array}$ & $\begin{array}{c}-0.80^{* * *} \\
(-3.19)\end{array}$ & $\begin{array}{l}-32.56 \\
(-1.32)\end{array}$ & 0.35 \\
\hline
\end{tabular}




\section{TABLE F.1: Maximum-likelihood estimates of ATSM}

This table reports reports the estimated parameter values for the affine term structure models discussed in Section F, with underneath bootstrapped standard errors in parentheses. Bold values are significant at the $5 \%$ level. In our analysis we employ three factors. The first two factors are the first two principal components (PCs) of the yield curve. The third factor is alternatively CPG (Panel A) or CP (Panel B), each of them orthogonalized with respect to the two PCs. The convergence gap, $\mathrm{CG}_{t}$, is defined as in Table 1. The sample period is $1964 / 01$ to $2017 / 12$.

\begin{tabular}{|c|c|c|c|c|c|c|}
\hline \multicolumn{7}{|c|}{ Panel A: Term Structure Model with the CPG factor } \\
\hline$\mu$ & \multicolumn{3}{|c|}{$\Phi$} & \multicolumn{3}{|c|}{$\Sigma$} \\
\hline $\begin{array}{c}0.0002 \\
(0.0008)\end{array}$ & $\begin{array}{c}\mathbf{0 . 9 9 3 5} \\
(0.0009)\end{array}$ & $\begin{array}{r}-\mathbf{0 . 0 1 8 0} \\
(0.0028)\end{array}$ & $\begin{array}{r}-\mathbf{0 . 0 2 1 1} \\
(0.0013)\end{array}$ & $\begin{array}{c}\mathbf{0 . 0 0 7 2} \\
(0.0004)\end{array}$ & - & - \\
\hline $\begin{array}{c}0.0000 \\
(0.0006)\end{array}$ & $\begin{array}{r}-0.0020 \\
(0.0011)\end{array}$ & $\begin{array}{c}\mathbf{0 . 9 2 6 5} \\
(0.0072)\end{array}$ & $\begin{array}{c}\mathbf{0 . 0 0 9 1} \\
(0.0016)\end{array}$ & $\begin{array}{l}-0.0001 \\
(0.0000)\end{array}$ & $\begin{array}{c}\mathbf{0 . 0 0 6 4} \\
(0.0010)\end{array}$ & - \\
\hline $\begin{array}{c}0.0001 \\
(0.0005)\end{array}$ & $\begin{array}{c}0.0252 \\
(0.0175)\end{array}$ & $\begin{array}{c}\mathbf{0 . 0 0 8 6} \\
(0.0040)\end{array}$ & $\begin{array}{c}\mathbf{0 . 9 4 3 0} \\
(0.0364)\end{array}$ & $\begin{array}{c}0.0000 \\
(0.0005)\end{array}$ & $\begin{array}{c}0.0001 \\
(0.0002)\end{array}$ & $\begin{array}{c}\mathbf{0 . 0 0 6 1} \\
(0.0024)\end{array}$ \\
\hline$\Lambda_{0}$ & & $\Lambda_{1}$ & & $\delta_{0}$ & & $\delta_{1}$ \\
\hline $\begin{array}{r}-\mathbf{0 . 1 1 4 9} \\
(0.0092)\end{array}$ & $\begin{array}{r}-\mathbf{1 . 8 5 7 5} \\
(0.1350)\end{array}$ & $\begin{array}{c}\mathbf{1 9 . 8 4 3 0} \\
(1.3656)\end{array}$ & $\begin{array}{c}\mathbf{- 1 0 . 4 2 7 7} \\
(0.7210)\end{array}$ & $\begin{array}{c}0.0496 \\
(0.0286)\end{array}$ & & $\begin{array}{l}\mathbf{1 . 0 3 2 9} \\
(0.0199)\end{array}$ \\
\hline-0.0065 & -3.6300 & -12.7379 & 4.8428 & & & 1.1898 \\
\hline$(0.0022)$ & $(0.2320)$ & $(0.8050)$ & $(0.2823)$ & & & $(0.0603)$ \\
\hline 0.2823 & 11.9129 & -2.4247 & -24.9070 & & & 0.0000 \\
\hline$(0.0206)$ & $(0.8226)$ & $(0.1604)$ & $(1.6056)$ & & & $(0.0107)$ \\
\hline
\end{tabular}

Panel B: Term Structure Model with the Cochrane and Piazzesi (2005) factor

\begin{tabular}{ccccccc}
$\mu$ & \multicolumn{3}{c}{$\Phi$} \\
\hline 0.0005 & $\mathbf{0 . 9 9 2 5}$ & $\mathbf{- 0 . 0 1 7 7}$ & $\mathbf{- 0 . 0 1 7 2}$ & $\mathbf{0 . 0 1 7 2}$ & - & - \\
$(0.0003)$ & $(0.0011)$ & $(0.0033)$ & $(0.0014)$ & $(0.0009)$ & & \\
$\mathbf{- 0 . 0 0 0 5}$ & $\mathbf{- 0 . 0 0 5 0}$ & $\mathbf{0 . 9 2 7 3}$ & $\mathbf{0 . 0 1 9 5}$ & $\mathbf{0 . 0 0 2 7}$ & $\mathbf{0 . 0 0 1 4}$ & - \\
$(0.0002)$ & $(0.0024)$ & $(0.0047)$ & $(0.0024)$ & $(0.0009)$ & $(0.0005)$ & \\
0.0000 & 0.0542 & -0.0567 & $\mathbf{0 . 9 0 0 0}$ & -0.0022 & $\mathbf{0 . 0 0 5 2}$ & 0.0066 \\
$(0.0008)$ & $(0.0346)$ & $(0.0648)$ & $(0.0428)$ & $(0.0025)$ & $(0.0023)$ & $(0.0058)$ \\
& & & & & & \\
$\Lambda_{0}$ & & $\Lambda_{1}$ & & $\delta_{0}$ & & $\delta_{1}$ \\
\hline $\mathbf{- 0 . 0 3 7 2}$ & $\mathbf{- 0 . 9 8 7 8}$ & $\mathbf{8 . 4 4 9 9}$ & $\mathbf{- 4 . 4 6 2 9}$ & $\mathbf{0 . 0 5 2 0}$ & $\mathbf{1 . 0 2 5 8}$ \\
$(0.0024)$ & $(0.0714)$ & $(0.6211)$ & $(0.3128)$ & $(0.0069)$ & & $(0.0279)$ \\
$\mathbf{0 . 2 2 6 9}$ & $\mathbf{- 1 6 . 5 0 8 9}$ & $\mathbf{- 3 0 . 4 8 1 2}$ & $\mathbf{1 1 . 6 5 0 0}$ & & & $\mathbf{1 . 2 3 7 5}$ \\
$(0.0155)$ & $(1.2376)$ & $(1.9620)$ & $(0.7416)$ & & & $(0.0590)$ \\
$\mathbf{- 0 . 5 2 9 0}$ & $\mathbf{2 4 . 1 5 2 7}$ & $\mathbf{- 4 7 . 6 1 0 7}$ & $\mathbf{- 2 8 . 8 6 0 4}$ & & & $\mathbf{- 0 . 1 0 9 9}$ \\
$(0.0354)$ & $(1.3702)$ & $(3.0420)$ & $(1.8172)$ & & & $(0.0284)$ \\
\hline \hline
\end{tabular}




\section{TABle G.1: Fama-Bliss (1987) Regressions}

This table reports OLS regressions in the spirit of Fama and Bliss (1987). The leftmost panel displays results for forecasting 1-year ahead excess returns on $n$-year bonds. The rightmost panel displays results for forecasting the 1-year ahead change in the $(n-1)$-year yield. Panel A: univariate regressions using the forward spread $f_{t}^{(n)}-y_{t}^{(1)}$. Panel B: univariate regressions using the Convergenge Gap orthogonalized with respect to the forward spread, denoted $C G_{t}^{\perp}$. Panel C: multiple regressions using the forward spread and the (orthogonalized) Convergenge Gap. The convergence gap, $C G_{t}$, is defined as in Table 1. In parentheses below the estimates we report $t$-statistics based on Newey and West (1987) standard errors with 60 lags. Significance: ${ }^{*} p<0.10,{ }^{* *} p<0.05,{ }^{* * *} p<0.01$. Significance is computed using the asymptotic theory of Kiefer and Vogelsang (2005). The intercept estimates are omitted. The sample period is 1964/01 to 2017/12.

\begin{tabular}{|c|c|c|c|c|}
\hline \multicolumn{5}{|c|}{ Panel A: Forward Spread } \\
\hline \multirow{2}{*}{$\begin{array}{l}\text { Maturity } \\
n=\end{array}$} & \multicolumn{2}{|c|}{$r x_{t+1}^{(n)}=a_{r}+b_{r}\left(f_{t}^{(n)}-y_{t}^{(1)}\right)+\varepsilon_{t+1}$} & \multicolumn{2}{|c|}{$(n-1) \times\left(y_{t+1}^{(n-1)}-y_{t}^{(n-1)}\right)=a_{y}+b_{y}\left(f_{t}^{(n)}-y_{t}^{(1)}\right)+u_{t+1}$} \\
\hline & $b_{r}$ & $R^{2}$ & $b_{y}$ & $R^{2}$ \\
\hline 2 & $\begin{array}{c}0.83^{* * *} \\
(4.57)\end{array}$ & 0.12 & $\begin{array}{c}0.17 \\
(0.92)\end{array}$ & 0.01 \\
\hline 3 & $\begin{array}{c}1.13^{* * *} \\
(5.21)\end{array}$ & 0.14 & $\begin{array}{c}-0.13 \\
(-0.61)\end{array}$ & 0.00 \\
\hline 4 & $\begin{array}{c}1.36^{* * *} \\
(5.69)\end{array}$ & 0.16 & $\begin{array}{c}-0.36 \\
(-1.50)\end{array}$ & 0.01 \\
\hline 5 & $\begin{array}{c}1.12^{* * *} \\
(4.25)\end{array}$ & 0.09 & $\begin{array}{c}-0.12 \\
(-0.45)\end{array}$ & 0.00 \\
\hline
\end{tabular}

Panel B: Convergence Gap

\begin{tabular}{lcccc} 
Maturity & $r x_{t+1}^{(n)}=a_{r}+b_{r, C G^{\perp}} C G_{t}^{\perp}+\varepsilon_{t+1}$ & $(n-1) \times\left(y_{t+1}^{(n-1)}-y_{t}^{(n-1)}\right)=a_{y}+b_{y, C G^{\perp}} C G_{t}^{\perp}+u_{t+1}$ \\
\cline { 2 - 5 }$n=$ & $b_{r, C G^{\perp}}$ & $R^{2}$ & $b_{y, C G^{\perp}}$ & $R^{2}$ \\
\hline 2 & $-0.29^{* * *}$ & 0.16 & $(5.06)$ & 0.19 \\
& $(-4.60)$ & & $0.50^{* * * *}$ & 0.16 \\
3 & $-0.50^{* * *}$ & 0.14 & $(4.81)$ & 0.14 \\
& $(-4.09)$ & & $0.64^{* * *}$ & \\
4 & $-0.64^{* * *}$ & 0.12 & $(4.64)$ & 0.11 \\
& $(-3.56)$ & & $0.73^{* * *}$
\end{tabular}

Panel C: Forward Spread and Convergence Gap

\begin{tabular}{lcccccc} 
Maturity & $r x_{t+1}^{(n)}=a_{r}+b_{r}\left(f_{t}^{(n)}-y_{t}^{(1)}\right)+b_{r, C G^{\perp}} C G_{t}^{\perp}+\varepsilon_{t+1}$ & \multicolumn{4}{c}{$(n-1) \times\left(y_{t+1}^{(n-1)}-y_{t}^{(n-1)}\right)=a_{y}+b_{y}\left(f_{t}^{(n)}-y_{t}^{(1)}\right)+b_{y, C G^{\perp}} C G_{t}^{\perp}+u_{t+1}$} \\
\cline { 2 - 6 }$n=$ & $b_{r}$ & $b_{r, C G^{\perp}}$ & $R^{2}$ & $b_{y}$ & $b_{y, C G^{\perp}}$ & $R^{2}$ \\
\hline 2 & $0.83^{* * *}$ & $-0.29^{* * *}$ & 0.28 & 0.17 & $0.29^{* * *}$ & 0.19 \\
& $(5.26)$ & $(-5.14)$ & & $(1.05)$ & $(5.14)$ & 0.16 \\
3 & $1.13^{* * *}$ & $-0.50^{* * *}$ & 0.28 & -0.13 & $0.50^{* * *}$ & 0.15 \\
& $(4.77)$ & $(-4.85)$ & & $(-0.56)$ & $(4.85)$ & \\
4 & $1.36^{* * *}$ & $-0.64^{* * *}$ & 0.28 & -0.36 & $0.64^{* * *}$ & 0.11 \\
& $(5.24)$ & $(-4.95)$ & & $(-1.38)$ & $(4.95)$ & \\
5 & $1.12^{* * *}$ & $-0.73^{* * *}$ & 0.19 & -0.12 & $0.73^{* * *}$ & \\
& $(4.38)$ & $(-4.22)$ & & $(-0.46)$ & $(4.22)$ & \\
\hline \hline
\end{tabular}

